\section{THE FINANCIAL CRISIS}

The financial turmoil that originated in 2007 and developed into an unprecedented crisis battering financial and real markets is the latest manifestation, on a grand scale and with new attributes, of a welldefined pathology in the process of market liberalization and integration in the post-Bretton Woods era. At the root of the crisis lies a fundamental inconsistency between financial globalisation - the process of liberalization and deregulation driving the impressive growth of world financial markets - and existing public rules and policies at both domestic and international levels. This pathology underlies virtually all the episodes of instability that have affected the developing and the emerging economies since the constraints on capital mobility started to be removed during the 1970s: from the debt crisis in the early 1980s to the financial and currency crisis in South-East Asia in 1997-98 (see e.g., Corsetti, Pesenti and Roubini 1999). Globalisation of financial markets has systematically and vastly outpaced the development of their governance: governments have lagged behind in reshaping domestic and international institutions as well as in changing and adapting policy behaviour.

In a nutshell, three are three main features of the crisis. The first two consist of excessive risk-taking and excessive leverage by financial institutions. These reflected an inconsistency between globalisation and market governance that created the possibility of originating and trading assets under massive underestimation of their risk characteristics; financial institutions were willing to accept excessive risk in part because the same inconsistency created expectations of contingent public guarantees on financial and real assets, in part because, in the presence of widespread agency problems, markets operated consistently with puzzlingly exuberant beliefs about asset price dynamics. Governments may have identified but failed to neutralise these agency problems, i.e., widespread conflicts of interest between asset managers and their clients, and between rating agencies and sponsors of securitisation programmes. Government guarantees and subsidies, exuberant expectations and agency problems reinforced each other, leading to snowballing effects on leverage and risk-taking.

It is the third feature however that sharply differentiates this from previous crises: the extreme level of opacity regarding the size and incidence of risks in the portfolios held by investors and intermediaries. Several layers of securitisation of loans and mortgages resulted in a loss of information and created network externalities across interconnected institutions, which made intermediaries and investors increasingly unable to assess how much risk was in their portfolio, eventually causing the illiquidity of markets directly or indirectly exposed to asset backed securities.

The cost of opacity vastly offset potential benefits from risk diversification - the motivation of securitisation in the first place - not only directly (by causing illiquidity of assets whose risk structure became impenetrable even to the owner) but also indirectly. This is because, at the onset of the crisis, banks and near banks felt obliged to buy back a large share of the "toxic" asset-backed securities they had previously sold to households and institutional investors with guarantees, and placed them in their balance sheets. As the crisis developed, losses from mortgage-related securities and market illiquidity eroded the viability of leveraged institutions, especially those relying on short-term financing. As losses caused depleted equity, intermediaries scrambled for new capital but over time started to reduce their target leverage, arguably implying less lending available for business and households (see Chapter 1 of this report). This is an important difference from other episodes of large market adjustment, which, while producing a dent in the stock of households' wealth of similar if not larger proportions did not undermine the working of the global financial system.

A crucial casualty of the crisis is the confidence in the models that financial intermediaries and markets adopt to assess risk. Especially, but not only, in the US, agents operated persistently as if the risk of downward adjustment in asset prices was quite con- 
tained (e.g., Shiller 2008), and most importantly, underestimated the risks of illiquidity and the problems of over-the-counter markets.

Because of opacity, excessive leverage and excessive risk-taking, a crisis that originated in a relatively small market segment (the subprime mortgage segment) grew out of proportion, causing a world-wide loss of confidence in private financial intermediation and markets - undermining the presumption that policymakers had learnt enough from the past to be able to effectively manage financial turmoil and contain its effects on the real economy. It is the loss of confidence in markets, but also in policies, that have created the conditions for a severe slowdown. Interestingly, while many observers appeared to be aware of the risk of a severe implosion like the one experienced since September 2008, few would actually go as far as predicting it.

The loss of confidence in markets, but also on policies, have now sowed the poisonous seeds of a severe slowdown in the years to come but also, and worse, of a sharp regress in international economic integration and cooperation. While the full extent of the damage is unclear at the time of the writing, we are fully aware that containing it will take decisive action, and time.

What to do crucially depends on one's view of the causes and nature of the crisis. For this reason, this chapter will first address the question: what caused the global financial crisis of 2007-2008? In this part of the chapter, we will lay out the main theories and pieces of evidence to understand the deep as well as the proximate causes of the financial turmoil. First, we will analyse the subprime mortgage markets and the process of securitisation, and reconsider the macroeconomic imbalances underlying the crisis. Second, we will account for the dynamics of the crisis and public intervention, distinguishing different phases: the first from 2007 to the end of summer 2008, corresponding to hopes for a soft-landing; the second, from autumn 2008 on, where the crisis exacerbates (hard landing at last!), with global contagion to financial and real markets. Third, we look ahead, discussing the main challenges to policy-makers from the deepening of the banking crisis and address issues in the reform of the international financial architecture. In this section, we will specifically analyse problems and perspective of reforms in the European Union and the link between fiscal and financial aspects of the crisis.

\section{What created overleveraging, excessive risk-taking and opacity of financial markets?}

\subsection{A close-up analysis of subprime mortgages and their securitisation}

The first step in our analysis consists of clarifying the nature and the functioning of the subprime mortgage market, and the way in which intrinsically heterogeneous contracts were securitized, i.e., pooled together and turned into homogeneous assets to intermediaries and investors. This is because, while the losses from the crisis have far exceeded the dimension of the losses from subprime lending and now has spread to many other parts of the international financial system, the origin of all the evil is commonly placed in this particular segment of the mortgage market.

Subprime is lending to individuals with a high perceived level of default risk, either because they have low income, or because their records show a less than perfect credit history relative to the standards of "prime" borrowers. Subprime lending has been around for quite a while. But it is only in the last few years that it became one of the fastest growing segments in the US mortgage markets - its exceptional growth being driven by a number of factors discussed below.

As is well known, credit markets are plagued by information asymmetries: the borrower is generally better informed than the lender about the merit of the project he/she is asking funds for; the borrower can take actions that affect the value of the project but are unknown to the lender. Economists refer to the former as "adverse selection", to the latter as "moral hazard". Information asymmetries explain why prices are not and cannot be the only mechanisms that clear credit markets. In the adverse-selection model of credit rationing by Stiglitz and Weiss (1981), for instance, if the lender sets high interest rates for projects with a given high level of risk, these high rates end up attracting a pool of borrowers with even riskier profiles. In an attempt to clear the market, the lender could try to raise the interest rate even more, but this clearly would be to no avail. In fact, the only outcome of raising prices would be that of discouraging some of the relatively safe borrowers from applying for funds. In the standard moral hazard model, a party in a contract takes on excessive risk because he/she does not face the full consequences of his/her action, leaving other parties to 
bear responsibility. ${ }^{1}$ One example of moral hazard is between borrowers and lenders: borrowers are tempted to take risky actions that are inefficient to the extent that they reduce the value of the firm to the creditors in the likelihood of bankruptcy. Since the borrower does not get anything in that event, they do not factor in this kind of loss when making their decision. Another example is due to the prospect of a government bailout: financial intermediaries may then invest in projects that are too risky because they gain from the prospect of greater gains while the associated greater losses are expected to be borne by the taxpayer.

Adverse selection and moral hazard are two key market pathologies needed to understand the subprime mortgage markets. With adverse selection and moral hazard, financial intermediaries allocate funds resorting to a number of instruments and mechanisms other than pricing, namely, they use screening of customers and credit rationing, and they request collateral. In the subprime mortgage market, indeed, intermediaries lend against the house value as collateral, supposedly after screening borrowers, and charging a premium over the interest rate paid by most secure, prime borrowers.

In addition, financial intermediaries can reduce their exposure to mortgage-related risk by selling some of it to other agents in the economy, via the process of securitisation that will be described below in detail. By allowing banks to diversify mortgage risks among market participants, securitisation reduces the risk faced by each financial intermediary at each level of lending. As a result, more resources are in principle available for borrowers in the aggregate.

Lending against collateral, screening and securitisation thus result in easier and cheaper access to financial markets by households and firms which would otherwise be severely rationed. Their benefits are however less obvious in the presence of other types of distortions, e.g., when a bubble leads to mispricing of the collateral, agency problems exacerbate moral hazard, or opportunities for regulatory arbitrage raise the risk exposure of banks beyond prudential standards. The boom in subprime mortgage market was indeed driven by the interaction of strong pricing dynamics in the housing market, agency problems and inconsistencies in regulation and supervision, to become the engine of overlever-

\footnotetext{
1 See Sinn $(1981,2009)$ for the implications of limited liability on
} risk-taking in general and banking behaviour in particular. aging and excessive risk-taking for the world financial system as a whole.

\subsubsection{Subprime mortgage origination and refinancing in the $U S$}

A brief overview of subprime lending and securitisation in the US is in order, to shed light on the main mechanisms that played a role in undermining financial stability in the US and worldwide. (For a detailed exposition of this mechanism, see e.g., Calomiris 2008, Gorton 2008, and IMF 2008a,b.)

In the period leading up to the crisis, subprime mortgages in the US were typically adjustable rate mortgages, with a "hybrid structure". To see what this means, consider common labels such as " $2 / 28$ " or " $3 / 27$ ": these referred to 30 year mortgages incorporating a fixed rate for 2 and 3 years, respectively, then switching to a floating rate for the remaining period, 28 and 27 years. The initial monthly payments in the first part of the mortgage were based on "teaser rates", adding a premium (e.g., 6 basis points) above the benchmark London Interbank Offered rate, Libor). After 2 or 3 years, the switch to floating rates was typically associated with a substantial increase in the dollar amounts of monthly instalments.

As further discussed below, these contracts flourished in a period of continuing house price appreciation. This is an important observation to understand their structure and practical implementation (see Gorton 2008). Namely, these contracts included very high prepayment fees - de facto, these fees discouraged borrowers from cashing in capital gains on the house by closing their debt in advance and walking away from the financial intermediary. On the contrary, they were designed in such a way that borrowers would have an opportunity/incentive to refinance their mortgage in the first few years, possibly before the switch from fixed to floating rates, when they would face substantially higher monthly payments. So, in an environment of increasing housing prices, poor households could avoid payment difficulties through refinancing. In fact, first subprime mortgages were typically rolled into second, or even a sequence of subprime loans. Gorton (2008) reports that for some types of mortgages, up to 80 percent were refinanced within five years from the start.

In this respect, it is worth stressing that financial advice was, to say the least, deficient. Adjustable rate 
mortgages with attractive teaser rates were overwhelmingly targeted to low-income and poorly uneducated households, who are the least informed about subtleties of contracts and market evolution (see Shiller 2008). In other words, complex financial products were sold to financially illiterate people.

Table 2.1 shows mortgage origination in the US between 2001 and 2007 by types of products: "conforming" and jumbo mortgages (the latter being larger, against more expensive houses), subprime and Alt-A mortgages, ${ }^{2}$ home equity loans (HEL),

2 In the US, Alternative A-paper mortgages, or Alt-A mortgages, are classified as riskier than A-paper ones (the "prime") and less risky than the subprime ones. Alt-A interest rates, which are determine by credit risk, therefore tend to be between those of prime and subprime home loans. as well as Federal Housing Administration (FHA) and Veteran Affairs (VA) mortgages. The total value of mortgages originated in the period fluctuates at around $\$ 3$ trillion per year. For our purpose, it is important to stress that the share of subprime in origination of all mortgages rose steadily between 2001 and 2006, from 7.2 to 20.1 percent. The share of subprime and Alt-A mortgages combined exceeded 30 percent at the end of the period. Also, the share of adjustable rate mortgages originated in each year quickly climbed to 50 percent between 2001 and 2004, remained above 45 percent in 2005 and 2006. Finally, refinancing activity was extremely high, always above 50 percent of originated mortgages, with a peak of 72 percent in 2003 . Thus, a large share of "mortgage origination" actu-

Table 2.1

Mortgage originations by product

\begin{tabular}{|c|c|c|c|c|c|c|c|c|c|}
\hline \multicolumn{10}{|c|}{ Mortgage originations by product (\$bn) } \\
\hline Year & FHA/VA & Conforming & Jumbo & Subprime & Alt-A & HEL & Total & ARMs & Refinances \\
\hline 2001 & 175 & 1,265 & 445 & 160 & 55 & 115 & 2,215 & 355 & 1,298 \\
\hline 2002 & 176 & 1,706 & 571 & 200 & 67 & 165 & 2,885 & 679 & 1,821 \\
\hline 2003 & 220 & 2,460 & 650 & 310 & 85 & 220 & 3,945 & 1,034 & 2,839 \\
\hline 2004 & 130 & 1,210 & 510 & 530 & 185 & 355 & 2,920 & 1,464 & 1,510 \\
\hline 2005 & 90 & 1,090 & 570 & 625 & 380 & 365 & 3,120 & 1,490 & 1,572 \\
\hline 2006 & 80 & 990 & 480 & 600 & 400 & 430 & 2,980 & 1,340 & 1,460 \\
\hline $1 \mathrm{Q} 06$ & 19 & 236 & 103 & 140 & 105 & 102 & 705 & 297 & 348 \\
\hline $2 \mathrm{Q} 06$ & 20 & 275 & 126 & 165 & 104 & 110 & 800 & 392 & 382 \\
\hline 3Q06 & 22 & 241 & 128 & 160 & 91 & 113 & 755 & 332 & 368 \\
\hline $4 \mathrm{Q} 06$ & 19 & 238 & 123 & 135 & 100 & 105 & 720 & 319 & 362 \\
\hline $1 \mathrm{Q} 07$ & 19 & 273 & 100 & 93 & 98 & 97 & 680 & 40 & 388 \\
\hline 2Q07 & 25 & 328 & 120 & 56 & 96 & 105 & 730 & 220 & 377 \\
\hline $3 \mathrm{Q} 07$ & 26 & 286 & 83 & 28 & 54 & 93 & 570 & 166 & 263 \\
\hline 4Q07 & 31 & 275 & 44 & 14 & 27 & 60 & 450 & 98 & 234 \\
\hline \multicolumn{10}{|c|}{$\%$ of originations by product (except for total loans) } \\
\hline Year & FHA/VA & Conforming & Jumbo & Subprime & Alt-A & HEL & ARMs & Refinances & $\begin{array}{c}\text { Total Loans } \\
(\$ B n)\end{array}$ \\
\hline 2001 & $7.9 \%$ & $57.1 \%$ & $20.1 \%$ & $7.2 \%$ & $2.5 \%$ & $5.2 \%$ & $16.0 \%$ & $58.6 \%$ & 1298 \\
\hline 2002 & $6.1 \%$ & $59.1 \%$ & $19.8 \%$ & $6.9 \%$ & $2.3 \%$ & $5.7 \%$ & $23.5 \%$ & $63.1 \%$ & 1821 \\
\hline 2003 & $5.6 \%$ & $62.4 \%$ & $16.5 \%$ & $7.9 \%$ & $2.2 \%$ & $5.6 \%$ & $26.2 \%$ & $72.0 \%$ & 2839 \\
\hline 2004 & $4.5 \%$ & $41.4 \%$ & $17.5 \%$ & $18.2 \%$ & $6.3 \%$ & $12.2 \%$ & $50.1 \%$ & $54.7 \%$ & 1510 \\
\hline 2005 & $2.9 \%$ & $34.9 \%$ & $18.3 \%$ & $20.0 \%$ & $12.2 \%$ & $11.7 \%$ & $47.8 \%$ & $50.4 \%$ & 1572 \\
\hline 2006 & $2.7 \%$ & $33.2 \%$ & $16.1 \%$ & $20.1 \%$ & $13.4 \%$ & $14.4 \%$ & $45.0 \%$ & $49.0 \%$ & 1460 \\
\hline $1 \mathrm{Q} 06$ & $2.7 \%$ & $33.5 \%$ & $19.9 \%$ & $19.9 \%$ & $14.9 \%$ & $14.5 \%$ & $42.1 \%$ & $49.4 \%$ & 348 \\
\hline 2Q06 & $2.5 \%$ & $34.4 \%$ & $15.8 \%$ & $20.6 \%$ & $13.0 \%$ & $13.8 \%$ & $49.0 \%$ & $47.8 \%$ & 382 \\
\hline $3 \mathrm{Q} 06$ & $2.9 \%$ & $31.9 \%$ & $17.0 \%$ & $21.2 \%$ & $12.1 \%$ & $15.0 \%$ & $44.0 \%$ & $48.7 \%$ & 368 \\
\hline $4 \mathrm{Q} 06$ & $2.6 \%$ & $33.1 \%$ & $17.1 \%$ & $18.8 \%$ & $13.9 \%$ & $14.6 \%$ & $44.3 \%$ & $50.3 \%$ & 362 \\
\hline $1 \mathrm{Q} 07$ & $2.8 \%$ & $40.1 \%$ & $14.7 \%$ & $13.7 \%$ & $14.4 \%$ & $14.3 \%$ & $35.3 \%$ & $57.1 \%$ & 388 \\
\hline $2 \mathrm{Q} 07$ & $3.4 \%$ & $44.9 \%$ & $16.4 \%$ & $7.7 \%$ & $13.2 \%$ & $14.4 \%$ & $30.1 \%$ & $51.6 \%$ & 377 \\
\hline $3 \mathrm{Q} 07$ & $4.5 \%$ & $50.2 \%$ & $14.6 \%$ & $4.9 \%$ & $9.5 \%$ & $16.3 \%$ & $29.1 \%$ & $46.1 \%$ & 263 \\
\hline $4 Q 07$ & $6.9 \%$ & $61.0 \%$ & $9.6 \%$ & $3.0 \%$ & $6.0 \%$ & $13.3 \%$ & $21.6 \%$ & $52.0 \%$ & 234 \\
\hline
\end{tabular}

Source: Inside Mortgage Finance, Morgan Stanley based on Greenlaw et al. 2008. 
ally consisted of the refinancing of outstanding mortgages.

The cumulative issuance of subprime mortgages between 2005 and 2007 should provide an approximate measure of the amount of these mortgages outstanding at the onset of the crisis (see Greenlaw et al. 2008). The outstanding stock amounted to 1.4 trillion dollars. Adjustable rates mortgages, accounting for 80 percent of the total, then reached 1 trillion dollars. Note that because of widespread refinancing with increasing housing prices, the performance of subprime mortgages in the years prior to the crisis provided little or no guide to risk and loss assessment. With adjustable-rate mortgages, default could be expected to climb quickly after the first two or three years in the life of each cohort of mortgages during which borrowers pay teaser rates. However, refinancing in 2004 through 2006 allowed many borrowers to postpone the passage to floating-rate instalments, which are usually more expensive than the initial ones.

Estimates of the direct losses on subprime mortgages at the start of the crisis varied widely (see e.g., Greenlaw et al. 2008). Initial estimates were in the range of $\$ 50$ to $\$ 100$ billion for subprime - figures proposed by Bernanke in July 2007 - plausibly corresponding to overall losses as high as $\$ 150$ billion for the US mortgage market as a whole. At the end of 2007 , estimates of total losses in this market had already climbed to between $\$ 250$ to $\$ 500$ billion, according to Lehman Brothers (2007) and Goldman Sachs (2007). Prudential estimates pointed to losses of the order of 4 percent of US GDP.

These initial estimates were profoundly revised over time, in view of a sizeable drop in housing prices and a severe slowdown of the economy, which translated into higher rates of default also in the prime segment of the market (accounting for more than three fourths of all mortgages). The estimates by the International Monetary Fund were revised from 1 to 1.4 trillion dollars in the course of 2008 (IMF 2008a,b). As we write this chapter, cost estimates have been substantially increased.

To the extent that these losses - although not completely unexpected - caught the private sector unprepared, they amounted to a sizeable negative shock to the economy, which would cause concern even if it did not cause extended malfunctioning in global financial markets. However, their magnitude was by no means unprecedented - the losses from the dot-com crash wiped out $\$ 5$ trillion in the market value of technology companies between March 2000 and October 2002.

\subsubsection{Mortgage securitisation}

By their very nature, mortgage contracts are very heterogeneous. Not only conditions and terms of these contracts typically vary over time, i.e., across vintages. They also display large differences within each vintage, depending on a variety of factors, ranging from the location of the house to be financed, to the economic profile of the borrower and the marketing strategy of the lender. What follows describes how financial intermediaries were able to transform vastly heterogeneous contracts into standardised securities to be traded in financial markets - while our discussion focuses on mortgages, what we write applies also to other types of banks' loans and credit.

It is useful to keep in mind that securitisation developed vis-à-vis a strong and growing demand for highly rated assets by individual and institutional investors, the latter often restricted in their portfolio choice by rules setting quality standards for the securities in their portfolios. Hence, the goal of the process was to satisfy this demand at the least cost, i.e., by creating the largest possible pool of standardised, high-rating (possibly AAA) securities from the underlying pool of mortgages.

To start with, it is useful to introduce some terms and definitions. By issuing a mortgage loan to a household or a firm, a bank or financial intermediary is the originator of an asset that generates a cash flow paid regularly over time (the monthly instalments). Securitisation occurs when the originator sells this cash flow to a special purpose vehicle SPV (or a structured investment vehicle SIV, or a special purpose enterprise, SPE, or other kinds of conduits/trusts ${ }^{3}$ ), administered by a financial institution called the administrator or the sponsor of the programme. Since mortgage holders may default on their loans, however, the (nominal) face value of the cash flow is not sure. To deal with default risk, the SPV (or SIV, SPE, conduits, trust) purchases a welldiversified portfolio of mortgages, pooling together the cash flows from many borrowers.

The key to securitisation is that the SPV finances its purchases of cash flows from mortgages by issuing securities, which are then called residential mortgage

3 Differences among these are discussed e.g., by Brunnermeier (2009). 
backed securities (RMBS), or commercial mortgage backed securities (CMBS) because they are backed by the payments by the holders of the mortgages in the SPV portfolio. Both RMBS and CMBS are forms of mortgage backed securities (MBS), which in the US account for most of the larger class of asset backed securities (ABSs). For simplicity, in what follows ABSs will be used as a generic term to refer to MBSs, RMBSs or CMBSs.

How can risky cash flows from heterogeneous mortgage contracts be turned into standardised ABSs? The trick consists of slicing the cash flow from a well-diversified pool of mortgages into tranches of increasing risk/return profiles. Namely, the cash accruing from the pool of assets is used first to pay interest and the principal to the tranche with the highest and most senior status; the remaining cash is then used to pay the holders of a second tranche, with lower status; what is left is paid to a third tranche, and so on. The basic architecture is shown in Figure 2.1a.

An example after Gorton (2008) will help illustrate the mechanism. For simplicity, assume that the mortgage lasts one period only. Under these assumptions, consider an SPV that purchases a pool of mortgages generating a cash flow with a face value of $\$ 100$. This cash flow is obviously risky: it will in general pay less than $\$ 100$ ex post. To finance its purchase, the SPV issues RMBS in two tranches, a senior one with par value $100-\mathrm{N}$, and a subordinate one with par value equal to $\mathrm{N}$. This means that while losses up to the first $\mathrm{N}$ dollars are borne by the second, riskier tranche;
Figure 2.1a

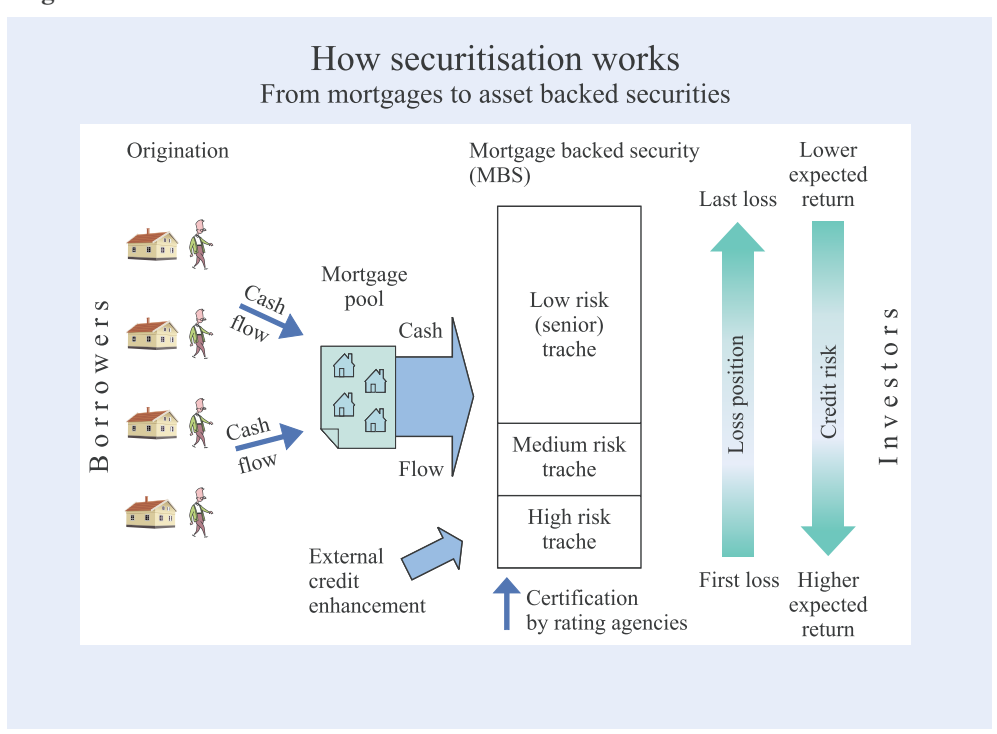

Figure 2.1b

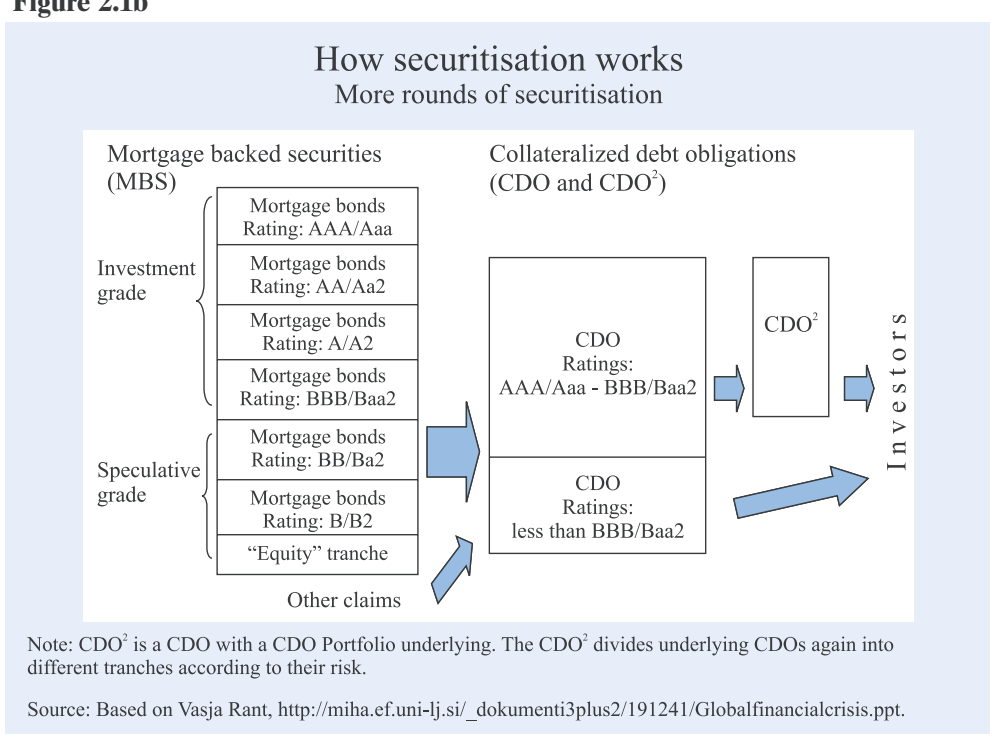

Figure 2.1c

The players in securitisation

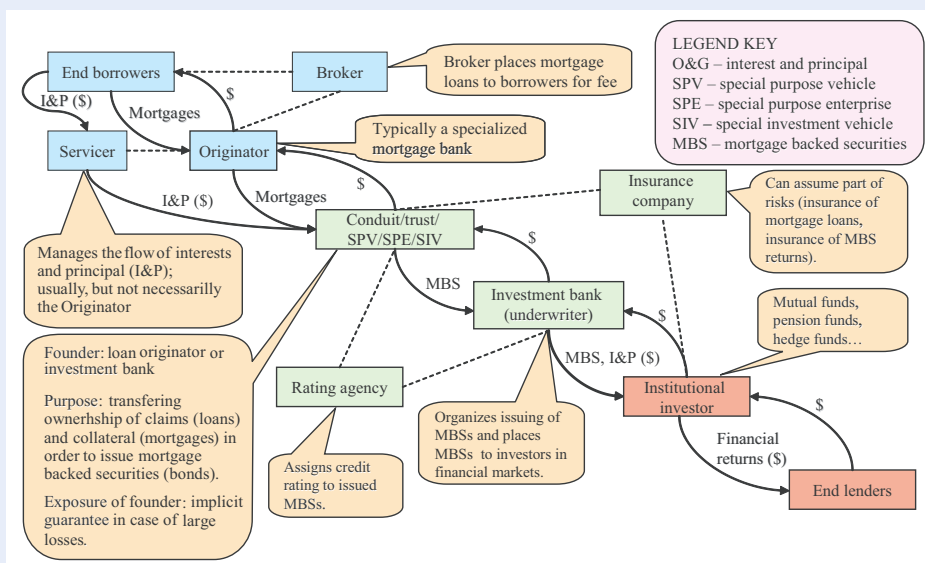

Source: Vasja Rant, http://miha.ef.uni-lj.si/_dokumenti3plus2/191241/Globalfinancialcrisis.ppt. 
larger losses also reduce the payoff of the first, senior one.

So, let $\mathrm{C}_{\mathrm{B}}$ denote the cash flow from the riskier tranche. This will be N-loss if this amount is positive, or 0 otherwise, as losses in addition to $\mathrm{N}$ are borne by the owner of the senior tranche:

$$
\mathrm{CB}_{\mathrm{B}}=\mathrm{Max}[\mathrm{N}-\text { Loss, } 0] \text {. }
$$

Conversely, the cash flow from the senior tranche $\mathrm{CA}$ will instead be either $100-\mathrm{N}$ if losses are contained below N, or 100-Loss:

$$
\mathrm{CA}_{\mathrm{A}}=\operatorname{Min}[100-\mathrm{N}, 100-\text { Loss] } .
$$

The scheme easily generalises to the case of more than two tranches. Say, with three tranches, the SPV stipulates that the bottom one bears the first losses up to NFL dollars (FL stands for First Loss). The second to the bottom tranche bears losses between NFL and N. The payoff of the senior tranche will be the same as above. For the other two, we will have ${ }^{4}$

$$
\begin{gathered}
\mathrm{C}_{\mathrm{FL}}=\operatorname{Max}\left[\mathrm{N}_{\mathrm{FL}}-\text { Loss, } 0\right] \\
\mathrm{C}_{\mathrm{B}}=\operatorname{Max}\left[\operatorname{Min}\left[\mathrm{N}-\mathrm{N}_{\mathrm{FL}}, \mathrm{N}-\mathrm{Loss}\right], 0\right] .
\end{gathered}
$$

In this example, the choice of $\mathrm{N}$ and NFL is based on the sponsor's best assessment of the risk of default in the pool of mortgages purchased by the SPV. Specifically, by setting a very high $\mathrm{N}$, all else being equal, the sponsor reduces the risk that the owner of the senior tranche will suffer a loss. Vice versa, a low $\mathrm{N}$ raises the risk of losses on the senior tranche.

An important point here is that by appropriately choosing $\mathrm{N}$, there will be at least one tranche of first class $A A A$ securities against the portion of the cash flow which satisfy the requirements for AAA securities set by a rating agency. The SPV can then create additional, risky tranches, e.g., $A A$ mezzanine, $B B B$ subordinated and first-loss position ones (see Figure $2.1 \mathrm{~b}$ ). The size of these tranches will of course depend on the overall risk of the pool as well as on the requirements for the ratings set by the agency. Interestingly, the worse, i.e., riskier, securities were generally held by the originator.

Figure $2.1 \mathrm{~b}$ also shows that the process of slicing the cash flows from original mortgages into bonds

${ }^{4}$ See Gorton (2008) for a generalisation for the case in which mortgages could be refinanced. of different risk class continues in successive rounds of securitisation - the figure includes collateralised debt obligations (CDOs) and so-called CDO squared. In each step, there are more and more contracts written on this cash flow, supposedly providing insurance.

As already mentioned, indeed, the objective of this process is to turn a pool of heterogeneous risky mortgages into the largest possible pool of standardised, high-rating ABS securities. In this respect, diversification of the underlying pool of mortgages is an important step but is not the only instruments that SPVs used to raise the "quality" of the ABS. Indeed, SPVs resorted to different kinds of so-called internal and external credit enhancement. The first depends on the way the programme is structured, the second on the availability of credit facilities (usually against maturity mismatches), letters of credit and credit insurance. Thus, the maps of financial intermediaries involved in the securitisation process include also insurance companies or other financial intermediaries that buy default risk from the SPVs (see Figure 2.1c). In this connection, Box 2.1 examines credit default swaps and Box 2.2 the special class of synthetic CDOs.

The quality of ABSs is certified by rating agencies, usually paid by the sponsor. Different rating agencies may set different criteria for securities to qualify as triple-A. For this reason, it was often the case that an SPV shopped around to find the agency whose rating criteria were the least expensive to satisfy, for any given quantitative target of issuance of high quality securities. In some cases, these practices created tension along the process of securitisation, especially when ABSs were further integrated into structured products promoted by sponsors employing different rating agencies. Conflicts in ratings of the same product among less and more conservative agencies are well documented (see Calomiris 2008). Further issues concerning ratings agencies are discussed in Box 2.3.

Market liquidity is an essential element in this process. Namely, the maturity of ABSs does not in general coincide with the maturity of the underlying mortgages: it is usually shorter. So over time the principal and interest on ABSs will be paid partly with the cash flow from the underlying mortgages, partly by issuing new securities, i.e., by rolling over debt. Namely, SIV, conduits and other vehicles issued asset-backed commercial paper $(\mathrm{ABCP})$ or medium-term notes, the former with an average maturity of 90 days, the latter 
Box 2.1

Credit default swaps (CDS)

Credit default swaps (CDS) are tradable securities that allow investors to swap the risk of debt default. They were introduced as a financial instrument by JP Morgan in the end of the 1990s. Their development over the past seven years is remarkable: The International Swaps and Derivatives Association (ISDA) reports a notional amount outstanding of \$US 55 trillion in the first half of 2008 after reaching its peak of \$US 62 trillion in the second half of 2007. The annual growth rate was $103 \%$ over the period from 2001 to 2007.

Why are CDS so popular in modern credit markets? In principle they can be compared to an insurance contract where the buyer pays a periodic fee to the seller, who guarantees him a payoff if a well-specified credit event occurs. Usually, protection buyer and protection seller agree on one of the following events as the trigger for the compensation payment to come into effect: failure-topay, restructuring, bankruptcy or default of the reference entity. The reference entity might be a company, a bond (including mortgage-backed bonds) or a sovereign. In contrast to the single-name form of CDS, there are also so-called basket CDS, which normally include up to ten reference entities. Here a first-to-default principle is most commonly applied by which the protection seller compensates the protection buyer for the first entity that defaults and the contract thereby terminates. Finally, much of recent growth in the CDS market is attributed to CDS indices, of which the two biggest insure the investor against the default of 125 corporate entities each. Again, if one of these corporate entities defaults, the protection buyer receives a payment.

According to a survey of the British Banking Association, hedge funds in particular gained importance, accounting for $28 \%$ of total protection buyers and $32 \%$ of total protection sellers in 2006 compared to only $3 \%$ and $5 \%$, respectively, in 2000 . At first glance, CDS seem to provide an effective means of hedging broad sources of credit risk while increasing liquidity and ensuring price discovery. Proponents of the CDS industry also argue that CDS reflect the true condition of companies much better than ratings of rating agencies do. One reason might be that CDS are more sensitive to market news. However, there are some crucial differences to an insurance contract that create problematic incentive structures as well as systemic risk.

On the one hand, clarity about the relationship between the protection buyer and the reference entity is important. When buying an ordinary insurance, the protection buyer and the reference entity must coincide in order to prevent fraudulent manipulations. However, since the reference entity does not necessarily have to be related to the protection buyer himself, there is room for speculative investment as an investor seeking to maximise its profit might buy CDS protection for the default of a reference obligation whose collapse would otherwise not affect him. This behaviour is problematic insofar as it may feed doubts about the company's solvency, up to leading to its default - the inefficiency being apparent if such outcome reflects market power and manipulation by some participant. On the other hand, CDS have been accused of being traded in a very non-transparent manner Although highly standardised, all contracts are privately negotiated and there is no clearing house for CDS. As CDS contracts are traded frequently, there is uncertainty about the property rights and whether the owner can fulfil his obligations in case of default. Lehman Brothers, for example, was an important counterparty of CDS contracts. After Lehman Brothers' bankruptcy the CDS issued by them provided no protection anymore and there was the threat that a complex interlinked chain of CDS contracts between financial institutions would unravel. As it was recognised that not only the reference obligation but also the protection seller might default, CDS are now also blamed for having amplified the financial crisis. Banks' exposure to risky CDS contracts is non-transparent, which may have contributed to the decrease in lending activity on the inter-banking market.

The figures on the size of the CDS market are impressive but the actual cash flows are obviously much lower since defaults and hence settlements have occurred only rarely. The net cash flow is mainly determined by the periodic payments (spreads) the buyers have to pay to the sellers of a CDS. The crucial question is how much of notional amount outstanding is at risk to default during the financial crisis and whether further defaults may initiate a fatal domino effect. Due to the uncertainties and the nontransparency CDS are still considered a risk to the stability of financial markets and regulation seems to be required

\section{Box 2.2}

\section{Synthetic CDOs}

A special class of ABSs is synthetic CDOs. These do not buy assets from originators but only the risk underlying their loans. Risk is bought via credit default swaps (CDS), a form of credit derivative that provides debt insurance (see Box 1). Essentially, the originators periodically pay a premium to the administrator of the synthetic CDO in exchange for a compensatory payment if the mortgage holder fails to pay interest or the principal on its debt (i.e., its financial contract with a third party default). Through $\mathrm{CDS}$, the originators could transfer risk to other parties, hence could relax the regulatory requirements on their equity even more.

Synthetic CDOs typically diversified their risk by pooling large number of CDS contracts and then investing in risk-free fixed income securities, so to collateralise the debt underlying the CDS in case of default. The entire operation is financed by issuing ABSs, once again in different tranches characterised by different risk-return profiles. The premia and interest payments on the fixed income securities generate a cash flow which accrues to ABS holders (after deducting compensatory payments for defaults under the CDS contracts).

If a synthetic CDO issue tranches up to covering the entire amount of debt that underlies the CDS in its portfolios, it is fully funded. Otherwise it is partially-funded. The rationale for partial funding for a synthetic CDO lies in the fact that some part of the securitised portfolio may be assigned an extremely low probability of default. In this case, the originator preferred to cover this risk by entering further CDSs (as these were quite cheap) with entities called super-senior protection sellers rather than by issuing (expensive) tranches. 
Box 2.3

\section{Ratings agencies}

One of the most significant factors in the financial crisis has been that the returns of many financial products have turned out to be less secure than had been thought. The creditworthiness of many of these products was certified by credit ratings agencies. As such, these agencies have come under considerable criticism. One typical comment was: "The credit rating agencies occupy a special place in our financial markets. The ratings agencies failed this bond of trust."1

Credit ratings agencies are independent companies that assess the risk of certain types of debt instruments and institutions. The highest ratings are AAA, and the lowest are C. Instruments rated at or above Baa or BBB are "investment-grade", below that they are "junk".

The three largest agencies are Standard and Poor's, Fitch Ratings and Moody's. The first two of these base their assessments of credit-worthiness entirely on default probabilities, while Moody's attempts to incorporate the expected return in the event of default. As pointed out by Morrison (2008), one problem with both of these approaches is that they entirely ignore the correlation of outcomes with the rest of the market. A bond that performs well when the rest of the market enters a downturn is valuable; a bond that performs well when the rest of the market also performs well is much less valuable.

A more common criticism, however, has been that the ratings agencies are employed and paid by the issuers of financial products not by investors. This is understandable where there are many investors in each financial product. However, this creates an incentive for the ratings agency to overstate the creditworthiness of a particular product in order to build a good relationship with the issuer. On the other hand, a rating would have no value in the market if investors lost faith in the agency that issued it. An agency must therefore balance any short-term gain from satisfying the issuer with its long-run reputation in the market.

The fact that investors took ratings seriously suggests that the long-run reputation of the agencies was intact, at least until recently. However, there is increasing evidence that in assessing some financial products, the methods used by agencies have produced ratings that are too high. This point is discussed for example by Benmelech and Dlugosz (2008), who examined 4,000 structured bonds that were backed by loan portfolios. The average rating of the loans was B+, yet $70 \%$ of the bonds were rated AAA.

These considerations have led to calls for increased regulation of agencies. But it is not clear that regulation would improve the situation. In fact, Morrison (2008) argues persuasively that some aspects of existing regulation have exacerbated the difficulties surrounding ratings agencies. For example, many investors face a minimum ratings constraint on products they are permitted to purchase. Bank capital regulations also rely on ratings. But this gives significantly more power to the agencies, which effectively become gatekeepers for financial products. They do not just sell their opinion on creditworthiness, but they also sell admission to markets for some financial products.

An issuer can combine assets of different risk into a single product with low average risk. Agencies can charge fees to advise issuers on how to structure products to achieve the rating required for it to be purchased by regulated investors who otherwise would not be able to purchase the more risky asset. Benmelech and Dlugosz (2008) explain their results by the fact "that most issuers were using the rating agencies' model to target the highest possible credit rating at the lowest cost".

Since regulators require that agencies play this role, the agencies themselves are also regulated. Seven agencies are approved by regulators in the US - and the three largest account for over $90 \%$ of the market. This creates a barrier to entry, which makes it more difficult for new methodologies to be introduced and makes it harder for existing agencies to lose out to newcomers.

What is crucial in the market for ratings is for the reputations of agencies to depend on their judgements. When ratings are poor, as they have been, then future ratings by the same agencies should be treated with more caution. Further regulation, with the possibility of greater barriers to entry, may undermine this as incumbents face less competition.

${ }^{1}$ Henry Waxman, chair of US House of Representatives' Oversight Committee, quoted in the Financial Times, 22 October 2008.

with an average maturity of one year. The drying up of liquidity in these markets could clearly compromise the activity of these intermediaries.

Investment banks acquired ABSs, serving as underwriters, and placed them in the market, where they could undergo another round of securitisation or ended up in the portfolios of institutional investors (mutual funds, pension funds, hedge funds) on behalf of end lenders (households and non-financial firms) or directly in the portfolio of end lenders.

5 The income for the SPV derived from the spread in interest rates between their assets and liabilities due to both the maturity mismatch and the credit spread between the original mortgages and the securities issued.
On the demand side, the new securities found eager investors who were attracted by the interest spread between these products over equally-rated triple-A standard bonds. Recall that many institutional investors are restricted in their portfolio choice to securities with high ratings: at a time of low interest rates, the spread on triple-A ABSs provides a means to improve a funds' performance. For sponsors and administrators, there was an opportunity to earn large fees as a percentage of the overall volume of transaction. ${ }^{5}$

Table 2.2 reports calculations by Moody's, mapping subprime mortgages originated in 2005 through 2007 into tranches of MBS with different rating 
Table 2.2

Estimates of subprime mortgage origination by tranche (\$bn)

\begin{tabular}{|c|c|c|c|c|c|c|}
\hline & $\begin{array}{c}\text { All subprime } \\
100 \%\end{array}$ & $\begin{array}{c}\text { AAA } \\
80.80 \%\end{array}$ & $\begin{array}{c}\mathrm{AA} \\
9.60 \%\end{array}$ & $\begin{array}{c}\mathrm{A} \\
5.00 \%\end{array}$ & $\begin{array}{c}\mathrm{BBB} \\
3.50 \%\end{array}$ & $\begin{array}{c}\mathrm{BB} / \text { other } \\
1.10 \%\end{array}$ \\
\hline \multicolumn{7}{|l|}{ Year } \\
\hline 2005 & 625 & & 60 & 31 & 22 & 7 \\
\hline 1Q06 & 140 & 113 & 13 & 7 & 5 & 2 \\
\hline $2 \mathrm{Q} 06$ & 165 & 133 & 16 & 8 & 6 & 2 \\
\hline 3Q06 & 160 & 129 & 15 & 8 & 6 & 2 \\
\hline 4Q06 & 135 & 109 & 13 & 7 & 5 & 1 \\
\hline $1 \mathrm{Q} 07$ & 95 & 77 & 9 & 5 & 3 & 1 \\
\hline $2 \mathrm{Q} 07$ & 56 & 45 & 5 & 3 & 2 & 1 \\
\hline 3Q07 & 28 & 23 & 3 & 1 & 1 & 0 \\
\hline 4Q07 & 14 & 11 & 1 & 1 & 1 & 0 \\
\hline Total & 1418 & 1145 & 135 & 71 & 51 & 16 \\
\hline
\end{tabular}

Source: Inside Mortgage Finance, Morgan Stanley based on Greenlaw et al. 2008.

(see again Greenlaw et al. 2008). The most striking piece of information from the table is that about 80 percent of subprime mortgages' origination was converted into triple-A pools. This percentage remained stable even into the crisis period - the last quarters of 2007 - although origination activity contracted. Conversely, less than 5 percent of these mortgages were converted into triple-B or lower rate assets. These percentages obviously contained the seed of the crisis, as securitisation flooded the market with triple-A products whose risk and prices were obviously quite sensitive to housing market conditions.

The evidence in the table raises the key issue concerning the extent to which a risky cash flow from mortgages could back triple-A securities. Even after accounting for credit enhancement, a percentage as high as 80 percent may hardly survive proper stresstesting of the market conditions underlying securitisation. In this dimension (with the benefit of hindsight) the models adopted by financial intermediaries to assess risk appeared to be far from adequate.

It may be useful to point out that the share of MBS varied widely across the portfolios held by SIV, conduits and other intermediaries and is not necessarily large. In many case, the exposure to subprime mortgage risk was very contained. So, when looking at the securitisation process, the main idea is clearly consistent with a straightforward diversification principle and should have resulted in a better pricing of risk to improve efficiency. What went wrong?

\subsubsection{Regulatory Arbitrage, Diversification and Opacity}

Non-bank financial intermediaries involved in the securitisation process (SIV, SPV, conduits etc.) borrow short and in liquid form, and just as commercial banks invest in less liquid long assets - thus they form a "shadow banking system". However, in contrast to commercial banks, they are able to operate outside normal banking supervision and regulation. This observation suggests a key motivation for financial houses to promote securitisation, that is, regulatory arbitrage.

The Basel Capital Accord requires commercial banks to satisfy risk-based capital standards, i.e., to maintain a minimum percentage of equity against their portfolio of loans, weighted according to their risk class. Under Basel I, by selling mortgages to SPVs/SIVs, banks were able to remove their mortgages from their balance sheets, hence they could subtract them from the computation of the Basel I equity requirements. By the same token, the capital requirement would not change when the bank extended some type of credit lines, like reputational credit lines, providing contingent liquidity assistance to their SIVs. Indeed, many originators were owned/controlled by financial groups and institutions that provided "warehouse" lines for their lending. Many banks owned/controlled SPVs/SIVs where they parked ABSs, financing them by issuing short-term, asset backed commercial paper (ABCP).

Basel II, which came into effect in 2007, ruled out the above opportunities for regulatory arbitrage but cre- 
ated others. For instance, by transferring mortgages to an SIV and providing liquidity enhancement, a bank could turn its lending into a large amount of triple-A rated securities, without suffering a downgrade of its rating to the same extent. By buying back some of the triple-A securities and placing them back in its balance sheet, the bank could save on capital charges (see e.g., Brunnermeier 2009).

The economic rationale of securitisation is that of improving risk diversification. Was it so? The answer would be positive in a world in which securitisation had led to an irreversible transfer of risk from the originator/sponsor to end-lenders who were not only distinct from the groups in the chain of securitisation but also non-leveraged entities. Note that in this case most of the losses from the subprime crisis would have been ultimately borne by end-lenders (households, firms, pension funds, etc.). However, sponsors only sold a fraction of the securities issued by their conduits. As mentioned above, banks actually bought part of the triple-A tranches of ABSs, as these had a favourable risk weight towards the satisfaction of capital requirements. Most importantly, ABSs were typically marketed to end-users with clear (if only implicit) guarantees by the financial groups sponsoring and/or distributing them. Indeed, when the crisis showed that the risk profile of ABSs was quite different than originally believed, banks/sponsors readily "accepted responsibility": commercial banks provided liquidity lines to off-balance-sheet vehicles. SIVs and banks bought these assets back at guaranteed prices from their (best) clients and placed them back on the consolidated balance sheet. De facto, securitisation resulted in an unregulated increase of leverage for any given bank equity.

Now, let's conjecture a world in which ABSs remain quite "close" to the underlying assets in the sense that (a) there is a single securitisation layer between originators of ABS and end-lenders and (b) there are no external intermediaries providing insurance and credit enhancement. In such a world, the risk of these assets would still be relatively transparent and manageable. In principle, even the discovery that most of the assumptions used to price ABSs were overoptimistic would not be too consequential. Surely, it would create losses either for the ultimate holders of ABSs, and/or for the originator, the sponsor and the investment bank doing the securitisation. But in our example "closeness" between the originator and the SPV translates into transparency and quality of information about assets, and, accordingly, there would be no "network externality", by which the rating of the securities would depend directly or indirectly on the rating of different institutions providing insurance. In this case, there would be relatively little uncertainty about prices. This uncertainty would mainly relate to the fundamental components of risk: the percentage of mortgage holders defaulting, the expected loss given default and interest rates. One can imagine that the risk of market illiquidity would be relatively contained. The actual world, however, was far removed from this model.

A key problem contributing to the implosion of the market in fact consisted in the opacity and loss of information inherent in (badly regulated) multiple securitisation layers, with strong interconnection among intermediaries. Typically, SPVs pooled together ABSs from previous programmes over and over again, in many successive rounds. In each round, there would be different forms of credit enhancement, involving different institutions. Some conduits built up asset pools exclusively with existing ABSs and CDOs. In each round, the administrator could only check the previous programme structure, and had to trust the assessment by rating agencies employed by other administrators. ${ }^{6} \mathrm{~A}$ rating mistake in the chain was clearly bound to affect all the tranches issued in each subsequent step, biasing the risk assessment in proportion of the exposure of each ABS to the overrated securities (see the examples in Stucke and Tsomocos 2008). Correcting a mistake, or adjusting a rating in response to a shock along the chain was clearly a daunting problem, as it required a cascade of revisions of rating by different agencies, each having to trust the work of their predecessor. Note that this makes ABSs particularly sensitive to changing market conditions or sentiments, as any correction in prices would be accompanied by a simultaneous increase in the pure uncertainty about the market value of these products.

Because of the complexity of these chains, not only assessing the value of these products against possible shocks could easily become nearly impossible for a single intermediary. It is also apparent that these assets generated strong interconnection among the balance sheets of all the intermediaries in the market. Uncertainty about the price of these products in one intermediary's balance sheet had a systemic compo-

6 Lack of transparency may have also facilitated under-reporting of information. Indeed there is evidence that bankers purposely placed inferior subprime mortgages into securitisation portfolios thus hid ing risk from buyers, including sponsors (see Keys et al. 2008 and Calomoris 2008) 
nent, as it depended on price assessment by many other intermediaries, as well as on their financial standing.

The lesson to draw from the analysis is straightforward. First, ABSs, including MBSs, were ultimately held to a large extent by (highly) leveraged institutions (such as off-balance sheet vehicles that banks had set up for the purpose of receiving these assets, or hedge funds) rather than by non-leveraged investors (this became apparent after the onset and per effect of the crisis). Second, because of the complications in the layers of securitisation, markets faced an unprecedented level of uncertainty and confusion about the incidence of the losses, i.e., which institutions and portfolios were most exposed to them. Thus, diversification of ABSs among intermediaries created network externalities, which actually magnified market liquidity risks. Securitisation thus resulted in a trade off between fundamental risk diversification and exposure to market liquidity risk, in which the second term quickly became predominant.

The puzzling question raised by these considerations is then why, exactly, market participants and intermediaries let this happen without taking sufficient prudential steps to protect their investment. ${ }^{7}$

\subsubsection{Public subsidies}

The boom of mortgage lending and ABSs occurred in an environment where different policies and market dynamics created distortions affecting both origination and securitisation. Many of the policies playing a role in the crisis were actually motivated by equity and efficiency considerations, in part reflecting a longstanding stance of the US government in favour of helping low income and disadvantaged groups to acquire homes. What turned these policies into destabilising factors was a macroeconomic environment that magnified the mutual inconsistencies among them.

In the US, home ownership is subsidized via a number of policy measures (see Calomiris 2008 for detail). As an important example, mortgage interest payments on one's home are deductible from taxes, as opposed to rent, which is not deductible. If interest rates are low and buying a house requires a small or no down payment, ${ }^{8}$ other things being equal, there is an obvious

7 For an analysis of securitisation and an in-depth analysis of the financial crisis focused on Europe,, see European Central Bank (2008a,b), and Bank of England 2007. tax advantage in buying rather than renting a house or an apartment. The tax benefits are actually even more pervasive. Since interest payments on a loan against a car or other durables are not tax deductible, there are tax advantages in refinancing housing mortgages against general household expenditure - as many commentators put it: US households could use their houses as ATM machines.

The mortgage market is also heavily influenced by the large government sponsored enterprises (or GSEs, including Fannie Mae, Freddie Mac and the 12 Federal Home Loan Banks), which were created with the explicit goal of enhancing access to credit by some targeted sectors of the economy as well as efficiency and transparency of capital markets. In the scheme of securitisation presented above, these institutions purchase mortgages from originators and package them into securities which are sold, after adding guarantees, to the secondary markets. They also buy and hold mortgage-related securities in 2008 together Fannie Mae and Freddie Mac held up to $\$ 5.3$ trillion in mortgage risk. Due to public guarantees, these institutions became simultaneously a direct and indirect source of market distortions and a fiscal risk. By virtue of public guarantees on their portfolios, they provided a large buffer for the excessive mortgage risk created by private institutions, and indirectly fed the demand for housing. Their ambiguous nature - not completely public but benefiting from public guarantees - is now recognised as unsustainable. After multiple initiatives to make them viable before and after the start of the crisis in 2007, they were finally placed under conservatorship in 2008, de facto nationalised, under the direction of a newly created agency, the Federal Housing Finance Agency, with ample access to special funds. This is still not a permanent solution; their fate will have to be resolved in the future.

Subsidies to low income households to enter the housing market may well be part of desirable redistributive policies. They could even be seen as a component of a strategy for the democratisation of finance that Yale economist Robert Shiller has been promoting in recent years (see Shiller 2008). In the presence of market distortions, however, they clearly became yet another factor feeding the disequilibrium dynamics of prices and facilitating excessive risktaking.

8 The "American Dream Downpayment Initiative" (signed into law on 16 December 2003) effectively targeted low-income first buyers with funds to eliminate the cost of initial disbursement. 


\subsection{Macroeconomic factors}

\subsubsection{Housing prices}

Between 2000 and 2006, US housing prices appreciated by 80 percent in nominal terms. To many, this strong appreciation, shown in Figure 2.2, is evidence of a bubble. It should be stressed, however, that estimates of the overvaluation in the stock of housing in the US (in terms of the deviation from long-term trend) remain in the range of 20-30 percent (see Shiller 2008). This overvaluation is relative small when compared to other famous episodes of strong real-estate appreciation. Namely, in Japan property prices kept falling for 15 years after their peak in 1991, ending up around 70-75 percent below their maximum values. Similarly, the Nikkei Index reached almost 40,000 in 1991, four times the level in the mid-1980s and five times the level that still prevailed in 2008 .

Yet one of most striking dimensions of the crisis is the puzzling evidence on beliefs of continuing US housing price appreciation, apparently shared by many market participants in the US and elsewhere in the world economy. For many years, market participants appeared to operate as if prices in the US housing markets would either not fall at all or fall only moderately. For instance, Shiller (2008) reports that as late as October 2006, stress tests of the impact of a possible housing price decline on the portfolio held by Freddie Mac assumed that prices would drop at most by 13.4 percent (Shiller 2008, p. 52).

In our interpretation, beliefs of continuing housing appreciation were the result of "social contagion of

Figure 2.2

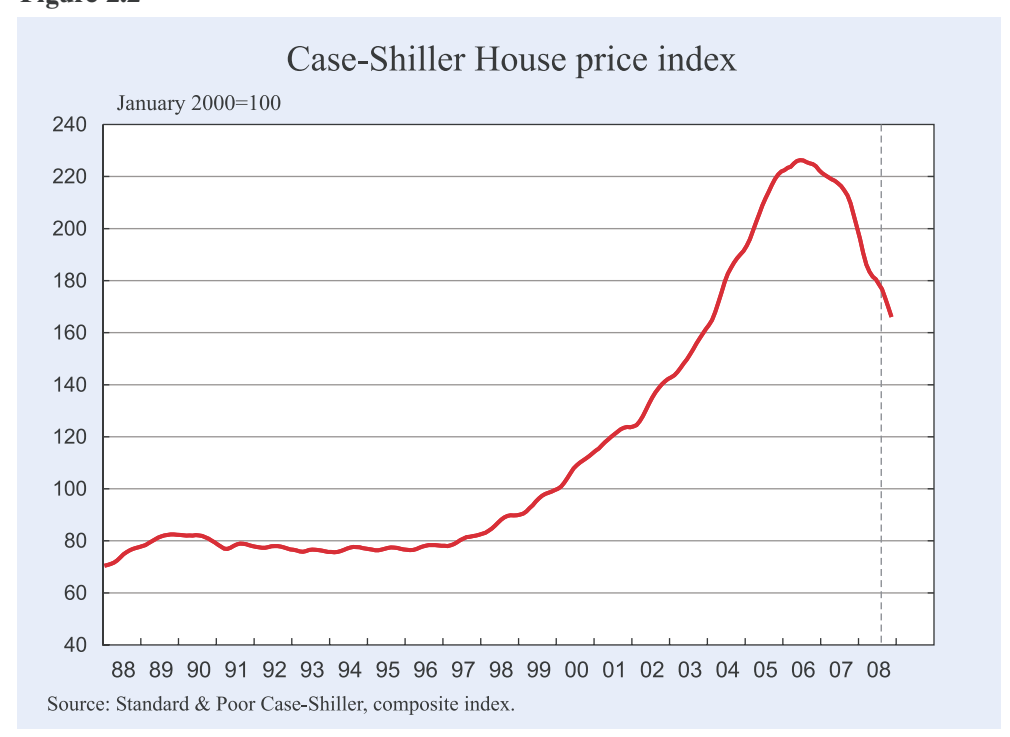

boom thinking", an insufficiently understood mechanism underlying social and economic dynamics in the presence of asset pricing bubbles. For instance, an argument often quoted during the years preceding the crisis was that housing prices had never fallen in the US in the post-war period; as mentioned by Shiller (2008), ads along US highways stated that "on average home values double[d] every ten years." This argument clearly fails to appreciate the distinction between real and nominal prices. Correcting for inflation, the real price of housing fell somewhat during the 1980s and remained stagnant for many years, even though its nominal counterpart kept rising, driven by inflation. Yet, the wording of the ads was obviously designed to appeal to people by providing an argument that reinforced their beliefs.

From the point of view of a financial intermediary, what matters for assessing expected losses from mortgage are both the probability of default by the borrower and the expected loss given default. ${ }^{9}$ Now, we have seen above that whether or not borrowers had income or assets in addition to the houses they were purchasing, contracts were designed in such a way that they had an incentive to refinance the mortgage systematically vis-à-vis the appreciating equity value of their property. In the event of default, banks expected to be able to limit their losses by capturing the capital gains on the repossessed houses.

In spite of the fact that subprime mortgages were relatively new products, these expectations appeared to be backed by some hard evidence. As stressed by Calomiris (2008), the market had already experienced a crisis in the wake of the 2001 recession. Estimates of total losses from mortgage defaults during this episode were in the range of 4.5 and 6 percent of the outstanding stock - figures that appeared to corroborate fully the relatively benign view of the magnitude of possible crises. Unfortunately, the recession at the beginning of the decade was special in one crucial dimension: the contraction in output was not accompanied by any drop in housing prices. With rising prices, both the probability of default and the expected losses

\footnotetext{
${ }^{9}$ According to basic principles of finance, one should also observe that the value of such losses generally depends on their correlation with the performance of the market as a whole.
} 
given default had clearly remained contained. This was, however, in striking contrast with most historical records, which suggest that, in general, fluctuations in economic activity are positively (not negatively) correlated with real estate values.

While estimated losses from the 2001 recession were widely fed as parameters in exercises of subprime mortgage risk assessment, the presumption of a persistent appreciation of housing prices was not without challenge. It clearly came into question in 2006, when the markets experienced a rapid increase in the number of sub-prime downgrades and were provided forecasts of sharp increases in delinquency rates (see Gorton 2008). Puzzlingly, however, mortgage origination and distribution did not slow down immediately, and for some time it kept developing at the same high rates as in the previous years.

For the contributions in the literature that attribute the US housing market dynamics to a bubble, the beliefs that reinforced the vast underestimation of risk during this period were possibly shaped by "social contagion" (Shiller 2008) or "plausible deniability" (Calomiris 2008). In this view, the ever-growing securitisation of mortgages was ultimately fed by different pieces of distorted information, making investors progressively blind to any signals that did not agree with their beliefs. According to anecdotal evidence, for instance, much of the origination and securitisation process occurred under the pressure of institutional investors that were eager to purchase triple-A ABSs. Sponsors chose rating agencies to maximise the amount of high quality tranches they could issue from any given pool of mortgages.

Yet it is hard to believe that such behaviour and beliefs could have been sustained without generalised agency problems and conflict of interests between originators, sponsors and rating agencies, severely distorting the securitisation process. As limited liability contained the size of the maximum losses that different agents faced along the chain of securitisation, the system obviously created strong incentives to expand leverage and take on risk. Supervisory and regulatory bodies may have been aware of these conflicts and distortions but failed to act effectively on them.

\subsubsection{Low interest rates}

For the US, nominal interest rates were quite low for many years after 2001. Short-term real interest rates, calculated by subtracting current inflation from the short-term nominal rates, were actually negative for almost three years, from autumn 2002 to spring 2005 . Similarly, over the same period, the long-term rates remained persistently low and became insensitive to policy rates - a phenomenon referred to as a conundrum by former Fed chairman Greenspan. Long-term yields are depicted in Figure (1.17) of Chapter 1.

Low interest rates clearly contributed to keeping housing prices high. If we formulate the market price of an asset (q) as the expected discounted value of the cash flow generated by the asset $(\mathrm{CF})$ :

$$
\mathrm{q}=\mathrm{E}((1 / \mathrm{R}) * \mathrm{CF})
$$

Here, the discount rate is the inverse of the interest rate $\mathrm{R}$, and $\mathrm{E}$ denotes expectations. For a given cash flow $\mathrm{CF}$, the lower the interest rate $\mathrm{R}$, the higher the current price of the asset. Moreover, to the extent that low interest rates support economic activity in the short and medium run, they can feed expectations of higher cash flows. This is true for bonds, equities as well as for houses.

Less clear, however, is the role of low interest rates in favouring the expansion of subprime mortgages, i.e., the participation of individuals with relatively low income and credit rating in the mortgage markets. The available evidence indeed points to apparent changes in the composition of demand for houses in favour of the lower segments of the market (see Shiller 2008, chapter 2). The sustained expansion of the subprime segment of the mortgage markets accompanies a widening differential in the price dynamics of houses - the strongest price increase prior to the crisis was indeed recorded by the lowest-value segment, i.e., by the smallest and cheapest houses.

One could argue that low interest rates make it possible for poor people to buy a house, taking advantage of favourable financing conditions. However, while low interest rates obviously make mortgages cheaper, they also make houses more expensive. It is far from clear that low interest rates per se would cause a disproportionate expansion in the subprime mortgage segment of the market. A plausible explanation is that low rates were accompanied by mispricing of credit risk, more so and with a stronger impact at the low end of the market. The erosion of lending standards was apparent. Brokers conceded mortgages against no documentation, allowed the combination of two mortgages to finance down payments (the called pig- 
gyback mortgages), lend to "NINJAs" - No Income, No Job or Assets).

A crucial question concerns the extent to which monetary policy-makers have a responsibility in connection with the strong housing price dynamics - a question implying that a stricter monetary policy could have contained the size of the imbalances leading to the crisis. The observation that the Fed pursued low or even negative interest rates after 2001 does not automatically imply that the increase in housing prices should be attributed to the Fed policy. First, these prices kept increasing through different phases of the Fed monetary stance, even when policy rates were raised in 2006. Second, and most importantly, there is the Greenspan conundrum: long-term interest rates, which are arguably more relevant for mortgages, remained low irrespective of (and insensitive to) policy rates.

Low long-term rates actually call attention to a second issue: the global implications of large external imbalances. According to the so-called "savings glut" hypothesis put forward by Fed chairman Bernanke, the large current account deficits run by the US essentially accommodated the strong inflow of resources from the rest of the world (this thesis is discussed in detail by the 2006 EEAG report). Not only global imbalances contributed to keeping long-term rates low; they generated a substantial flow of resources in pursuit of financial assets, arguably influencing, directly or indirectly, US housing demand. We discuss this issue further in Box 2.4.

\section{I.2.3 Leverage cycles}

Before delving into an analysis of the crisis, it is appropriate to clarify how asset prices are linked to leverage by financial intermediaries. This is an essential element to understand not only how continuing housing appreciation has led to excessive risk-taking by financial intermediaries, but also how limited losses in a particular market translate into a recessionary impulse for the economy as a whole.

Drawing upon Greenlaw et al. (2008), we let A denote the total (dollar) value of the assets managed by a financial intermediary (a bank). Let $\mathrm{E}$ denote the value of the bank's capital. Then the ratio $V=\mathrm{E} / \mathrm{A}$ measures the "value at risk" per dollar of assets held by the bank. Obviously, the larger E, the larger the total losses that a bank can absorb. By the same token, define the leverage ratio 1 as the ratio $\mathrm{A} / \mathrm{E}$ : clearly this is just the inverse of the unit value at risk $\mathrm{V}$, that is, $l=\mathrm{A} / \mathrm{E}=1 / \mathrm{V}$. By targeting some given level of leverage, the bank implicitly set a given level of "value at risk".

Three general features of leverage 1 are worth stressing. First, leverage varies across type of financial intermediaries. Commercial banks, which finance their assets through deposits and operate under relative strict regulation and supervision, typically maintain a leverage ratio close to 10 or 12 . Investment banks maintain much higher ratios, of the order of 20-25. So, to the extent that securitisation raises the share of business going to investment banks and other near-banking institution, overall leverage in the system increases. Also, these institutions finance their assets in the market for short-term debt: the maturity structure of their liabilities tends to be quite short. On the asset side, commercial banks have a large proportion of loans that are usually carried at face value. Investment banks instead tend to have a large proportion of short-term claims (e.g., repurchase agreements), so that their balance sheet values closely approximate the market-to-market values of the securities they hold. The same applies to the other nearbanking institutions described above.

Second, historical records show that $l$ moves procyclically: when macroeconomic conditions are perceived to be good (for instance, in a boom or in a bubble economy), demand for loans is buoyant, and the balance sheets of banks/financial intermediaries expand. During a downturn the opposite is true.

Third, leverage amplifies financial cycles. To see this, consider the following simple example, featuring a financial intermediary with securities valued $\$ 100$ at market prices, against liabilities consisting of debt for $\$ 90$, and equity for $\$ 10$.

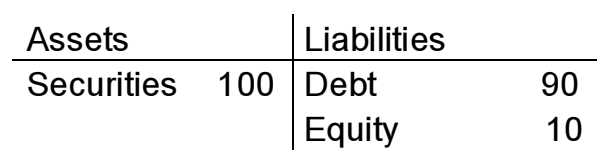

The initial leverage ratio is $100 / 10=10$. Suppose now that the price of securities rises by 1 percent, bringing the total value of assets to 101. If debt value remains constant (this is tantamount to assuming that debt does not respond appreciably to small changes in market values), the value of equity increases by 1 : 
Box 2.4

\section{The crisis and global imbalances}

In recent years, the EEAG reports have devoted chapters and comments to the root causes of global imbalances, corresponding to the emergence of large and persistent US current account deficits associated with financial globalisation, reviewing work on the causes and consequences of them and suggesting possible policy corrections. In this box we address a specific question: whether some of the models in the literature can offer a consistent framework to interpret not only the rise of the imbalances but also their role in the current crisis.

The main argument often quoted by the press is that the critical behaviour of the shadow banking system in the US was fed by the pressure of money flowing from abroad, chasing investment opportunities. By and large this is a popular version of the idea attributed to Ben Bernanke that the US external imbalance has been driven by a global "savings glut", due to the financial integration of the US with economies with a much lower level of development and governance of financial markets, especially the Asian economies.

This vision has been modelled by at least two contributions. A model of a savings glut was proposed by Caballero, Fahri and Gourinchas (2008a,b), henceforth CFG, who build a comprehensive framework to explain, simultaneously, US current account deficits, low interest rates at global level, and the emergence and bursting of bubbles (including bubbles in the commodities market). At the root of this model is "excess demand for assets" by residents in growing emerging-market economies. Excess demand is due to the fact that weak financial systems in their countries prevent these agents from appropriating fully the income generated by assets supplied in domestic markets. When capital liberalisation allows these agents to invest abroad, they look for investment opportunities in countries with better financial systems. As a result, the US (but not Europe) becomes a global intermediary: loosely, the US supplies (the services from) assets to the financially less-developed world in exchange for goods and services. In this interpretation, the US is pushed into a structural equilibrium with low savings and large current account deficits, with the world real interest rates at historical lows.

Now, when global growth is high (reflecting the dynamics of China and India in the last decade), the world is "dynamically inefficient": the equilibrium real interest rate falls below the world growth rate. Economic theory has long made it clear that in an economy with this characteristic, speculative bubbles actually perform a desirable role, i.e., they redress issues raised by a global shortage of assets. In other words, they create the financial means to satisfy the demand for assets from emerging market economies. Which bubble performs this role does not matter. In economies with these characteristics, the collapse of one bubble (internet) is not necessarily bad for the world economy, as long as growth remains high and another emerging bubble (say, in housing), which still provides the financial means to meet the excess demand for assets. In this sense, the CFG model provides a rationalisation of the soft-landing phase of the crisis, discussed in the text. In the first part of the crisis period, the collapse of the housing bubble (which had replaced the previous internet bubble) coexists with a strong rise in the price of commodities, driven by "financial speculation".

What is instead devastating for the world economy is a negative shock to growth prospects. To the extent that lower growth means that the economy is no longer dynamically inefficient, the fall in the demand of assets forces bubbles to burst and thus causes a damaging contraction in asset supply - which can be seen as a deleveraging scenario.

One problem in the analysis by Caballero et al. (2008b) is that as a first approximation, the negative shock to growth is exogenously given rather than modelled as an implication of the financial crisis. Interestingly, under this maintained assumption, Caballero et al. show that a hard landing will not necessarily reduce the US external deficit: as long as the world remains financially integrated, the US will keep its role of world financial intermediary. In other words, the crisis will not influence the root problem of global imbalances - excess demand for assets. For the CGF analysis to become a comprehensive model of global imbalances and a hard landing, however, it must provide an explanation of the link between a financial crisis (associated with a collapse of a bubble) and a persistent (permanent) revision of growth expectations.

A second view of the savings glut hypothesis is proposed by Mendoza et al. (2007) and Corneli (2008) among others, who stress the role of precautionary saving. In this approach, agents in financially less-developed countries have fewer opportunities for smoothing income and production risk (the latter is stressed by Corneli 2008 drawing on early work by Angeletos and Calvet 2006). Hence, residents in the least advanced countries are in need of a larger financial buffer - they save more because of a precautionary motive and invest less because of undiversifiable production risk. Given asymmetric financial structures and/or asymmetric income and production risks across countries, other things being equal, globalization creates a flow of savings from the countries where agents have fewer opportunities to diversify risk to countries where agents have more opportunities to do so.

If, as in Angeletos and Calvet 2006, one envisions production uncertainty as a by-product of financial market frictions, the model can actually account for a strong contraction in production and consumption at the global level following a crisis in financial intermediation, as this naturally translates into a rise in uninsurable production risk. The challenge for modellers in this case is to clarify the link between financial crisis and idiosyncratic production and income uncertainty. This link will also be crucial for understanding the effects of the crisis on global imbalances. Whether US deficits persist after a hard landing will depend on the relative magnitude of production and income risks in various regions of the world.

As an alternative to the savings glut view of global imbalances, many contributions focus on the role of policies pursued in the US and abroad, especially from the 2001 recession on. According to many commentators, these policies translated into a postponement of the required adjustment in savings in the US via the combination of low interest rates, expansionary fiscal policies and a variety of measures with direct or indirect spillovers in the financial markets. An extreme version of this view interprets disfunctional aspects in the supervision/regulation of financial markets as a by-product of the goal of maintaining macroeconomic growth in the US after 2001, even at the cost of excessive macroeconomic risk. In contrast to the analyses reviewed above, this view establishes a more direct link between global imbalances and the crisis, via lenient monetary, fiscal and financial policies in the face of extraordinary housing appreciation

Independently of what generated global imbalances, the link between financial frictions and growth slowdown is explored by a variety of business cycle models that stress fluctuations in confidence and risk premia. An interesting example is provided by Karel Mertens' (2007) analysis of the deep recession in Korea during the crisis in South East Asia in 1997-98. In his analysis, financial inputs are essential to production plans before these can be implemented. In this case, events signalling the possibility of a sharp slowdown in the future can actually create the premise for an expectations-driven, deep slowdown in the short run even if fundamentals remain sound. Note that according to the model, credit shrinks in conjunction with the crisis, but this is no indicator of a credit crunch on the supply side of financial intermediation. 


\begin{tabular}{ll|ll} 
Assets & & Liabilities & \\
\hline Securities & 101 & Debt & 90 \\
& & Equity & 11
\end{tabular}

If the bank did not react to the change in prices, the leverage ratio would fall from 10 percent to $11 / 101=9.18$ percent. This would be inefficient. Maintaining the same target level of value-at-risk profits can, in fact, be increased by raising the volume of business up to the point where leverage is brought back to 10. This would imply an expansion in both debt and securities by 9 dollars

\begin{tabular}{ll|ll} 
Assets & & Liabilities & \\
\hline Securities & 110 & Debt & 99 \\
& & Equity & 11
\end{tabular}

Figure 2.3a
In this example, for a given $V$, one dollar of capital gains in securities raises the level of financing provided by the financial intermediary to the economy by 9 dollars. If the positive capital gains occur in an economic expansion, the growth of financing is actually likely to be larger, for two reasons. First, to the extent that the economic boom generates optimism, the bank may be willing to take more risk: a higher $V$ translates into a lower $l$. Were the leverage ratio raised to 11 , for instance, the securities on the balance sheet would be further increased from 110 to $\mathrm{A}=\mathrm{E}^{*} l=11 * 11=122$. Second, as the additional demand for securities by the bank raises the demand for assets, this may further increase their price: the leverage cycle feeds price appreciation. The graph in Figure 2.3a below illustrates these considerations:
Financial cycles

Figure 2.3b

Financial cycles
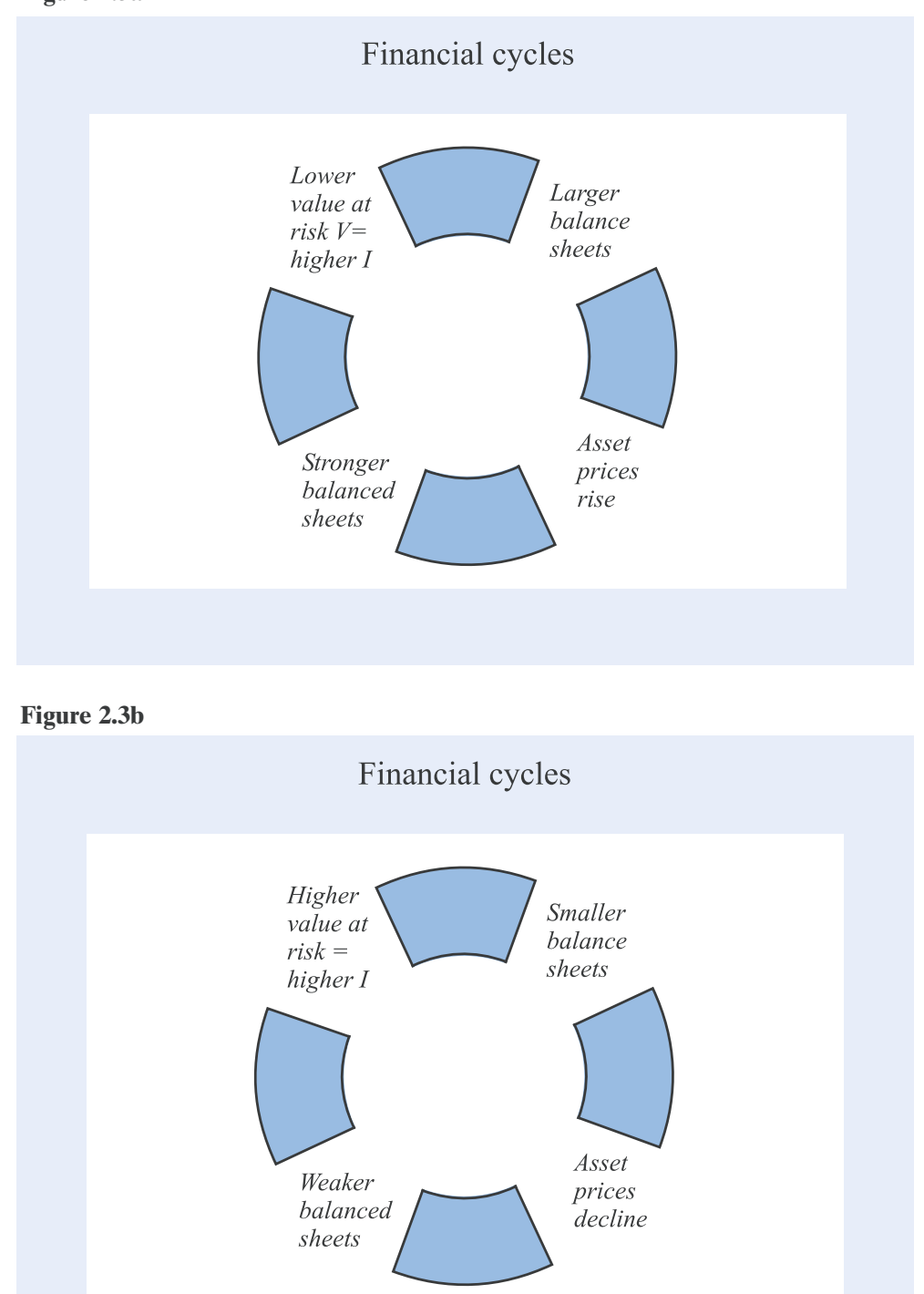

The argument however works symmetrically in the case of capital losses: a drop in the value of securities translates into a contraction of credit which is a multiple of it, see Figure 2.3b. The contraction will be crucially sensitive both to the decision by banks about their target level of value at risk and to possible feedback effects of the credit contraction on asset values and the level of economic activity, which generates the demand for loans. Experience suggests that the interactions of these elements can contribute significantly to economic downturns.

This scheme is quite useful in analyzing the dynamics of the recent crisis, which is apparently characterised by two distinct phases. The first phase starts in 2007, with a run on the so called shadow-banking system, generating extreme stress in some markets but leaving other markets substantially unscathed. Despite the turmoil, somewhat surprisingly, deleveraging is limited in this first phase. The second one begins in summer 2008, when, apparently in response to some policy developments, the crisis 
generalises to all markets, generates threats of runs on commercial banks and spills over to the real economy. At the time of writing, an important question concerns the extent to which deleveraging will contract the activity of financial intermediaries, and how much of this will translate into a constraint on economic growth.

\section{From the panic of August 2007 to the system-wide crisis in autumn 2008: partial recapitalisation, limited deleveraging and liquidity injection}

\subsection{The onset of the crisis}

The crisis erupted at the end of July 2007, after a gestation of a few months. In fact, between autumn 2006 and summer 2007, the macroeconomic context recorded two important changes, possibly interconnected: the first was a moderate slowdown in housing price dynamics; the second was the switch by major central banks toward a more conservative monetary stance, aimed at stemming high inflation rates, in large part fuelled by strong appreciation in commodities. Details about market events and policy initiatives can be found in the chronology appended to this chapter. ${ }^{10}$

Doubts about the sustainability of the mechanism of refinancing and growth in the subprime mortgage markets, and about the real magnitude of risks in ABSs were clearly spreading. A synthetic indicator of these doubts was provided by the asset-based securities index, ABX.HE, launched in January 2006 to track the evolution of RMBSs, based on an equally weighted index of 20 RMBSs, and subindexes of tranches with different rating, for different vintages of mortgages. Gorton (2008) stresses two important functions performed by this index. First, its creation provided the market participants with transparent information about aggregate market valuation of subprime risk, although pricing in these markets may have already reflected some liquidity problems. Second, it provided investors with an instrument to cover their positions in ABSs, by shortening the index itself.

${ }^{10}$ Important collections of opinions and analysis provided in rea time during the development of the crisis are included in Felton and Reinhardt (2008) and Eichengreen and Baldwin (2008). Real time news and analysis are available through many blogs, e.g. "Maverecon," by Willem Buiter, and web services, e.g., the Globa Economic Monitor by Nouriel Roubini, or Vox.
At the start of the trading in $\mathrm{ABX}$, sub-indexes for triple-B securities initially traded at par then moved slightly downward at the end of 2006. They then dropped dramatically in 2007: the subindex for the 2007-Q1 vintage started nose-diving upon issuance; the 2007-Q2 vintage opened far from par, at 60. Most importantly, a similar behaviour was displayed by the CMBX, a synthetic index corresponding to the ABX including 25 credit default swaps on commercial mortgages. In 2007, the strong doubts by investors were clearly systemic rather than concentrated on the subprime RMBS segment.

The high visibility of these indexes obviously had a strong influence on markets: problems in pricing and trading ABSs became common knowledge. Anecdotal evidence points to increasing liquidity problems in placing portfolios including AAA-rated ABSs ultimately backed by mortgages. Indeed, the period from January to August 2007 recorded a series of negative news on late and missing payments on mortgages, especially in the subprime segment, bankruptcies and earning warnings for originators, downgrading of ratings for various RMBSs bonds and CDOs, and large losses for hedge funds, some of which were closed down.

The panic started at the beginning of August 2007, with a run on financial institutions, associated with skyrocketing risk premia and drying up of liquidity the economics of panics is briefly discussed in Box 2.5. However, in contrast to many historical examples, the panic did not spread among depositors of commercial banks, with the exception of the case of Northern Rock in September 2007: instead depositors lining up in front of banks, investors simply stopped extending credit to financial intermediaries, and these stopped extending credit to each other, in fear that direct and indirect contamination of balance sheets with subprime loans would create solvency issues. Also unlike other crisis episodes, many markets were left almost unscathed for many months into the crisis. What follows analyses what happened and discuss the reasons for this differential impact of the panic in different parts of the economy.

\subsection{How the financial turmoil has jeopardised the functioning of the money and financial markets}

As explained above, when the adverse news on the performance of subprime hit the markets, information about the size and incidence of losses was scarce among market participants. The panic spread when 
Box 2.5

\section{Panics and information}

To explain the logic of "runs", it is useful to draw on the seminal work by Diamond and Dybvig (1983) to build the following simple analytical scheme. Consider a three period horizon, 0,1 and 2 . In period 0 , a financial intermediary, a bank, finances a project (or an asset) maturing in period 2, by borrowing short from investors in period 0 and 1 . In addition to financing this project the bank also keeps liquid assets in anticipation that some fraction of the investors will have a need for liquidity in period 1 , thus they will not roll over their debt. To these investors, the bank promises a short-term return $\mathrm{r}$. To investors who keep rolling over their debt for two periods, the bank promises R, equal to the long-run returns on the projects, unless the bank is forced to close down by a "run" in the first period. In the event of a run, the fact that many investors withdraw their credit forces the bank to liquidate projects in advance at a cost, and pay all investors pro rata using the liquid assets and the proceedings of the fire-sale of projects.

A fundamental solvency problem for a bank arises when the return on the projects in period 2 is below what it has promised to investors. Due to the maturity mismatch between the banks' assets and liabilities, however, insolvency may also arise because of the risk of illiquidity, independently of fundamental solvency. The key reason is liquidation costs, which in the event of a run reduce the value of the banks projects below their fundamental value, say R-k. Because of liquidation costs, financial fragility arises because of what economists call "strategic complementarities" among investors.

For given fundamentals, in fact, there are two possible equilibria, vastly different, on which markets can coordinate their expectations: one with, the other without runs. First, suppose that the bank benefits from a good reputation, and markets are calm. In this case, there is little incentive for a single investor to withdraw his/her credit to the bank in the first period, unless he/she really needs the cash - by assumption, this will be true only for a fraction of investors. Waiting until the second period yields a much better return. As everybody follows the same reasoning, everybody ends up following the same strategy: roll over the credit to the bank unless in need of liquidity in the first period. This is the first, good equilibrium. However, suppose now that rumours spread, hinting that people have lost confidence in the bank and a run is likely. Every investor knows that if a sufficiently high number of investors decide to withdraw their credit, the bank will be forced to liquidate all projects and fail. Anticipating a run, he/she will have a good reason to act pre-emptively, and try to withdraw his/her credit as soon as possible. Following this line of reasoning, all will run, confirming in equilibrium the initial rumours, even if these were completely unjustified based on fundamental analysis.

Information and beliefs are key to runs. Asymmetric information of course matters in shaping investors' beliefs about the fundamental value of projects that banks finance, i.e., of their portfolios. The argument above, however, also stresses the importance of beliefs about the behaviour of other investors. Some pieces of information are common knowledge among market participants (public signals), some are owned by specific investors (private signals). As information is costly to produce, the amount and structure of information is in large part endogenous.

In the scheme above we have referred to rumours, which may be interpreted as a public signal reaching all market participants The literature after Diamond and Dybvig has provided many more insights on the role of information in a run (see e.g., Jacklin and Battacharya (1988), Postlewaite and Vives (1987), Morris and Shin (2001,2003) and Rochet and Vives (2004)). A relevant point for our chapter is that the amount of information in the market will depend, to large extent, on the efforts by investors and intermediaries to process data. A recent contribution by Zwart (2008) will help us understand how, starting with a situation of imperfect, noisy information, this could contribute to generate a run, and in turn the run will coincide with further loss of information.

In the first few months of 2007, we saw that public signals (common to all market participants) about the quality and value of ABSs were unequivocally negative. In principle, investors could have improved their judgement by acquiring or producing "private signals", i.e., private research on portfolios. However, given the uncertainty surrounding the chain of securitisation, getting accurate estimates of values was clearly a daunting and costly task. Under the circumstances, the costs of acquiring or producing private signals with sufficient precision were unusually high.

As shown by Sanne Zwartz (2008), if agents expect fundamentals to be relatively bad, they will choose to run and give up investment in private information altogether, as, in equilibrium, the expected benefits (in terms of profits) from acquiring an extra piece of private information is low relative to its cost. In light of this analysis, one could conjecture that the recent panics in 2007 and 2008 actually exacerbated opacity in the market, as during the run investors had little or no incentive to spend resources in figuring out the size and location of subprime risk in different market segments and portfolios. Opacity was at the same time a cause and a result of the crisis.

markets fully realised the scale and scope of information asymmetries engrained in the financial system. During the previous years, expectations of sustained and generalised increases in the prices of housing somewhat reduced the incentive to look carefully into the fundamental components of different ABSs, while collateralised and uncollateralised short-term financing was abundant for the most disparate classes of securities. In 2007, these two conditions failed to persist. Investors clearly realised that they needed to know more about the ABSs in their portfolios: extreme opacity meant that the cost of getting information had become very high; at the same time, growing market illiquidity reduced the benefits from better fundamental knowledge, as all ABSs were dumped together in the same class of "toxic assets". In the absence of a market mechanism valuing transparency, investors simply chose to withdraw from any portfolio exposed directly or indirectly to ABSs.

The main chapter of the panic included runs and illiquidity, rising default risk and flight to quality (a 
detailed description can also be found in many texts, including IMF 2008a,b, Gorton 2008, and Calomiris 2008).

The run on structured investment vehicles (SIVs). A classical run on intermediaries hit vehicles such as SIVs and ABCP conduits, which (a) contained some percentage of securities ultimately backed by subprime mortgages, however small and (b) were funded with short maturity papers. Because of the latter feature, investors could run quite simply, that is, by ceasing to roll over their credit and no longer buying the ABCPs issued by these vehicle (see below). As financing dried up, sponsors intervened and absorbed many of these portfolios back onto their balance sheets: in practice, the SIVs disappeared as a result of the crisis.

The ill-fate of SIVs is revealing with regard to the main features of the crisis. These vehicles did not have a large direct exposure to subprime risk: only a minor portion of their portfolios were invested in CDOs of ABSs, although one could argue that they were exposed indirectly because they held a large share of assets issued by the financial sector. As information problems prevented in-depth scrutiny of their portfolios, the fear of losses of undefined entity and location made investors walk away from them.

Illiquidity of structured products. As investors retreated from any institution and portfolio exposed, if only to a small extent, to mortgage risk, liquidity dried up. The most apparent victim of market illiquidity was the market for repurchase agreements, "repos". Repos are secured loans, i.e.,, lending against collateral. They constitute the basis for inter-bank borrowing and lending, and are one of the largest financial markets in the world.

Starting in August 2007, dealer banks would no longer accept any structured product as collateral, because they anticipated that there would be no market to sell it in case they had to seize it. Once again, there is a clear element of self-fulfilling prophecy: since there was no market to evaluate the price of assets offered as collateral, these assets could not be employed in repos; on the other hand, as these assets were not employed in repos, no

\section{Figure 2.4}

one wanted to trade them in the marketplace. Not only subprime RMBS were rejected as collateral but virtually all types of asset backed securities. A key source of bank financing essentially disappeared.

Spreads and illiquidity of money market instruments. The drying up of liquidity caused a sharp increase in the cost of borrowing in key short-term funding markets for financial intermediaries. This can be measured by the spreads between interest rates that intermediaries charge each other and interest rates paid on instruments which are not exposed to the default risk of intermediaries.

A good example to illustrate this pathology is provided by the spread between the London Interbank Offered Rate, Libor, and the Overnight Indexed Swap, OIS, of the same maturity, both in dollars and in euros. This spread is an indicator of the markets evaluation of credit and liquidity risk of banks. The Libor is an index of interest rates at which banks borrow unsecured funds from each other - the market of reference being the London wholesale money market; it results from the sum of the interest rate on a "sure" loan with a certain maturity and a premium due to the possibility of counterparty default over the terms of the contract. The overnight interest swaps instead track daily (floating) overnight rates - it is a geometric average of them and is referred to as the Fed Funds Rate in the US, or Euro Overnight Index Average (EONIA) in the euro area.

Before the crisis, regardless of the currency denomination, the Libor-OIS spread averaged slightly above 10 basis points. As shown by Figure 2.4, there

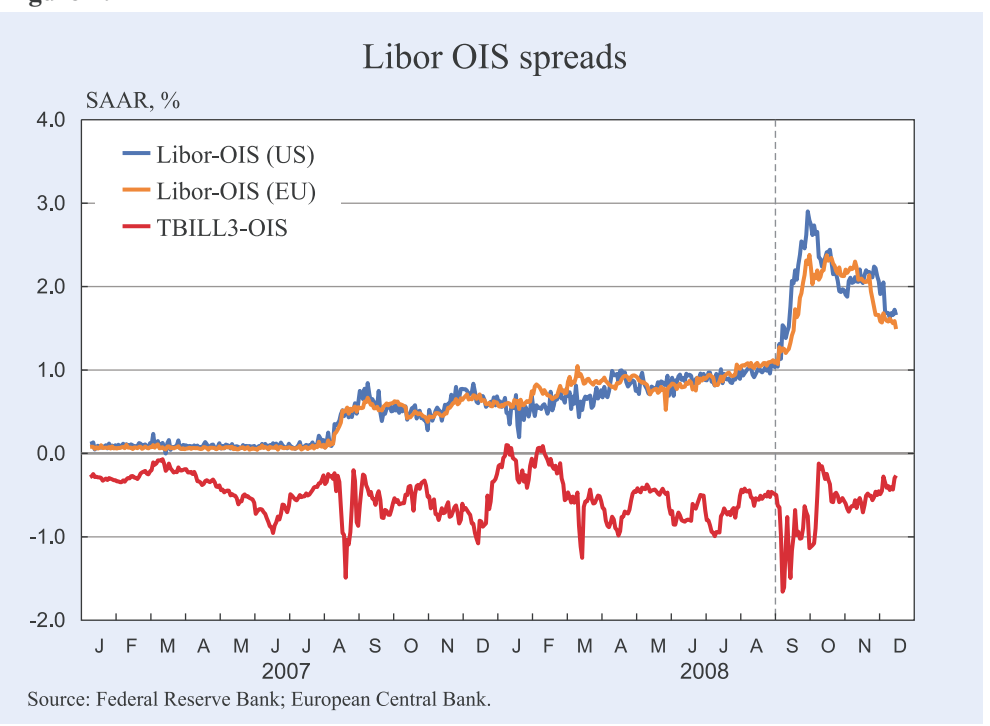


are two apparent discontinuities in the series. One occurred in 10 August 2008, when the spread shot up to 50 basis points, after which date it kept fluctuating widely and far above its pre-crisis average. The other occurred in September 2008, when the spread more than doubled relative to the previous months - this date is marked by a vertical line in the graph.

Since the inception of the turmoil, interbank markets became essentially illiquid for maturities longer than a few days: the maturity structure of the interbank market collapsed. Banks only agreed to trade Libor deposits over a few days. Markets for one or threemonth deposits became one sided, raising issues over the meaning of quoted prices used to construct the interest rate indexes. To date, these markets are still not functioning.

Cross-border and cross-market contagion. The crisis spread rapidly among European banks with large holdings of dollar assets, thus in need of cross-border dollar financing. When the crisis hit the wholesale market in the US, these banks faced higher rates and a lack of liquidity in an important source of their short-term financing need. Their initial response consisted in raising funds in other currencies (euro, yen, sterling) and then turning them into dollars by means of foreign exchange and cross-currency swaps. Through this channel, the crisis rapidly infected currency swap markets, driving up spreads and causing illiquidity.

Marking-to-market and collateral calls. The demand for cash was also fuelled by collateral calls from credit derivative markets. In these markets, collateral calls rise when the spread increases: a rise in the spread means that, in the markets assessment, the sellers of protection are more likely to pay. Hence, these are requested to put down some cash. ${ }^{11}$

As the new Financial Accounting Standard Board Rule 157 became effective, many new positions by financial intermediaries were required to be markedto-market. For the banking and the near-banking system as a whole, a much larger fraction of assets in their balance sheets were thus linked to market prices. While such practice has many merits, a problem arises during illiquidity crises, when asset prices

${ }^{11}$ An interesting observation is that in a situation of market illiquidity, there is a specific funding advantage for the buyer of protection to make a collateral call. Funds received as collateral are paid the Libor. As market rates were well above Libor, collateral usage in derivative markets became an attractive means of financing. arguably move away from fundamental, fair values. Once again, this can generate a self-fulfilling mechanism; as banks try to sell assets and clean up their balance sheets, this depressed asset prices even further.

The spread of the crisis across mortgage markets. We have seen above that the whole ABS sector was fully infected by the crisis. It is worth stressing once again that doubts about the sustainability of the mortgage market clearly spread well beyond the subprime segment. Clear evidence is provided by the spread between jumbo mortgages and conforming mortgage rates. The first are mortgages exceeding the cap defining the "conforming" status, that is, they are large. They are originated in relatively wealthy areas or in locations where the housing price bubble was stronger: roughly 50 percent of them are originated in California. The spread picked up in August 2007, clearly showing that markets were wary about housing prices and anticipated bigger problems exactly where capital gains had been large in the past and values at stake were substantial.

Flight to quality and the price of government debt. In the first phase of the crisis, the loss of confidence in the system of private intermediaries generated a "flight to quality", with a corresponding increase in the demand for government assets. The effect of this flight in the US can be fully appreciated looking at the spread between Treasury Bills and the Libor, the socalled TED (Treasury-Eurodollar Deposit) spread. This spread can be seen in Figure 2.4. This shows the T-Bill-OIS spread together with the Libor-OIS spread: the TED spread is the (negative) difference between the two.

Mirroring the Libor-OIS spread, the absolute size of the TED spread also jumped at the onset of the crisis and fluctuated widely afterwards, vastly exceeding any previous records, e.g., during the 1998 Long Term Capital Management (LTCM) hedge fund crisis. The sign of the spread is negative, however: government assets were perceived as much safer than private assets. Also the TED spread shows two apparent discontinuities: one in August 1997, the other in September 2008 .

Interestingly, however, for many months into the crisis the flight to quality did not hit sovereign debt from emerging market economies, which maintained their access to international markets at relatively favourable conditions. 
Figure 2.5



Virtually no market was spared, however, when the crisis generalised in September 2008, corresponding to the second widening of the spreads in Figure 2.4.

\subsection{Liquidity or solvency crisis?}

Especially during the first months into the crisis, a view that informed much of the debate was that the crisis was essentially due to illiquidity, not to insolvency, of financial intermediaries. Using again the simple balance-sheet example at the end of the previous section, it is worth exploring the differences in these views in

Contraction in the market for commercial paper. The stock of asset backed commercial paper (ABCP) also dropped dramatically with the crisis, by more than 30 percent in the first few months of the crisis. This is shown in Figure 2.5, where the outstanding stock of $\mathrm{ABCP}$ is plotted together with the stock of non-asset backed commercial paper.

The figure illustrates two important and crucial features of the crisis. First, the contraction in the size of the market for asset-backed commercial paper after August 2007 was abrupt and enormous reflecting the above mentioned speculative run, with investors walking away from financial ABCPs. The crisis completely eroded the extraordinary growth experience by that market since 2004, hitting the shadow banking system the most. Second, for a number of months after its eruption, while illiquidity affected money and interbank markets, together with the market for structured products, many important classes of assets and markets remained largely unaffected. Indeed, as shown by the figure, the market for non-asset backed commercial paper, unrelated to financial firms, remained on trend until summer 2008.

Similar considerations could be made for US equities, high-yield bonds and emerging market debt. For instance, the Dow Jones Industrial Average reached an all-time high on 9 October 2007. A clear divide between financial and non financial assets emerged while the market for financial commercial papers contracted immediately, non-financial commercial papers kept being traded for many months into the crisis. some detail. The premise of the liquidity view of the crisis is that fundamental losses from the subprime segment of US mortgages - the segment where the crisis was perceived to be originated - were not too large relative to the capital of financial intermediaries. In other words, consolidating the balance sheets of all intermediaries in the market (netting out their bilateral credit and debit position), one should have obtained according to this view an aggregate balance sheet like the following:

\begin{tabular}{ll|ll} 
Assets & & Liabilities & \\
\hline Securities & $100-2$ & Equity & $10-2$ \\
& & Debt & 90
\end{tabular}

In this example, losses are arbitrarily set equal to $\$ 2$, out of $\$ 100$ of original securities (this example is actually far more pessimistic than the initial estimates of losses from subprime mortgages). Losses on assets obviously reduce equity, in the example from $\$ 10$ to $\$ 8$. As a result of the crisis, the value at risk, measured by the ratio of equity to assets, falls from $10 / 100$ to $8 / 98$, which is from 10 percent to 8.16 percent. Leverage (the inverse of value at risk) increases from 10 to 12.25 . Note that if financial firms wished to restore the initial (pre-losses) target of value at risk, in the aggregate the reaction to the loss of 2 would consist in either an increase in equity by the same amount or a contraction in debt and securities by 10 , according to the logic of de-leveraging cycles described above.

However, even if the consolidated aggregate losses were indeed small relative to equity, at the onset of the 
2007-2008 crisis the balance sheet of each single intermediary looked more like the following

\begin{tabular}{|c|c|}
\hline Assets & Liabilities \\
\hline Securities 100-? & $\begin{array}{ll}\text { Equity } & \operatorname{Max}[10-?, 0] \\
\text { Debt } & 90-\operatorname{Max}[0, ?-10]\end{array}$ \\
\hline
\end{tabular}

where the estimate for aggregate losses (2) is replaced by question marks, reflecting the inability to locate risk with any precision. Specifically, neither the managers nor the investors and creditors were able to produce a precise assessment of losses on the balance sheet of an intermediary - although, obviously, the amount and quality of information would typically differ across creditors, equity holders and managers.

In our example, equity will remain positive as long as the losses specific to an intermediary (bank or near-bank) remain below 10 , at which point the value of equity would be completely wiped out. Because of limited liability, the value of equity can be written as the maximum between "10-losses" and 0 . Correspondingly, debt is safe for losses up to 10. For larger losses, the value of debt will decrease by the size of losses minus equity. Hence, the value of debt will be 90 less the maximum between 0 and "losses minus 10".

If the consolidated financial sector's aggregate losses were indeed below aggregate equity, a number of financial intermediaries should have been in relatively good shape. Yet, the high level of uncertainty apparently prevented investors from telling insolvent institutions apart from sound ones. This uncertainty was clearly conducive to financial fragility, as investors were weary of the quality of the intermediary's assets. Since August 2007, this has been enough to create generalised illiquidity in money markets, notoriously characterised by zero risk tolerance.

Opacity also blurred the assessment of the amount of resources required to intervene in support of the banks. This amount should be measured up to their net liabilities: if two banks insure each other against different events, ex post only one will be paying the other, thus at most one will be in trouble, of course to the extent that it had not priced risks appropriately - including the risk of being unable to raise cash from the market when this becomes illiquid. However, a high level of opacity about magnitude and incidence of risk and generalised market illiq- uidity considerably complicates the picture. Given the strong interconnection among intermediaries via opaque securitisation, it is ex ante unclear which bank will be in trouble under which contingency. Hence, the perceived need for ex-ante public support to banks tends to be measured up to their gross liabilities - i.e., the sum of liabilities of all intermediaries (see the discussion in Buiter 2008 and Caballero and Krishnamurthy 2008).

Consistent with the liquidity view of the crisis, the discovery of the aggregate magnitude of losses would be facilitated by some institutional arrangement resulting in a de facto large, economy-wide clearing house for all structured products - an institution which would stand ready to purchase all outstanding assets at their fundamental value, financing these purchases by issuing clearinghouse securities to the market. Some of the initial plans were indeed inspired by this view.

Over time, the confidence in the liquidity view of the crisis was shaken not only by adverse news about fundamentals but also by protracted illiquidity of markets. Consider the event of a run on a financial intermediary which is forced to sell its assets in an illiquid market at a loss (see the box on panics). As the total value of the assets on its balance sheet is not necessarily in line with their fundamental values (whatever this is), the expectations that drive the run in the first place are validated ex post. For the representative intermediary, asset and liabilities look as follows:

\begin{tabular}{ll|l} 
Assets & \multicolumn{2}{|l}{ Liabilities } \\
\hline Securities & $100-2-k$ & $\begin{array}{l}\text { Equity } \quad \operatorname{Max}[10-2-k, 0] \\
\text { Debt 900-Max[0,50+k-100] }\end{array}$
\end{tabular}

The illiquidity-related cost $\mathrm{k}$ can be high, up to wiping out equity and eroding substantially the value of debt. By the very nature of illiquid markets, the exact amount of $\mathrm{k}$ is uncertain and volatile: even small sales may move prices substantially. Any ex ante estimate of asset sale prices may turn out to be far removed from what is effectively realised in a fire sale (see e.g., Allen and Carletti 2008).

In principle, since asset backed securities (ABSs) in the portfolios of intermediation are collateralised, one may expect that losses are bounded from below by the market price of the collateral, e.g., ultimately the price of houses for residential mortgage-backed securities (RMBSs). However, first, a run on financial institu- 
tions may exacerbate the decline in house prices that undermine financial stability in the first place. Second, the (illiquid) market price of houses, which is relevant for the owner, is above what accrues to the intermediary in case of repossession.

These considerations suggest that during a crisis concerns about fundamental solvency and illiquidity become strictly interwoven: it is quite hard to disentangle their role in market assessments of bank-specific risk. Indeed, studies addressing this issue by looking at the determinants of the Libor-OIS spread reach contrasting conclusions (see e.g., ECB 2008a,b, IMF 2008a,b and Michaud and Upper 2008). These empirical exercises are nonetheless valuable as they tend to show the overwhelming weight of systemic aspects of the distress, for instance, by detecting an "epicentre" for the turmoil consisting of a relatively small group of intermediaries playing a major role in the interbank market.

Whether because of fundamental considerations or as a result of the erosion of values due to persistent illiquidity, the view of the crisis switched to "insolvency" in summer 2008 .

\subsection{The dynamics of the crisis and public interventions: the hopes for a "soft landing"}

A crucial feature of the turmoil is that for a number of months after the eruption, many markets remained untouched by the crisis. Most importantly, there was little evidence of spillovers on to the real economy, of the gravity that the ongoing financial turmoil could be expected to generate. What exactly can account for the relatively benign transmission in the early phase?

In the literature on global imbalances, a soft-landing is generally envisioned as a dynamic equilibrium in which the US reduces the current account deficit with contained dollar depreciation and no deep recession (see e.g., Obstfeld and Rogoff 2007, Krugman 2007, Faruqee et al. 2007). ${ }^{12}$ In many dimensions, this soft-

12 The recent literature on global imbalances has often referred to "soft landing" and "hard landing" to build scenarios for the rebalancing of international portfolios, i.e., capital and trade flows, associated with a reduction in the US current account deficit (a distinction reconsidered by Bilbiie and Corsetti 2008 in relation to the crisis). In the policy debate on the "excessive US current account", a hard landing refers to an abrupt crisis of the dollar, with the US being forced to close its external deficit in a short time span (see for instance the analysis of Roubini and Setser 2004, stressing the financial dimension of the crisis). The EEAG 2008 emphasised that the function of dollar movements envisioned in these different scenarios of global adjustment is more that of rebalancing relative national wealth across regions of the world rather than enhancing narrowlydefined competitiveness of the US goods market (see also Corsett 2007, Corsetti, Martin and Pesenti 2008) landing scenario appears to describe well the first phase of the crisis, from early 2007 to summer 2008 . This was so despite the fact that the illiquidity of structured products persistently jeopardised the normal functioning of money markets and progressively undermined the viability of highly leveraged financial intermediaries relying on short-term financing, most notably investment banks.

Over this first phase, the prevailing view among policy circles was that the fundamental problems at the root of the admittedly dangerous pathology in money markets were relatively manageable, in the sense that they could be absorbed over time by adopting a twoarmed policy approach. On the one hand, central banks would make up for the lack of liquidity in the interbank markets by providing financial intermediaries with enough cash to operate without relying on each other for credit. Liquidity provision would then buy time for banks to restructure, namely, to raise new equity capital and write-down bad debt - while containing the need for sharp de-leveraging with the associated negative effects on real activity. On the other hand, treasuries and central banks would intervene on a case-by-case basis to support banks under threat of failure - either as a result of a run or because of fundamental losses. (The main principle driving interventions being the need to preserve the functioning of large intermediaries with many market interconnections, whose failure would have strong systemic effects.)

In this respect, a first important piece of evidence is that in the months after September 2007, the financial sector was able to raise new capital of more than $\$ 430$ billion (calculated up to September 2008). The ability to raise capital under crisis conditions (i.e., illiquidity and falling bank security prices) was clearly remarkable relative to previous crisis episodes (see Calomiris 2008). In 2007, the new capital came in large part from institutional investors and sovereign wealth funds - the presence of the latter raising an issue in the control of large corporations in the US and Europe by foreign states; in 2008 most of the new capital came from public investors. Banks raised new capital by issuing hybrid securities, i.e., combining features of both bonds and equities, especially in the US, whereas banks relied more on stocks in European countries (see IMF 2008b). ${ }^{13}$

${ }^{13}$ Over the same period, banking institutions undertook an estimated $\$ 580$ billion in write-downs. Write-downs were mostly concentrated in the US and in Europe (see IMF 2008a,b). 
Figure 2.6a

Quarterly changes in assets and leverage of US investment banks

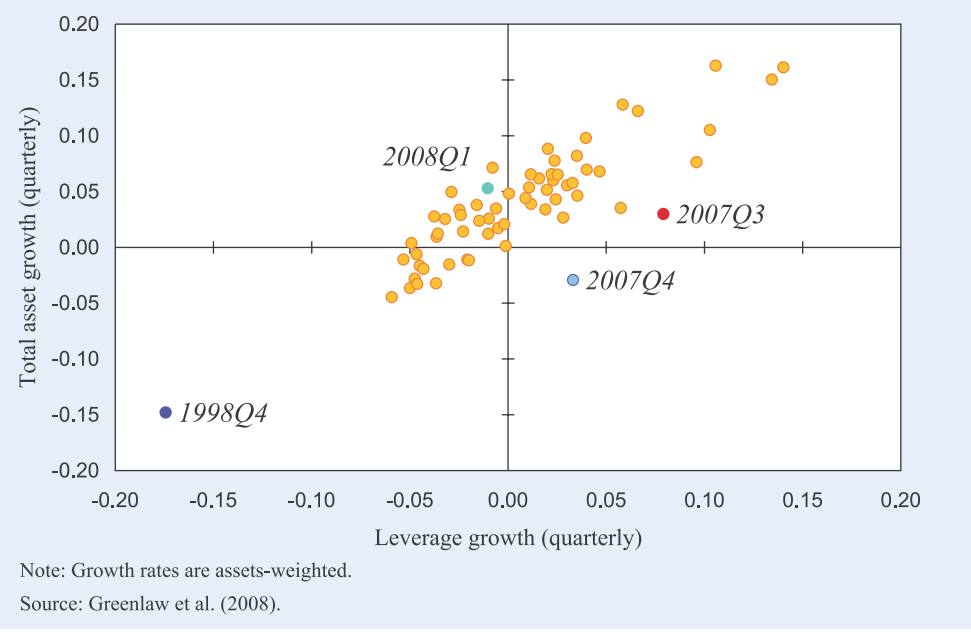

Figure 2.6b

Changes in leverage and assets for major US commercial banks

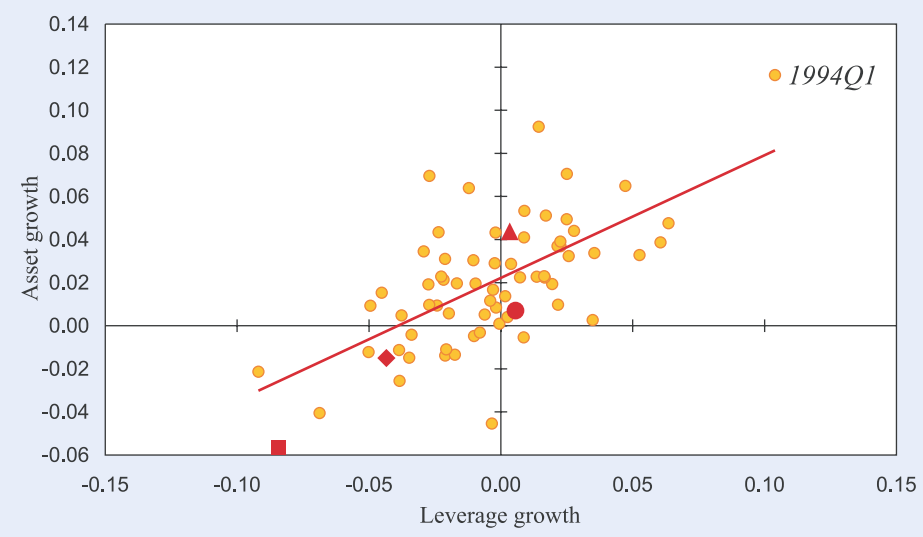

Note: Data are adjusted for mergers. $\boldsymbol{\Delta}=9 / 30 / 2007,0=12 / 31 / 2007, \square=12 / 31 / 2001, \diamond=12 / 31 / 1990$.

Source: Greenlaw et al. (2008).

What did this equity injection imply for the intermediaries' balance sheets? To address this question, we reproduce two figures from from Greenlaw et al. (2008). For US investment banks and major US commercial banks, Figures 2.6a,b plot total assets growth against leverage growth (data are adjusted for mergers) at a quarterly frequency between 1998 and the first quarter of 2008. The two figures confirm two well-known stylized facts: typically, (a) the correlation between the two growth rates is strongly positive, and (b) periods of slowdown and asset market crisis are associated with a contraction of both leverage and asset growth, while periods of real and asset market booms are associated with an expansion in the same variables.

Coming to the crisis period, the graphs suggest that the first quarters into the crisis were special in two respects. First, in contrast to the other critical episodes for financial intermediaries, such as the LTCM crisis in 1998 and the 2001 stock market turmoil, there was little evidence of a "deleveraging cycle", which should have placed the observations corresponding to 2007-Q4 and 2008-Q1 in the lower left-corner of the graph. Second, especially for US investment banks, leverage growth was actually unusually high, given total asset growth.

To a large extent, the expansion in leverage of investment banks reflected the fact that these intermediaries provided liquidity and credit support of SIVs and other ABS conduits - as a consequence of explicit and implicit contracts between intermediaries and their clients, to whom structured products were sold with guarantees. Whatever the reason, however, the message from the graphs is that balance sheets of financial intermediaries did not shrink in the early months of the crisis. While this is no evidence that credit conditions remained easy - conditions for lending could have been tighter - this behaviour, anomalous relative to the typical cycle, arguably contributed to delaying the effect of the crisis on the real economy.

On the policy side, the strategy of recapitalisation and write-downs was supported by liquidity interventions on a progressively larger scale. Over time, central banks intervened more frequently, with larger amounts, providing longer term funds, broadening the collateral and counterparty list and opening lending facilities for non-commercial banks. Central banks also reinforced cross-border cooperation in liquidity management and provision by establishing cross-border dollar swap lines. They made it clear that they could (and did) adopt non-conventional intervention measures whenever deemed necessary (see e.g., Bank of International Settlement 2008, and Borio and Nelson 2008). Indeed, the balance sheets of central banks changed in composition and size after 2007, and sharply so in autumn 2008 - the compara- 
Figure 2.7

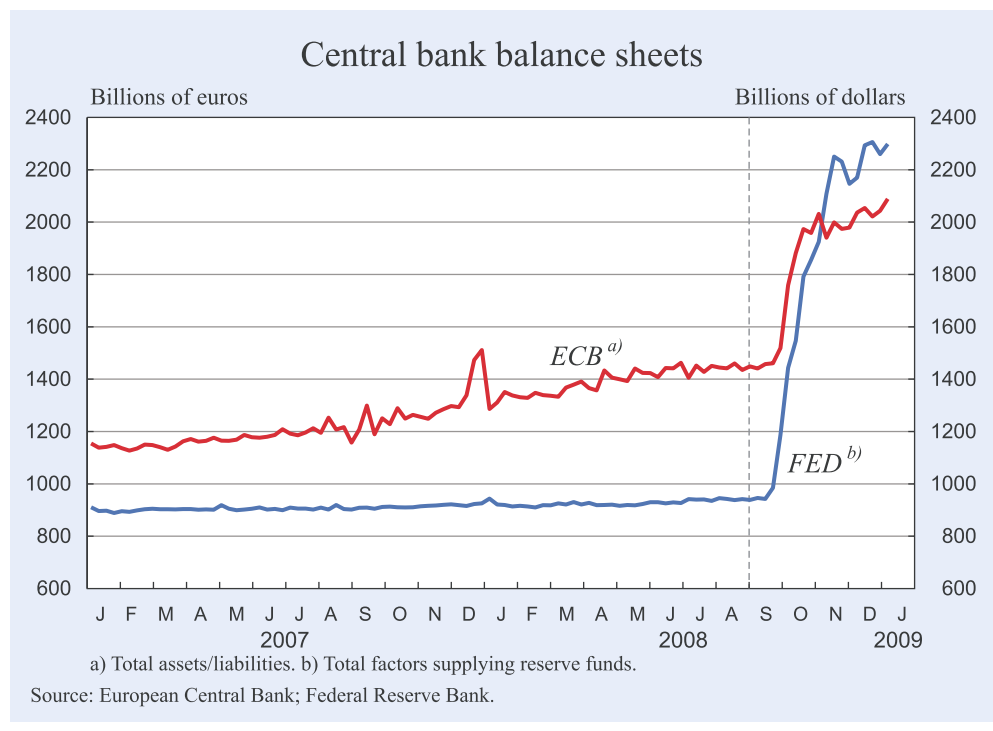

tive evolution of the size of the balance sheet of the Fed and the ECB is shown by Figure 2.7.

The strategy appeared to work, at least initially. As shown in our chronology of the crisis, autumn 2007 was characterised by a series of important writedowns by major international banks worldwide. It was clear that the crisis would spare virtually no corner of the global market, from German banks, which were particularly exposed to ABSs, to the Bank of China, which revealed $\$ 9$ billion losses as early as 4 September 2007. The UK authorities were not able to avoid a run on the deposits of Northern Rock, the first bank run after more than a century. Arguably, the picture of depositors standing in line before the bank doors became a powerful image, reinforcing awareness of the fragility of the financial system, despite the fact that no one lost money. The event made it painfully clear that monetary, fiscal and supervisory authorities should have quickly verified the consistency of their framework and action. Coordination across borders also emerged as a priority but has remained an unsolved issue - see e.g., the lack of communication among authorities when Société Générale announced huge losses due to unauthorised activity by one of its traders in January 2008.

Central banks intensified liquidity injection and refined their intervention to make sure they could reach commercial banks in need of funds. One important issue faced by the monetary authorities was in fact the reluctance of banks to ask for assistance, because of the implied "stigma effect". Banks wanted to avoid the negative feedback from letting the market know about their need for emergency funds - a piece of information which could have clearly triggered a revision of market assessment of the bank solvency for the worse. Monetary authorities moved to guarantee the anonymity of banks asking for funds. For instance, complementing new rules governing the discount window already in place for some years, on 12 December 2007 the Fed set up a Term Auction Facility (TAF), allowing banks to bid anonymously for 28-day loans against a set of collateral broadened as to include MBSs. While some of these measures turned out to be effective, at different stages of the crisis the stigma effect remained a key constraint on the effectiveness of policy intervention.

As the magnitude of losses mounted in size and crossborder contagion became more pervasive, on 12 December 2007 the Fed, the European Central Bank and the Swiss National Bank established a swap line, an important milestone in international monetary coordination. However, a clear divide emerged regarding interest rate policy. The Fed had already cut rates in three steps of 25 points in autumn 2007 and in an emergency move, it cut them by 75 basis points on January 22, and by 50 basis points at the end of the same month; it continued to lower rates in March and April. Fed officers during this period defended their choice on the ground that while commodity prices were rising, headline inflation and core inflation remained quite subdue. On the other hand, the Bank of England remained focused on inflation risks and did not cut rates in the first months of the crisis, despite the Northern Rock episode; it then cut them three times between the beginning of the crisis and October 2008, however keeping rates at 5 percent throughout the spring and summer of the year. The ECB also remained focused on inflation risks, explicitly pursuing the strategy of separating liquidity support from the cyclical monetary stance. In the euro area, rates remained untouched at 4 percent until summer 2008, when they were actually raised by 25 basis points.

In addition to continuing announcements of losses and write-downs by major international financial institutions, the beginning of 2008 saw the emergence 
of the crisis among monoline insurers, traditionally active as insurers of municipal bonds - because of the guarantees by monoliners, these bonds could benefits from a AAA rating. The markets became aware that monolines had progressively extended their business to ABSs and different types of structured products. Because of their small capitalisation, there was the risk of a generalised downgrade of monoliners, with important systemic effects. In fact, a downgrade of monoliners would have had a cascade effect on the rating of municipal bonds and other private bonds, as well as structured products, markets with an estimated face value of $\$ 2.4$ trillion. In turn, a downgrade of these securities would have forced many institutional investors (such as money market funds) to sell them off, with an obvious dramatic effect on their prices and the liquidity of these markets (see Brunnermeier 2009). Not surprisingly, the downgrade of the monoliner insurer Ambac by Fitch triggered a large drop in stock market values world-wide. Markets for municipal bonds as well as a number of other markets (e.g., student loans) suffered a sudden drying up of liquidity.

The bailout of Bear Stearns in mid-March 2007 was interpreted as a successful intervention against the risk of systemic shocks from the failure of a relatively large, interconnected intermediary. The bailout was justified on the grounds that the collapse of Bear Stearns appeared to be driven by marked illiquidity rather than insolvency. The reliance on short-term financing by investment banks created a heavy exposure to liquidity risk, pointing to a problem that eventually led to the end of the model of investment banking as highly leveraged institutions financing their asset positions by rolling over short-term debt instruments. Yet, it has been noted (Vives 2008a) that the Fed did not have first-hand information on Bear Stearns, as this was outside its supervision. How can a central bank with no supervisory power over investment banks tell whether one such institution is or is not insolvent?

The extension of the lender of last resort facility outside the commercial banks de facto started on 11 March, 2007, when the Fed created the Term Securities Lending Facility (TSLF), which essentially granted investment banks the same terms of the TAF. With an endowment of $\$ 200$ billion, the TSLF enabled investment banks to swap different mortgagerelated bonds for Treasury Bills for a period of up to 28 days in secrecy.But liquidity support was not enough to save Bear Stearns, which had suffered from the collapse of the Carlyle Capital Corp. early on in the month, and was hit by widespread rumours of insolvency. ${ }^{14}$ Over the weekend of March 14-16, the New York Fed engineered its rescue by granting a loan of $\$ 30$ billion to JPMorgan, which in turn agreed to buy Bear Stearns initially for \$2 per share (these shares were valued $\$ 150$ one year before).

At the same time, the Fed announced the Primary Dealer Credit Facility (PDFC). Since primary dealers are mostly investment banks, this facility in effect is a discount window for such intermediaries. This was regarded an important step, as the bailout of Bear Stearns was in part justified as a way to prevent others institutions, such as Lehman Brothers, from collapsing. The new facility eased liquidity concerns in the market.

While the stock market reacted positively to the Bear Stearns deal, markets and commentators noted that equity holders were severely hit, while bond holders completely spared in the rescue. Under some pressure, JPMorgan agreed to raise its initial bid from $\$ 2$ to $\$ 10$ per share. Moreover, emerging political opposition to the Fed loan to JPMorgan created tension among the customers of Bear Stearns. To stem political opposition, JPMorgan agreed to assume the first billion of losses in the $\$ 30$ billion loan by the Fed.

In the same period, the US treasury eased the capital requirements on Fannie Mae and Freddie Mac to prevent the negative spillovers from a contraction of liquidity in the ABS markets (and the housing markets). At the end of May, the crisis seemed under control, although illiquidity in the money markets remained somewhat critical.

The essential prerequisite for placing confidence in the intervention strategy described above was its macroeconomic counterpart, that is, confidence in the fact that growth would remain relatively strong in many emerging markets and to a lesser extent in Europe, even if the US were to experience a slowdown. Obviously, without sustained global growth, the financial side of the soft-landing strategy would be much more demanding.

From a macro perspective, real-financial decoupling corresponded to a growth decoupling: according to many observers, some trimming of growth expecta-

14 The crisis was apparently triggered by miscommunication by email between a hedge fund and Goldman Sachs on March 11 and 12, see e.g., Brunnermeier (2009). 
tions in the developed world would have had little impact on activity in emerging markets. This view had three important implications. First, the financial crisis in the US and elsewhere could have been addressed in a context where the US current account deficit would remain on a declining path, thus redressing global imbalances. Figure 2.8 shows the US current account together with the multilateral exchange rate of the dollar since the year 2000. Indeed, there is a mild sign of a turnaround in the US deficit after 2006, which persisted in 2007, despite the fact that the hike in oil prices (see below) clearly slowed down adjustment in this period.

A strong external sector would have helped sustain the level of activity in the US. Figure 2.9 shows calculations by the Fed on the net export contribution to real GDP in the US, showing that during the crisis period, external demand was indeed a strong engine of growth.

Second, a positive growth differential between the rest of the world and the US could be expected to keep the dollar weak in real terms. Indeed, the dollar kept depreciating well into the crisis until summer 2008. Figure 2.10 reports the dollar exchange rates over the same period. On a multilateral basis, the dollar remained weak in the softlanding period. It depreciated against the euro sharply in March, at the time of the Bear Stearns bailout and of the 75 basis point cut in the target Federal funds rate. An interesting question is whether the progressively expansionary stance of US monetary policy at the time and the associated debate on the need to rebalance growth and inflation

\section{Figure 2.8}

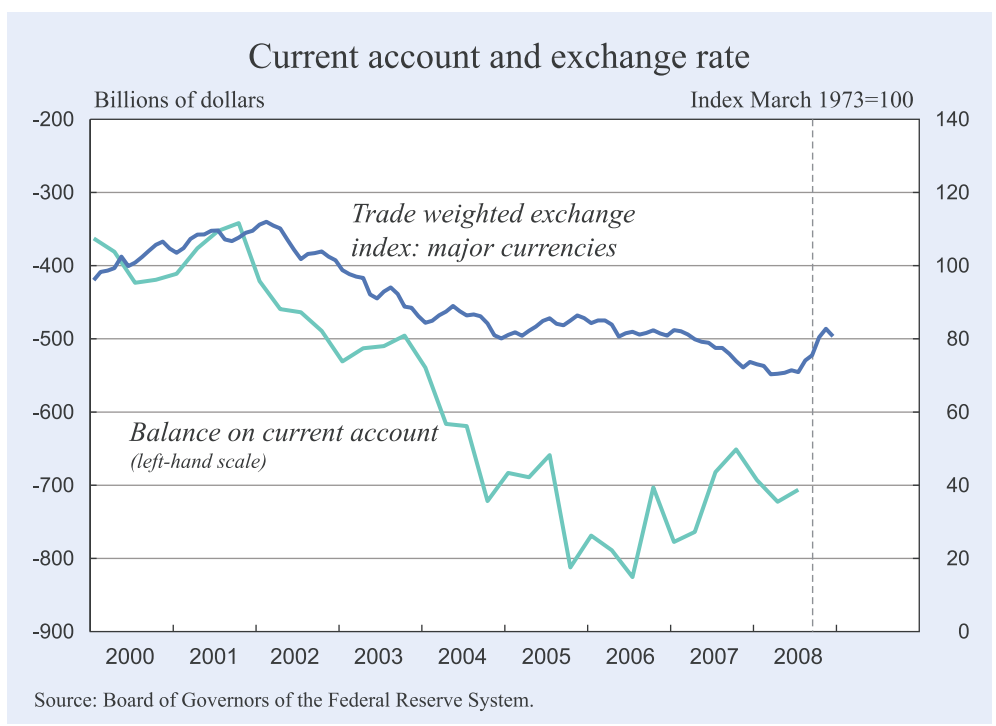

Figure 2.9

Net export contribution to real GDP in the USA

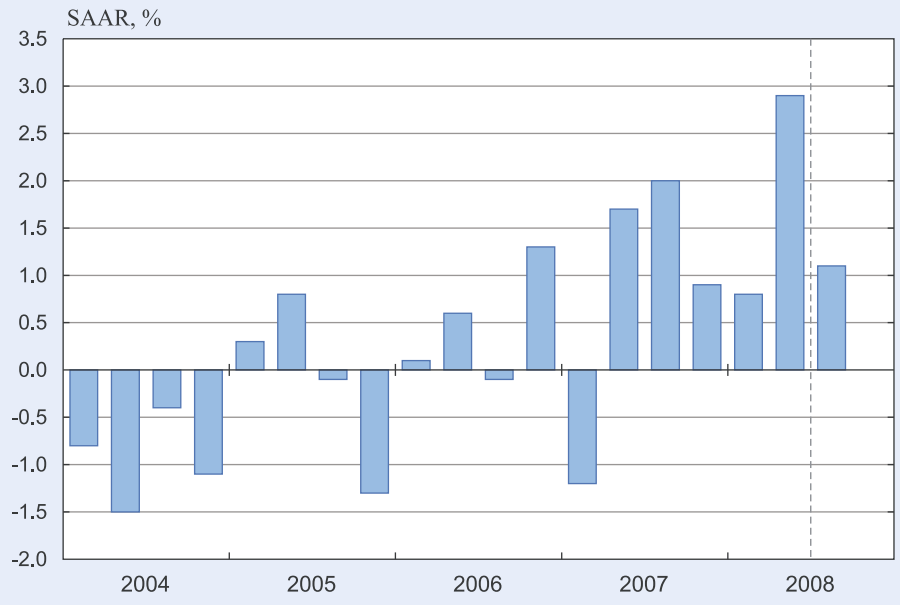

Source: Federal Reserve Bank of New York.

Figure 2.10

Dollar exchange rate

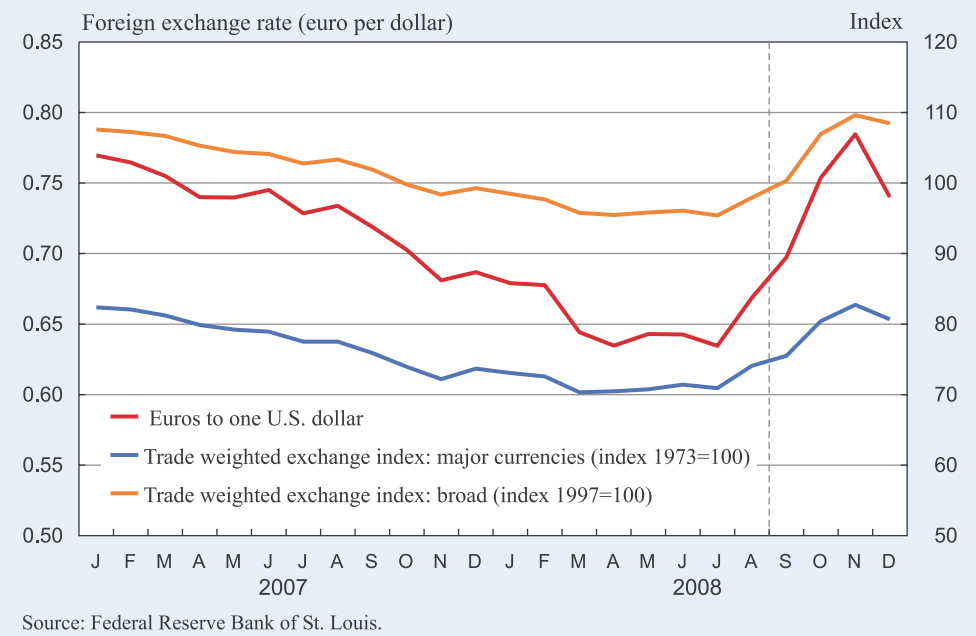


Figure 2.11

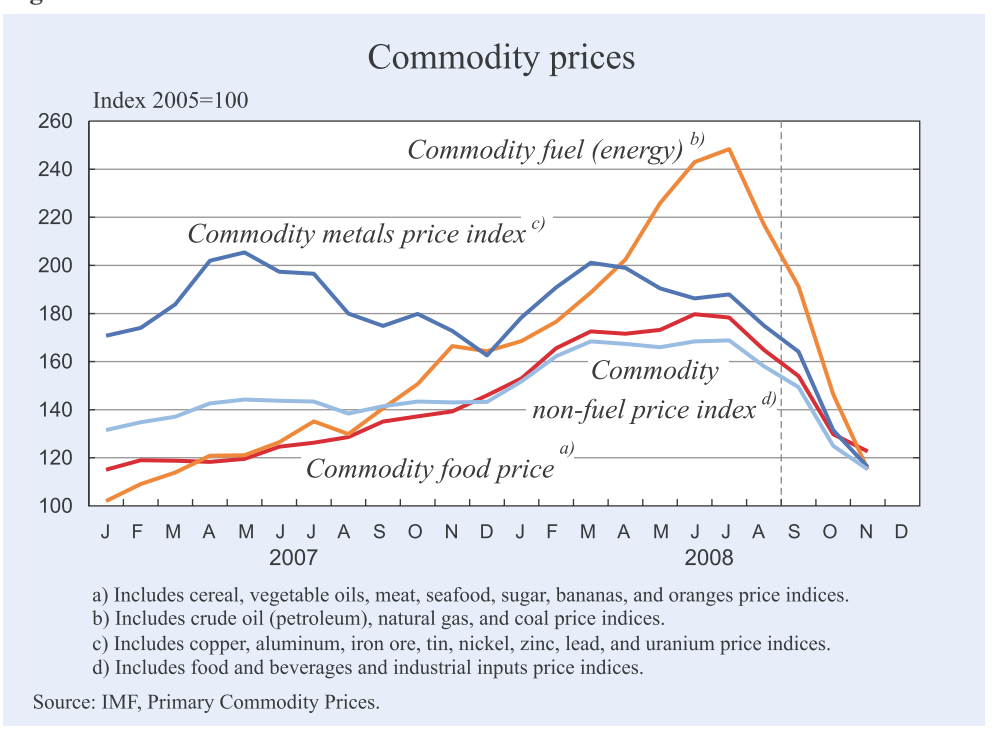

economy. Growth decoupling meant that possible difficulties of the US would not compromise economic activity in the rest of the world. Notable by-products of these two decoupling hypotheses were buoyant commodity prices, global inflation and a weak dollar. In 2007 and 2008, the weak dollar helped the US in sustaining employment and output, with net exports becoming the most dynamic component of demand. The dollar steadily weakened over the first months of the crisis, accelerating its decline during the bailout of Bear Stearns.

risk, could have induced market expectations of a widening in the inflation differential between the US and Europe over the medium term.

Third, the increase in the price of commodities, especially energy, experienced already in the previous year, was not expected to abate. Even observers who attributed it to speculative forces would recognize that as a result of world growth and some other intervening factors (e.g., the expansion of bio-fuel), the world had entered a new era characterised by higher relative prices for food and oil. Figure 2.11 shows the development of selected indices of commodity prices from January 2007 on.

Not surprisingly, the soft landing period was dominated by the policy debate on global inflation and stagflation. As mentioned above, while there was little evidence that core and wage inflation had accelerated significantly, the European Central Bank (and other monetary authorities) preferred to maintain rates at a constant level, even increasing them at the beginning of the summer. Thus strong liquidity support to the market was not matched by a looser stance of interest rate policy.

To sum up, the financial and macro policy in a soft-landing scenario through summer 2008 rested on a double decoupling hypothesis. Real-financial decoupling meant that the problems of the financial sectors could be addressed so as to minimize the negative implications for the real
A descriptive summary of the features of soft-landing phase is provided by Table 2.3 below.

\subsection{The near collapse of September-October 2008 and the onset of the deleveraging cycle}

Coordination of expectations on the soft landing hypothesis ended in July-August 2008. The assessment and perception of the magnitude of the financial crisis rose with new figures on mortgage delinquency rates and also as the Federal Deposit Insurance Corporation took over the California-based Indymac Bank, then hit by a run on deposits. In response to spreading financial turmoil, the Treasury stepped up its commitment to support Fannie Mae and Freddie Mac in July, making the government guarantee explicit at first, before placing them under federal conservatorship at the beginning of September.

Most crucially, the real-financial and growth decoupling hypotheses no longer held up against the evi-
Table 2.3

\begin{tabular}{|l|l|}
\hline Beliefs: & It is a liquidity crisis (contained losses) \\
\hline & $\begin{array}{l}\text { Financial-real decoupling (contained } \\
\text { deleveraging) }\end{array}$ \\
\hline Financial & $\begin{array}{l}\text { Growth (US-EU-Emerging markets) } \\
\text { decoupling }\end{array}$ \\
\hline & Recapitalization \\
\hline Monetary Authorities: & Write-downs \\
\hline Lovernment: & $\begin{array}{l}\text { Lase-by-case approach to bailout } \\
\text { intermediaries }\end{array}$ \\
\hline
\end{tabular}


Figure 2.12

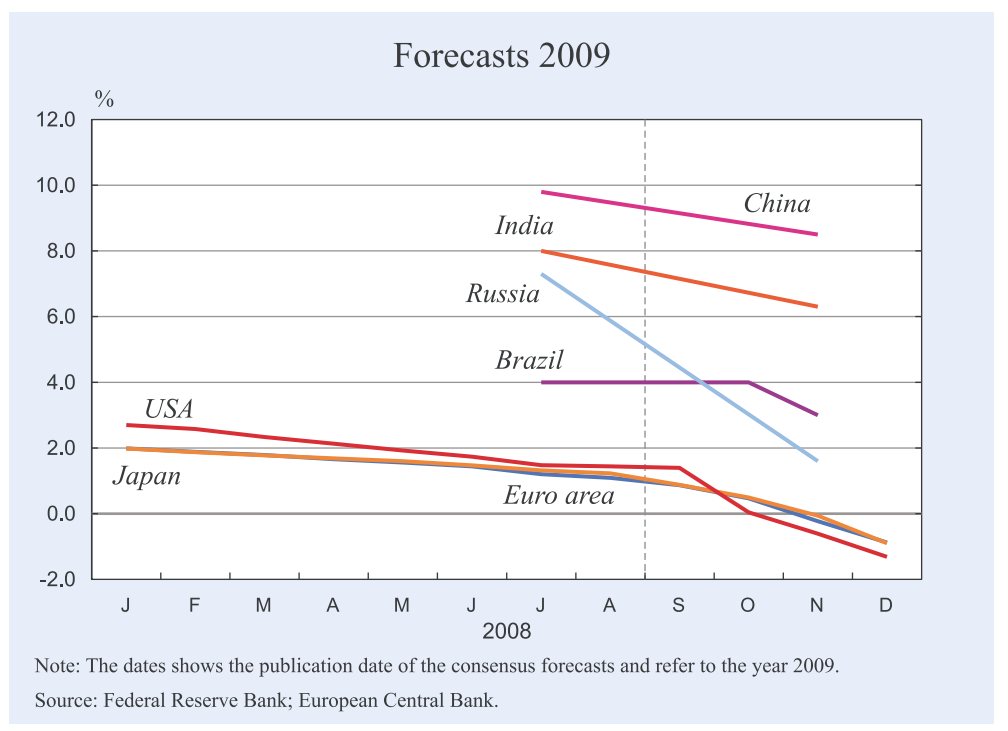

- shattered hopes for a soft-landing. Lehman Brothers had narrowly escaped a collapse in March, thanks to the positive effects on market confidence of the rescue of Bear Stearns in March as well as by virtue of the access to the new facilities set up by the Fed. It was however unable to raise new equity, as its management apparently perceived to be in a Catch-22 situation: new equity was needed to restore the economic viability of the bank; however, trying to raise new equity would have signalled to markets severe balance sheet problems. Lehman conditions sharply deteriorated when

dence. Figure 2.12 reports the consensus forecast for the US, euro area and Japan, together with the IMF forecasts for Brazil, China, India and Russia. As shown by this figure, and discussed in Chapter 1, they all started to fall in summer 2008.

With the revision in global growth rates, not only the price of commodities started to fall synchronically and dramatically (see Figure 2.11). Most strikingly, the dollar started to appreciate substantially, despite the US clearly remaining the epicentre of the crisis (see Figure 2.10).

In September, the large and generalised run on financial intermediaries in the aftermath of the decision to let Lehman Brothers fail - almost turning into a run on deposits by the public in mid-October the Korea Development Bank, which had expressed an interest in buying the firm, decided not to do so. In mid-September, the NY Fed started a process to rescue the bank, involving Barclays and Bank of America. However, unlike in March, the US government made clear that no government guarantee involving taxpayers' money would be provided. When Barclays withdrew and the Bank of America bid for Merrill Lynch, Lehman was forced to file for bankruptcy.

While Lehman was as interconnected as Bear Stearns, according to many commentators the US Fed and the Treasury believed that possible systemic effects from a collapse would have been contained, as market participants had time to prepare for it. This presumption was clearly wrong. The bankruptcy of Lehman jeop-

\footnotetext{
Box 2.6

Risk assessment of CDSs and CDOs at AIG

AIG sold insurance on debt securities backed by financial assets such as subprime mortgages, and corporate and personal loans. The insurance sold took the form of a credit default swap (CDS). AIG promised the buyers of the CDS that if the underlying securities defaulted, AIG would cover the losses. This obviously exposed AIG to default risks of the underlying securities (say the subprime mortgages). According to models based on historical data, this type of risk was assessed as being very small. However selling CDS involved other types of risks that were not contemplated by AIG. Namely, the contracts stipulate that the buyers of the CDS can demand collateral from AIG if the underlying securities decline in value (it is like a margin call in a futures market) or if the very rating of the debt of AIG is downgraded. AIG did not consider this type of risk until the second half of 2007. As a result, AIG was exposed to very large collateral calls (for example from Goldman Sachs) without being adequately protected. ${ }^{1}$

AIG had started in 2004 to provide insurance on complex securities such as collateralised debt obligations (CDOs) based in turn on securities like mortgage bonds. Some of these CDOs were extremely complex, covering many securities backed by different types of financial products (from mortgages to auto loans to credit cards receivables). In early 2006 AIG decided to stop exposure to such complex CDOs. In any case from mid-2007 on mortgage securities started to be downgraded and the buyers of insurance from AIG grew worried. The demands for collateral by these insurance purchasers started a dispute with AIG - How much collateral should AIG post? - which was settled with Goldman at some point. Meanwhile in late 2007 and 2008 AIG undertook major write-downs of the value of the swaps. The failure of Lehman Brothers in September 2008 induced a downgrade of the credit rating of AIG, which would have required AIG to post more than $\$ 18$ billion in additional collateral to the purchasers of insurance. At this point the US government bailed out AIG. The loan commitment of the government to AIG, up to $\$ 123$ billion, seems to have been eaten up to a good portion by further collateral calls from AIG's counterparties.
} 
ardised counterparties of its contracts around the world, with far reaching effects. For instance, the bankruptcy had a strong impact on the industry of money market funds, many of which "broke the buck", i.e., their share prices went below $\$ 1$, because the underwriters of their (AAA) assets - then under severe distress - could no longer buy these assets back. The price of default risk skyrocketed.

Nonetheless, contemporaneously, the US authorities decided to intervene in defence of the US insurance giant AIG, which, operating world-wide, had become increasingly exposed to the crisis through business in the credit default swap market - the case is discussed in Box 2.6. After providing a $\$ 20$ billion lifeline on September 14 (when Lehman Brothers filed for bankruptcy), the US authorities took control of AIG and injected $\$ 85$ billion in the firm on September 16.

The decision to let Lehman Brothers fail while supporting AIG was clearly seen by the markets as the outcome of a piecewise policy lacking coherence and vision. Both markets and policy-makers understood that confidence in financial intermediaries (hence money market standards) could not be restored without a systemic and comprehensive strategy, addressing both current market illiquidity and medium and long-run solvency. With the switch of market expectations towards a situation of global systemic crisis, market illiquidity became widespread. Investors ran from both financial and real private assets, marking the end of some classes of intermediaries, such as investment banks - forced by market illiquidity and turmoil, Morgan Stanley and Goldman Sachs gave up their status and became commercial banks on 22 September 2008. Following the familiar patterns of flight to quality, investors raised the demand for government debt which was perceived to be relatively less risky than private assets. However, risk assessment worsened for largest and more advanced countries such as Germany, and risk premia widened interest differentials across government debt by different countries, a salient example being the spectacular in the risk assessment of the UK. Investors ran on fragile economies, causing currency and financial crises especially in small countries which were perceived as lacking the tax base and tax capacity to offer credible guarantees on gross liabilities by their intermediaries (such as Iceland). Many emerging market economies which had remained (surprisingly) unscathed for many months fell victim to the waves of speculation that jeopardised any hope for continuing financial and fiscal stability.
The difficulties of the government to present a coherent and possibly co-ordinated plan to address the crisis almost caused a run on deposits in mid-October, when nervous investors started to withdraw cash from banks (many newspapers reported an unusual rise in the demand for home safe-boxes), and many switched banks, looking for intermediaries backed by the strongest government guarantees.

Most interestingly, the dollar appreciated sharply with the exacerbation of the crisis, raising issues in the perception of risk by the markets. The response of the dollar is quite intriguing in light of the vast literature envisioning the resolution of the global imbalances as a large and sustained fall in the value of this currency. ${ }^{15}$ Envisioning an international run on the US, many commentators in the past would indeed have predicted a crisis in terms of large dollar devaluation possibly associated with a US recession (perhaps undermining the role of this currency as an international vehicle currency). That is obviously quite different from what we experienced in 2008, with the cross-border run on financial institutions spreading throughout the largest (and most financially advanced) countries.

An important element in our interpretation of the phase of soft landing is the fact that, initially, the effect of the crisis on deleveraging was quite contained. In the hard landing scenario after autumn 2008, it is quite likely that the world experiences a deleveraging cycle, possibly with an impact on the level of activity by firms and the spending plans of households. Since September 2008, global rebalancing has been proceeding in the form of substantial write-downs by financial intermediaries. At the end of 2008 total reported write-downs amounted to around $\$ 1$ trillion, as shown in Table 2.4. How much more is to be expected, crucially depends on the total size of losses by financial intermediaries. The $\$ 1.4$ trillion estimated by the IMF (2008b) at the end of 2008 appeared utterly unrealistic at the beginning of the new year.

A caveat is in order. Looking at banks' activity it may be quite difficult to ascertain a strong delever-

\footnotetext{
15 This argument essentially draws on the tradition of the "transfer problem" (popularised after the debate between Keynes and Ohlin regarding German reparations after World War I), whereas a hard landing consists in the "double punishment" from falling terms of trade when a country pays back what it owns: intuitively, because of relative price movements, the economic cost of adjustment raises the debt. There are variants of this double punishment - most peop th EEAG 2008); Corsetti, Martin and Pesenti (2008) work out the economics of transfer with product differentiation and sectoral re-allocation of production, showing that high welfare costs may occur independently of terms of trade movements.
} 
Table 2.4

Writedowns and credit losses

\begin{tabular}{|c|c|c|}
\hline Banks & Company & $\begin{array}{c}\begin{array}{c}\text { Total writedowns and credit losses } \\
\text { since Jan } 2007 \text { (\$bn) }\end{array} \\
\end{array}$ \\
\hline 1 & Wachovia & 95.5 \\
\hline 2 & Citigroup & 67.2 \\
\hline 3 & Merrill Lynch & 55.9 \\
\hline 4 & UBS & 48.6 \\
\hline 5 & Washington Mutual & 45.6 \\
\hline 6 & HSBC & 33.1 \\
\hline 7 & Bank of America & 27.4 \\
\hline 8 & National City & 26.2 \\
\hline 9 & JPMorgan Chase & 20.5 \\
\hline 10 & Lehman Brothers & 16.2 \\
\hline 11 & Royal Bank of Scotland & 15.8 \\
\hline 12 & Morgan Stanley & 15.7 \\
\hline 13 & Bayerische Landesbank & 14.8 \\
\hline 14 & Wells Fargo & 14.6 \\
\hline 15 & $\mathrm{IKB}$ & 14.4 \\
\hline \multirow[t]{2}{*}{16} & Credit Suisse & 14.2 \\
\hline & Worldwide & 741.2 \\
\hline Insurers & Company & $\begin{array}{c}\text { Total writedowns and credit losses } \\
\text { since Jan } 2007 \text { (\$bn) }\end{array}$ \\
\hline 1 & $\mathrm{AIG}$ & 60.9 \\
\hline 2 & Ambac & 10.6 \\
\hline 3 & Hartford Financial & 7.9 \\
\hline 4 & Metlife & 7.2 \\
\hline 5 & Allianz & 4.5 \\
\hline 6 & Prudential Financial & 4.4 \\
\hline 7 & Allstate Corp & 4.4 \\
\hline 8 & MBIA & 4.3 \\
\hline 9 & Swiss Re & 4.2 \\
\hline \multirow[t]{2}{*}{10} & Aegon & 3.8 \\
\hline & Worldwide & 146 \\
\hline \multicolumn{3}{|l|}{ GSEs } \\
\hline & Company & $\begin{array}{c}\text { Total writedowns and credit losses } \\
\text { since Jan } 2007 \text { (\$bn) }\end{array}$ \\
\hline 1 & Freddie Mac & 58.4 \\
\hline \multirow[t]{2}{*}{2} & Fannie Mae & 56 \\
\hline & Total & 114.4 \\
\hline
\end{tabular}

Source: Bloomberg.

aging cycle in the 2008 data - a strong position in this respect has been taken by Chari et al. (2008) in a provoking piece showing evidence that credit has in fact not collapsed with the crisis. However, as stressed by Adrian and Shin (2008a), in judging the extent of the contraction in credit, it is crucial to disentangle the role of commercial banks from other market-based institutions. Market-based credit (including credit cards, auto loans and student loans) has shrunk dramatically with the crisis; bank lending may have held its own or even correspondingly increased, arguably because of the role of banking in providing a financial buffer when market conditions deteriorate.
Equally difficult is the assessment of the potential impact of a credit crunch on real economic activity (see early calculations by Greenlaw et al. 2008). Yet, it should be stressed that even in the absence of any crunch, a simple assessment of the wealth effects from portfolio losses (stocks and financial instruments) and declining housing prices (with the caveats stressed e.g., by Buiter 2008), suggests that private spending will contract by several percentage points, dragging output many points below potential.

Indeed, stock values around the world fell sharply in 2008 - the most well-known indexes lost between 30 and 50 percent in domestic currencies, in many cases setting disturbing historical records. In the context of the crisis, this global contraction in financial wealth can be expected to have far-reaching implications, well beyond the immediate impact in demand. Combined with the loss of confidence in the ability of financial intermediaries to price, manage and diversify risk, the market downturn is likely to translate into widespread changes in the modalities of households' participation in financial markets as well as strong pressure on governments to intervene beyond normal standards of regulation and supervision.

As in the previous subsection, we can conclude our analysis with a descriptive account of the hard landing as we experienced it by the end of 2008 in terms of the following scheme, where most entries are the negative of the soft-landing scenario, but there are also additional important new entries, listed last, which refer to the willingness by governments to counteract the crisis with high doses of fiscal policies, and possibly pursue some form of coordination (see Table 2.5). 
Table 2.5

\section{Hard-landing}

\begin{tabular}{|l|l|}
\hline Beliefs: & It is no longer a liquidity crisis \\
\hline & No financial-real decoupling \\
\hline & No growth decoupling \\
\hline Financial & Write-downs \\
\hline & Deleveraging \\
\hline Monetary & Liquidity provision \\
\hline Government: & Search for a comprehensive approach \\
\hline & Fiscal expansions and deficits \\
\hline & $\begin{array}{l}\text { International policy coordination in fiscal, monetary } \\
\text { and exchange rate? }\end{array}$ \\
\hline
\end{tabular}

Comparing this with the previous scheme raises the question of whether the soft-landing phase was driven by misleading expectations of a relatively benign solution to the crisis, or whether such prospect was in fact jeopardised by policy mistakes - ranging from the reluctance by central banks and treasuries to intervene more directly at the root of market illiquidity at global level already in 2007, up to the decision to let Lehman fail, which apparently coincided with a vast shift in market expectations.

Perhaps, had expectations of growth and real financial decoupling been less optimistic, policy makers would have intervened more swiftly and comprehensively early on, preventing market illiquidity from eroding progressively the value of banks' assets well beyond the toxic ABSs.

\section{The deepening of the banking crisis: challenges to policy-makers}

The sudden worsening of the financial and economic outlook in autumn 2008 radically changed the policy landscape. The mix of market pathologies underlying the crisis posited formidable challenges to public intervention. In the very short run, policymakers had to stop the liquidity crisis from escalating, up to turning into a run on commercial banks. At the same time, it became clear that restoring conditions for the normal functioning of markets and financial intermediaries would not be possible unless toxic assets were removed from the intermediaries' balance sheets and governments found a way to deal effectively with widespread bankruptcy of major global players. All this while the extraordinary slowdown of the economy created enormous demand on fiscal resources to support growth via public spending and tax cuts.
Stemming liquidity runs. In the weeks after the bankruptcy of Lehman Brothers, the first issue governments world-wide had to address the generalised liquidity run that stormed intermediaries, and at some point (in midOctober) threatened to affect commercial banks. Political failures and weaknesses in the response to the crisis (with the uncertainty created in the process of approval of the Paulson plan by the US congress, and the uncoordinated and weak response by Europeans governments) apparently raised the risk of a global financial meltdown. Eventually reacting to this threat, governments extended public guarantees to creditors and depositors. Public funds were committed to this end in most countries to complement deposit insurance funds. These measures were indeed effective in stemming the incipient run on commercial banks. However, they added to the stock of contingent public sector liabilities, i.e., implicit government debt which may become explicit in the event of a financial turmoil jeopardising people's trust in banks.

Notably, the initial reaction in Europe revealed the lack of political will and/or capacity to coordinate in a timely manner: some countries (notably Ireland) moved first to raise substantially the ceiling for deposit guarantees, as to gain first-mover advantages in the global competition for savers' deposits, and thus relax the financing constraint on domestic intermediaries. This early move forced other countries to react swiftly in the same direction. Ironically, agreements at the European level could only be reached on the floor, rather than the ceiling, for deposit guarantees.

Restarting the interbank market. Throughout the crisis period, massive collateral lending by the central banks and governments virtually came to replace interbank markets. This is clearly a problem for central banks and governments. While potentially affecting the transmission of monetary policy in unknown ways, it adds to the stock of contingent public liabilities by exposing monetary authorities to massive default risk.

The extension of government guarantees also to transactions among intermediaries to revive the interbank market did not appear to be equally effec- 
tive, let alone desirable. With the development of the crisis, it had become clear that the lack of confidence among banks is rooted in doubts about one another's solvency. A bank contemplating invoking guarantees on its transactions would be significantly discouraged by the stigma effect associated with them. On the other hand, while extending public guarantees on all transactions would eliminate the stigma effect, it would also create severe moral hazard distortions, somewhat defeating the ultimate goal of restarting these markets.

In the current equilibrium, the commitment of central banks to provide ample liquidity against broad collateral clearly crowds out private collateralised lending, if anything by exacerbating adverse selection problems. The magnitude of central bank lending is boosted by the effect of the crisis on banks' preference for liquidity. Essentially, banks hoard liquid assets as self insurance against their own liquidity needs and losses, and perhaps as a means to profit from future opportunities to acquire assets at minimum fire-sale prices.

Cleaning up financial intermediaries' balance sheets. Consistent with the view that the crisis mostly reflected a large component of market illiquidity, in the US the initial proposals for a comprehensive approach to cleaning up the balance sheet of financial intermediaries focused on the idea that the government should buy illiquid toxic assets from banks at a price closer to their fundamental value, than to the (fire-)sale price in illiquid markets. At the root of the Troubled Assets Relief Programme (TARP) was the notion that the main distortion jeopardising the economic viability of financial intermediaries was market mispricing.

The simple balance-sheet example adopted above helps illustrate how this strategy could work (see also Kaplan 2008). Suppose that a bank owns toxic assets for a face value of $\$ 10$, which are however valued by (illiquid) markets at only $\$ 5$. Accounting for fundamental losses, the value of holding them to maturity at the current interest rates could instead be set at $\$ 8$. Through a program like TARP, the government could buy these assets from the bank for $\$ 8$, insulating the overall balance sheet of the intermediary from the cost of illiquidity. The effect of such purchases is shown at the bottom of the page.

Note that the intervention does not prevent the bank from remaining undercapitalised (although not to the same extent as before intervention), hence in need of either expanding equity, or reduce assets (loans).

This strategy would pursue two interrelated goals. The first is to address the distortions due to market illiquidity. By valuing assets at some notion of their "fundamental value", the government can improve the value at risk of banks, therefore relaxing an important constraint on bank lending. To the extent that the difference between the market and the purchase price is only due to illiquidity, there is not a cost for the taxpayers: over time the cash flow from the asset will compensate for the initial disbursement.

The second, crucial goal is to reduce the opacity on assets and liabilities on the balance sheets of intermediaries, which has been feeding the mistrust at the root of market illiquidity. Cleaning up the banks from toxic assets could re-create the conditions for intermediaries to trade among each other according to normal competitive standards. Note that this benefit could materialise even if the purchase price of assets were relatively low, i.e., closer to their evaluation by illiquid markets than to their fundamental value.

This strategy runs into at least two issues. The first is how to set the purchase price. To pursue the first goal (addressing pricing distortions due to illiquidity), the purchase price cannot be set too low, close to the (illiquid) market valuation of $\$ 5$. If so, the intervention would not improve intermediaries' balance sheets. Not only there would be an unnecessary transfer from bank creditors to taxpayers, but the intervention would do nothing to improve leverage in the banking system, with the risk of causing a large reduction in loans and credit. In principle, the price should be set as close as possible to the "fundamental value" of an asset: in this case the intervention would come at no cost to the taxpayers and would contain the risk of unnecessary deleveraging. But toxic assets are quite heterogeneous, and information on them is limited and strongly asymmetric: the scheme exposes the government to severe adverse-selection distortions. At any given price, intermediaries would be willing to sell only assets for which their subjective 
evaluation is lower than the cash offered by the government. The government could then end up paying systematically too much, implying a transfer of taxpayers' resources in favour of bank owners and managers, and raising the cost of the desired clean up of the financial system.

The issues related to taxpayers protection can however be addressed by entitling the government to some of the capital gains accruing to banks from the intervention. Among the possible measures, banks can be required to issue to the Treasury equity warrants (which entitle the Treasury to buy a certain amount of equities at a pre-specified price) or senior debt securities - in either case, the Treasury would acquire no voting rights, thus there would be no public interference on the intermediaries' decision process. By the same token, banks benefiting from public funds should be required to adopt high standards of disclosure and transparency.

Consistent with the logic of this approach is the use of funds to help marginal mortgage holders to avoid default, for instance, supporting families whose house price has fallen marginally below the value of the mortgage (Feldstein 2008a,b, Geanakoplos and Koniak 2008). Some public help would not only spare banks the cost of repossession - it could substantially reduce the risk of a fire-sale of a large stock of houses, which could feed a negative spiral on market prices. Once again, the taxpayer could be protected by requiring families or firms benefiting from the programme to entitle the public sector with a claim on future capital gains on their houses. A well-designed intervention avoiding the spread of default on mortgage could clearly limit the magnitude of fundamental losses undermining the price of ABSs.

The toxic assets bought by the government should be placed in a large intermediary, which would possibly act as a clearinghouse and therefore net out the complex web of debt and credit positions created by the securitisation process. Once again, to the extent that toxic assets are bought at their fundamental value, there is no loss for the taxpayers. This large intermediary should be in charge of liquidating the bad assets slowly over time, or holding these assets to maturity. In either case, it can be expected to remain in operations for decades.

Note that the purchase of bad assets can be "leveraged", as the funds initially provided by governments could be complemented by the issuance of "clearinghouse" bonds. If so, the intervention scheme would not necessarily place an undue demand on the current government budget. It would however raise the supply of bonds with some implicit public guarantees, hence indirectly subject to the scrutiny of markets as regards public sector solvency.

As an alternative to outright purchase of toxic assets, the same goals could be pursued with the injection of new equity in distressed banks, with the government acquiring a participation in the capital of troubled institutions. The government would then have a more direct role in the process of restructuring, and could scrutinize more closely the assets in the balance sheet. To be consistent with its ultimate objective, however, this form of intervention should be strictly temporary, with well-defined goals shaping the mandate of the government participation in a bank decision.

Direct public participation in banks' equity would not per se offer an alternative solution to setting up a centralised clearinghouse for toxic assets in some form. Rather, public acquisition of equities in banks should be seen as a different strategy for selecting toxic assets in the process of restructuring, possibly reducing information asymmetries and increasing the public control on bank resources, accompanying the removal of those assets from the balance sheet of banks.

Cleaning up toxic assets would obviously be insufficient and ineffective, however, when fundamental losses are large enough to jeopardise the solvency of the financial intermediary, that is, when a bank's balance sheet before and after intervention would look like the one shown below.

Regardless of the purchase of assets, the equity of the bank would be zeroed. All the revenues from the public intervention would go to repay existing debt. Unfortunately, the same would be true for new equity: any injection of new capital would in part go to bond holders. In this condition, a debt overhang problem jeopardizes attempts to raise new capital. Note that, in principle, restructuring could take the form of

\begin{tabular}{ll|ll} 
Assets & & Liabilities & \\
\hline Securities (face value 100) & & Debt: short & 10 \\
a. Value in illiquid markets & 80 & Debt: long (face value 80) & \\
b. Value after intervention & 85 & a. before intervention & 70 \\
& & a. after intervention & 75 \\
& & Equity & 0
\end{tabular}


debt-to-equity swap, by which bond holders would recognize part of the losses. The advantage of some form of debt-to-equity swap consists of providing an instrument to rebalance equity ratios directly, and therefore restructure bank balance sheets without the need to raise new capital or to decrease credit (see Zingales 2008).

There are a number of policy trade-offs in the alternative between buying assets from banks and financial intermediaries, and acquiring some form of control over these institutions. The second alternative is more effective if fundamental losses are large, since market-based restructuring of intermediaries may turn out to be a slow and costly process and if the distressed bank is a major player in the markets, so that its bankruptcy could create systemic distress. In the short and medium run, with a direct stake of the government in banks, it may be possible to ensure the adoption of competitive lending standards (reducing the risk of a credit crunch, if any) and a faster return of financial intermediaries to the interbank market. However, the government will also be tempted to direct banks' behaviour towards specific policy objectives and delay its withdrawal from the participation for an indefinite period of time. How to design a timeconsistent plan of temporary public participation in the banking system is an open issue.

In the current crisis, many banks are turning out to be essentially in the situation illustrated by our second balance sheet above, including both small (regional)

Box 2.7

The Savings and Loans Crisis

The savings and loans industry in the United States, made up of several hundred savings and loans associations (S\&Ls), originally undertook the straightforward business of accepting retail deposits and using the funds to provide residential mortgages. It had its own regulator and had its own insurance fund to protect depositors, which was funded by the industry but backed by the US government. Despite this, it was the subject of a major financial collapse which between 1985 and 1995 cost US taxpayers more than $\$ 120$ billion.

Problems in the industry first arose in the 1970s as a result of high inflation, and deregulation of US interest rate markets. These factors led to high and volatile nominal market interest rates which created problems for S\&Ls as a result of their structure. That structure was essentially that funds were raised from short-term deposits subject to an interest rate ceiling and used to fund longterm mortgages, mainly on a fixed rate basis.

Higher market interest rates made deposits in S\&Ls unattractive compared with that available elsewhere in less regulated institutions. But in trying to compete for new funds by paying higher rates on deposits, S\&Ls found themselves paying rates above those that they were charging on fixed rate mortgages. By the end of the 1970s, hundreds of S\&Ls were close to insolvency. And the insurance fund (the Federal Savings and Loan Insurance Company, FSLIC) did not have the funds to meet the insured deposits.

In the early $1980 \mathrm{~s}$, the response of the US government and regulators was to loosen restrictions on S\&Ls. Regulatory rules were changed to allow them to diversify away from mortgages into more lucrative, but more risky, assets. Accounting rules were changed in ways that made it seem that their "net worth" positions were stronger. The level of deposits insured per depositor was raised from $\$ 40,000$ to $\$ 100,000$, which made S\&Ls appear to be a safe haven for depositors. The interest rate ceiling was phased out. And regulations on ownership were also abandoned, allowing smaller groups to take control of S\&Ls.

As a result of these reforms, S\&Ls changed their nature, in particular their investments became much riskier. For example, many S\&Ls became closely involved with risky real-estate development that paid upfront fees and high interest rate margins but that were particularly susceptible to a downturn in a cyclical market.

It seems clear that just as in the events leading up to the current crisis, S\&Ls greatly underestimated the risk of the new ventures into which they entered. In addition, the easing of regulation meant that bad management practices were allowed to develop, and some accounting practices were at best dubious, and at worst fraudulent.

Developments in the oil, property and farming sectors in the US in the second half of the 1980s effectively revealed the risks that were by then in S\&L investment portfolios. By 1986, the FSLIC was itself insolvent in the face of huge losses. The government attempted to recapitalize it, and for 3 further years it continued to operate and restructure S\&Ls mostly through mergers and acquisitions.

However, in 1989, Congress finally passed a new law (the Financial Institutions Reform, Recovery and Enforcement Act) which abolished the regulator and the FSLIC, created a new Office of Thrift Supervision, and set up the Resolution Trust Corporation (RTC) to oversee the liquidation of hundreds of S\&Ls. The RTC effectively took ownership of the failed S\&Ls and sold off their assets. In 1989 and 1990 alone, it liquidated over 500 S\&Ls with total assets of over \$260 billion. By 1996, when it was wound up, the RTC had overseen the liquidation of 747 S\&Ls, with a total value of nearly $\$ 400$ billion

The model of the RTC has been advocated as a sensible policy in dealing with the current financial crisis. However, the situation now is different. While scale of failures during the S\&L crisis was huge, the current crisis is bound to be several times larger. Moreover, individual S\&L institutions under distress were relatively small, and none of them posited systemic threat (although the sector as a whole did). The RTC in effect could take ownership of toxic financial assets as part of a process of liquidation, in effect taking ownership of the failed S\&L. In the current crisis, many distressed institutions are actually large (global) and interconnected. As discussed in the text, the liquidation strategy pursued by the RTC is less appropriate in this case. 
and large (leading global) institutions. Small intermediaries can and should be simply liquidated - as happened during the Savings and Loan crisis (see Box 2.7). For major lenders, however, liquidation may not be desirable or politically feasible - for some variant of the too-big-to-fail doctrine. Governments have indeed been increasingly involved in taking over and recapitalizing major banking institutions, acquiring majority stakes. It may not be impossible to envision a financial system with many banks ending up being completely nationalised.

As suggested by the case of Citibank at the end of 2008, we may expect governments to follow a model in which, after taking control of a major bank with zero equity, these are split into a good and viable intermediary, and a residual "bad bank". The bad bank or some part of it could still be liquidated, merged with or taken over by another institution. The toxic assets extracted from the bank could be placed in some vehicles like the one described before. The equity stake of the government is in exchange for taking care of the bad assets. The experience of Sweden in this respect is discussed in Box 2.8.

From September 2008 on, different countries have pursued variants of the above strategies, with the US struggling to design an effective version of the TARP, and the UK acquiring direct control over troubled intermediaries. However, while virtually all governments have so far struggled to commit resources to the rescue of banks, details are often vague and contradictory. The process of disclosure of losses is expected to bring more negative news to light, hampering banks' attempts to raise new equity

\section{Box 2.8}

\section{The Swedish banking crisis}

The background to the Swedish banking crisis can be traced to 1985, when Sweden decided to lift the regulation on banks' lending volume. This in combination with generous rules for tax deductions of interest payments led to a very large credit expansion and high growth rates of prices on houses and commercial property. Fiscal policy was not sufficiently contractive and wage inflation was high. When the international business cycle turned down in 1990 , banks and other credit institutions started to encounter problems. Many investments in Swedish commercial property had been financed with loans denominated in foreign currency. The Swedish central bank feared that a devaluation of the Swedish currency would cause credit losses of a scale endangering the whole financial system. In the end the futile attempt to defend the Swedish fixed exchange rate lead to very high interest rates - the discount rate hiked to $1.5 \%$ per day. The high real interest rate together with bleak forecasts for Swedish economic growth and a reduction in the possibility to deduct interest payments against tax liabilities led to a collapse of the inflated real estate market, in particular for commercial property, in 1991-92.

The major Swedish banks where hit by massive credit losses totalling around $12 \%$ of Swedish GDP. These losses threatened to quickly put all but one of the seven major Swedish banks, controlling most of the Swedish market, below the capital requirements of $8 \%$. The Swedish recession developed into the worst since the 1930 's. Swedish GDP fell by almost $5 \%$ between 1990 and 1993 , unemployment rose from $3 \%$ to $12 \%$, the output gap fell to $-8 \%$ and the government budget surplus changed into a deficit of $11 \%$ of GDP

In September 1992, the conservative Swedish government decided to guarantee all Swedish banks. All debt of the banks should be honoured and repaid in a "timely fashion". It was, however, clear that a) shareholders of the banks should not be bailed out, and b) the government should not be a permanent majority owner of banks that needed support. The guarantee was formulated in an explicit and transparent way.

The guarantee received wide support in the parliament, also from the social democratic opposition. The broad political consensus around the unlimited mandate to the government to safeguard the financial system was arguably of key importance for the credibility of the support programme.

The bank support was administered by a newly created agency under the finance ministry, the Bank Support Authority. It required a full disclosure of the best estimates of the true value of the asset side of each troubled bank's balance sheet. As a consequence of the crisis, the government took control over Nordbanken (now Nordea) that took over the failing Gotabanken. Non-performing assets, largely in the form of commercial real estate, were lifted from the two banks and put in separate companies (Securum and Retriva) leaving a bank that soon became profitable.

Föreningssparbanken (now Swedbank), giving shares as collateral, received a guarantee from the Bank Support Authority that its capital requirements should be safeguarded. Also the SE-bank started discussion with the Authority regarding support. However, neither of the banks in the end needed any direct support but was recapitalized by their owners.

The support programme succeeded in its major goal - to prevent a collapse of the financial system. No bank runs occurred and the financial system continued to function during the whole crises. The budgetary cost of the bank support between 1992 and 1994 totalled 63 billion krona, corresponding to about 4\% of GDP. In 1997, it was estimated that the net cost, including the value of shares and dividends from Nordea, Securum and Retriva, was around 35 billion krona, i.e., approximately half the gross cost. ${ }^{1}$ By 1997 , both Securum and Retriva had been dismantled, but the Swedish government still holds a minority position of $20 \%$ in Nordea.

${ }^{1}$ Jennergren \& Näslund, (1998), Ekonomisk Debatt 26:1 (in Swedish). 
capital - as recapitalisation could be seen as an indicator of bank distress and need for funds - and creating uncertainty about the size of fiscal costs of the crisis. Perhaps for this reason, the emphasis of the policy debate is currently on its quantitative dimension, i.e., on the required size of public intervention. The truth is that the protracted period of market illiquidity and the sudden spread of the crisis to the real side of the economy have profoundly dented the value of intermediary's assets, producing losses that are a multiple of those that could directly be attributed to the "toxic assets" produced by securitisation. Yet it is hard to envision the end of the crisis without linking banks bailouts to some coherent and possibly concerted framework to reform the international financial system.

Box 2.9
Banks bailout and competition policy
Competition policy enforcement in banking is under attack worldwide.
Vives (2008b) issues a strong warning that the ongoing massive bank bailouts are distorting competition in financial services, both
in the US and in the European Union. Instances are provided by the British government, which blocked a referral of the HBOS-
Lloyds TSB merger to the national competition commission on the grounds that the stability of the U.K. financial system was an
overriding concern. By the same token, potential threats to competition policy are implicit in harsh complaints by the French,
German and other governments that the European Commission is too slow in approving bank-recapitalisation packages, on the
ground that the process is delaying the much needed resume of credit to firms and consumers.

In other words, the bailout is doing much more than recapitalising failing institutions. Public help is reaching even relatively sound institutions, which are therefore gaining a competitive advantage in terms of a lower cost of capital and probability of failure. This race to recapitalize national banking systems has the flavour of a national champion contest. Not surprisingly, its positive effects on getting credit to the private sector are not really apparent, as banks will resume their credit policy only if and when they find it profitable.

Moreover, political spillovers from the systemic banking bailout to other sector also pose severe fundamental risks for competition policy in general. With the automotive industry at the forefront, many sectors are now calling for help on the grounds of "horizontal" equity across industries. A key issue is how to prevent the present distortions in banking not only from becoming permanent but also from spilling over to other sectors.

It was not long ago that competition was considered detrimental to financial stability, an idea that often made central banks and regulators quite complacent about monopoly practices and collusion agreements among banks. This has changed over time, as it became progressively clear that lack of competition meant costly inefficiency. Competition policy is now taken seriously also in the banking sector. For instance, the European Commission has intervened against national protectionism, cartels and anticompetitive mergers. The new thinking shaping this intervention is that competition per se cannot be responsible for the fragility of the banking system: even a monopoly bank may be subject to a run.

Yet, the question remains. Should competition authorities treat banks as if they were exactly like any other sector? One issue is that excessive competition may erode the charter value of a bank - that is, its value as a going concern - and create incentives to take excessive risks: when there is not much to lose, there is a tendency to gamble. This tendency is accentuated in the presence of limited liability, which restricts the losses but not the gains. As is well understood, zombie institutions, distressed and barely alive, may awake to gamble for resurrection, using very risky strategies with scant chance of success.

Another, obvious, problem is that systemic failure of banking may create large real costs, or even grind an economy to a halt Arguably, this is what happened during the Great Depression, and it is a concrete threat nowadays. No sensible government will allow this to happen if it can prevent it. In recognition of the risks of a systemic crisis, banks are strictly regulated and supervised to a larger extent than other sectors in the economy. Policy-makers should also recognise the uniqueness of the banking sector as regards to competition policy. In other words, we should reconsider whether some degree of market power could be tolerated, and define conditions under which some limits to competition could be established. Regarding mergers, one should consider whether the standard concentration thresholds - which, roughly speaking, proscribe unions that would create a company with market share above a certain level - should be modified in banking. More market power may make a merged entity more prudent but if the bank becomes systemic and "too big to fail" then the outcome may be excessive risk taking. State aid rules should account for the need for swift intervention when there is a systemic problem, and should be adapted to the specific restructuring needs of banks. By the same token, rules should strictly limit activities of severely distressed institutions, as these have the stronger incentives to gamble for resurrection. The same should apply to institutions that are de facto fully insured, because they are "too big to fail".

The view that banking is like any other sector in the economy and should be treated as such in all circumstances is naive. In addition to what we have already discussed, moving somewhat away from it would have the following important benefit: it would contain the risk that adding ex post some flexibility to competition policy for banking would automatically relax the standards for other sectors. Partial exceptions to the competition policy regime for the banking sector would be founded in its systemic position in the economy.

As stressed by Vives (2008b), recognising the singularity of the banking sector would allow Europe's competition policy to retain its fundamental role of keeping markets open and protecting the single market: these goals are today under threat because of the uneven playing field generated by banking bailouts that have activated lobbies from other sectors to seek help based on horizontal equity considerations. There is a danger in the alternative of remaining or becoming pragmatic and flexible - today with banking, tomorrow with another sector, that is, making competition policy progressively weaker and weaker. Arguably, the Great Depression was aggravated by the protectionist, anticompetitive spiral that ensued. This mistake can and should be avoided. 
A massive bailout will not provide a solution for all the problems raised by the crisis. First, it would not necessarily prevent a credit crunch. We have stressed above that the contraction of credit is mostly driven by the collapse of trade in market-based instruments, not by bank lending. A bailout can hopefully avoid a financial meltdown, but could be effective against a possible credit crunch only to the extent that restoring market liquidity helps halt the turmoil in marketbased credit, thus recreating conditions for markets to provide financing.

Second, for a variety of (politico-economic) reasons, a massive bailout could create zombie banks, i.e.,, it could result in the survival of insolvent banks that would use massive liquidity injection to maintain nonperforming assets on their balance sheets. Arguably, the experience of Japan shows that this could ultimately jeopardise a speedy resolution of the crisis. Banks without a large enough probability of survival should simply not be recapitalised but closed down or, if too large to disappear, taken over by the government, split, restructured and merged with others.

Third, a massive bailout could raise the temptation to protect national champions and restore state aid as a normal instrument of "industrial policy". ${ }^{16}$ In the European Union, this risk has potentially important negative implications for the single market. But the political call for extending the bailouts to industries other than the financial one (e.g., cars) is a global phenomenon. In Box 2.9, we discuss reasons why the specific feature of the financial industry should be emphasised as the foundations of a differential treatment in the case of crisis, consistent with competition policy principles.

\section{Restoring stability and reforming the international financial architecture}

\subsection{General lessons from the crisis}

What are the main lessons to be drawn from the crisis? In this section we single out a few lessons from our analysis, and relate them to broad-based principles for strengthening the stability of the international financial system after the current crisis. Our considerations refer to the following four points: central bank policy, banking regulation, market regulation, corporate governance/incentive systems.

\footnotetext{
${ }^{16}$ See Chapter 4 in our 2008 EEAG report.
}

Central banks' policy and mandate. Monetary authorities have been criticised for keeping interest rates too low for too long in the years preceding the onset of the crisis, thus either feeding asset market bubbles, or failing to act to stem them. Yet, there is little or no consensus in monetary theory and policy analysis on whether and how central banks should react to strong asset price dynamics, and the extent to which interest rate policy is an efficient way to address the issue. It would be difficult to draw any conclusion regarding specifically the monetary policy reaction function.

However, it seems clear that central banks should have a mandate for maintaining financial stability. In some cases this mandate is formally already in place. But the current crisis clearly requires a reconsideration of past strategies and experiences, especially as regards the role of the analysis of balance sheet quantities in shaping monetary decisions. The explicit recognition of the importance of monetary analysis in the strategy of the European Central Bank has been seen as a potential advantage of this institution relative to others, which have sharply focused on inflation targeting. Nonetheless, the analysis of the evolution of monetary aggregates in relation to the risk for inflation may not be effective or sufficient for identifying threats to financial stability - on which the ECB has limited or no jurisdiction. It is reasonable to expect some important development in the direction of restructuring central banking so as to address these issues (see e.g., Adrian and Shin 2008a,b, Buiter 2008).

For a year and a half, the too-big-to-fail argument has driven massive government support to private institutions, confirming the expectations of bailouts ex post. Central banks found it necessary to extend their lender of last resort facilities outside the realm of traditional commercial banks to entities like Bear Stearns that they do not supervise and, therefore, over which they have no first-hand information (see e.g., Buiter 2008, Buiter and Sibert 2008a, and Vives 2008a). In this respect, early Fed interventions in support of the investment bank and other similar institutions are not consistent with Bagehot's doctrine of helping illiquid but solvent institutions (see Vives 2008a).

The basic lesson emphasised by the crisis is that any institution that does maturity transformation is subject to runs and needs the coverage of a lender of last resort and, therefore, cannot escape supervision. 
Banking regulation. In the years preceding the onset of the crisis, the shadow banking system grew at extraordinary rates within and across borders, linking different markets in a global network of intermediaries. Many of these perform the basic functions of a bank - maturity transformation and monitoring of opaque loans - without being regulated as such.

The second lesson from the crisis is that any institution that performs the function of a bank needs to be regulated and needs a safety net because of the systemic concerns from its failure. This is particularly so for large institutions that occupy a central place in the financial system, for which the TBTF doctrine applies more forcefully. Because of the presence of these institutions in global markets, global regulatory standards should be set with internationally coordinated supervision.

A third lesson is that a piecemeal approach to financial regulation will not work: what is needed is a clear alignment of incentives covering the overall system and in particular every step from the board room to the customer going through executives, analysts, salespeople and rating agencies.

With Basel II, the foundations of banking regulation rest on three pillars: risk-based capital requirements, supervision and market discipline (disclosure). Relative to Basel I, the new framework has disciplined the treatment of some types of off-balance sheet activities, and has included an attempt to weight different risks towards the satisfaction of the capital requirement. Still, this framework did not prevent the accumulation of large risks in offshore conduits not included in the balance sheets, which turned out to be a major problem for German banks. The new framework neither tackles systemic risk (whose underestimation has arguably played an important role in generating the crisis), nor prevents adverse pro-cyclical lending effects of regulation (effects that are currently generating concerns about a possible credit crunch). Some countries, such as Spain, regulated banks more strictly and forced them to accumulate reserves in excess of the Basel requirement, but this was on their own initiative.

The core problem remains risk assessment. We have already discussed the potential failure and limits of internal models. The crisis also made clear that agency problems can severely distort the performance and effectiveness of rating agencies. Rating agencies are bound to underprovide "transparency" when paid by issuers of assets rather than investors. Their role should thus be redesigned so to make sure that no conflicts of interest interfere with their activities.

Transparency in the form of risk disclosure and information to investors is enhanced by accounting rules that require intermediaries to mark-to-market their asset. The crisis has nonetheless confirmed ex post early concerns that asset price distortions in periods of market illiquidity would misrepresent risk in the balance sheet of the intermediary. Note that, by symmetry, one should recognize that similarly dangerous distortions arise in periods of "irrational exuberance" and bubbles causing asset overvaluation: possible solutions to the problem should tackle both cases.

Modifying the accounting rules going back to less transparent standards would hardly help. Regardless of accounting rules, agents are well informed about the current market conditions, i.e., about the extent of illiquidity, or exuberance. Reducing the information on a bank's assets only raises uncertainty and speculation. What instead can make a difference is to make sure that banks pursue prudential standards, with rules that reverse adverse cyclical patterns in banks' behaviour. An instance of theses rules consists of prescribing higher accumulation of reserves in periods of strong price dynamics - as was the case for Spanish banks in the years of booming housing prices, thanks to the wisdom of the Bank of Spain.

Despite the effort placed in designing good rules, the effectiveness of prudential regulation and supervision can be expected to be systematically impaired by financial innovation. New instruments can create loopholes and opportunities for regulatory arbitrage. In view of this consideration, many observers recently have increasingly focused on limited liability as the root of moral hazard. Limited liability raises the temptation for equity holders of a bank to engage in large risky bets, as they are able to appropriate the full extent of the profits in case of success, while shifting the cost of failure onto other stakeholders (including society at large). As is well known, this problem is exacerbated in crisis periods, when equity holders may hope to restore the economic viability of the bank with some ultimate stroke of luck.

There is widespread consensus that new rules should guarantee higher capitalisation of financial intermediaries and avoid the combination of high leverage 
and dependence on short-term financing that jeopardised the viability of the international financial system in 2007 and 2008. A possible approach in principle consists of directly raising the minimum equityasset ratios. The argument is that with more equity capital at stake, shareholders will require their boards to adopt more prudent business models, as they would suffer higher losses in the case of failure, containing the inefficiency resulting from the ability to impose part of the losses on creditors or tax payers would be. However, in light of Basel II and the crisis, it is clear that the main issue is not so much a numerical requirement for the equity ratio, but how the value at risk of a bank is assessed.

Market regulation. Transparency is the key concern in reforming the regulation of financial markets. With the extraordinary development of market-based credit, an over-the-counter (OTC) organisation of trade resulted into generalised opacity. To wit, in our account of the crisis, markets appeared to react strongly to the introduction of the $\mathrm{ABX}$ derivative market for mortgage backed securities, which for the first time provided aggregate information about market evaluation. Market regulation can be expected to (and should) foster a shift from OTC to organized exchanges, with clearing houses assuming counterparty risk.

More controversial is the adoption of rules limiting alleged destabilising practices, such as short sales. Should short-sales restrictions be part of market rules, if only to be invoked contingent on some welldefined market conditions? An important concern motivating such rules consists of market manipulation, since when there is no ability to manipulate the market the possibility to short sell should be efficiency enhancing. Furthermore, in those circumstances short-selling reduces volatility by bringing today's prices more in line with tomorrow's prices, whenever the latter are expected to fall.

Corporate governance. The "new attitude" towards corporate governance is summed up well by the famous quote of Alan Greenspan:

"I made a mistake in presuming that the self-interest of organisations, specifically banks and others, was such that they were best capable of protecting their own shareholders" (A. Greenspan, 23 Oct. 2008).

This late confession is bound to have an impact on the current debate among academics and practitioners.
Namely, should we consider the crisis to be the result of a paradigm failure (shareholder value), or rather should we see it as the consequence of failure in the current system of corporate governance? We tend to side with the latter interpretation.

The moral hazard distortions already discussed in relation to limited liabilities of equity holders can clearly be referred to executive compensation schemes, rewarding generously good performances in the short run without punishing losses at any horizon. These distortions can be corrected by realigning managers' incentive with the interests of the shareholders and a firm's stakeholders at large. Proposals discussed in this respect include the reduction or elimination of cash bonuses and resorting to compensation in the form of restricted shares, to be held for years after leaving the firm. ${ }^{17}$ Whether these proposed corrections to past and current practices are efficient, however, is an open question.

\subsection{Problems and perspective of reforms of the European financial architecture}

The crisis created the first true stress-test of the European financial and monetary architecture. In this architecture, the European Central Bank occupies a unique position to address liquidity issues at the euroarea level and preventing gridlocks in the payment system. However, it is up to the national central banks to provide emergency liquidity to individual institutions. Furthermore, as discussed in the 2003 EEAG report, banking supervision in the euro area is in the hands of member states, according to the home country principle. The same home country principle applies to deposit insurance. Corresponding to the fragmentation of supervision and deposit insurance, there is fragmentation of market regulation.

The response to crises is de facto left to "improvised cooperation". In May 2005, the European Union agreed on a financial crisis plan, through a memorandum of understanding between central banks, regulators and finance ministries. In light of this agreement, but only as late as May 2008, ECOFIN invited the EFC to organize an EU-wide crisis simulation exercise for spring 2009 to report in September 2009.

This architecture suffers from at least four well-known problems. First, the line of command in a crisis situa17 The chapter on private equity in this report discusses the benefits
of compensation schemes rewarding performances in the medium run. 
tion is left unspecified. Who is responsible for which action if a large pan-European bank with systemic interconnection is threatened by a liquidity run? The large number of institutions with a direct or indirect role in a rescue is so large that even communication among them could in principle translate into a waste of valuable time, hampering speedy reactions to incipient crises. Second, trans-national crises are likely to create conflicts among national agencies and treasuries, which will require a (possibly time-consuming) political arrangement. Not only could this delay initiatives whose success crucially depend on their timing, but these conflicts could also generate dangerous setbacks in other areas of cooperation, indirectly relevant to the financial turmoil as indicators of cohesion. Third, such architecture is bound to lead to excessive help at the country level and insufficient help at the EU level, hampering the development of a single market and cross-border institutions. Namely, and this is a fourth problem, the current framework provides no effective guideline for how to provide liquidity support and address solvency problems of panEuropean institutions.

How could the framework be improved in light of recent experience? It seems apparent that crisis resolution cannot be left to a memorandum of understanding, i.e., de facto improvised cooperation, but it requires a more explicit framework. In this framework, the European System of Central Banks should assume an explicit role of guarantor of the system. In particular, it makes sense that the European Central Bank should acquire supervisory powers over European groups, and coordinate with national central banks the national financial intermediaries.

A readily possible reform could pursue the construction of a two-tier system. For pan-European financial groups, supervision should be attributed to the European Central Bank. These groups should then be required to subscribe to a European Deposit Insurance Fund, to complement national deposit insurance schemes. This does not solve all possible conflicts about commitment of public resources by member states to rescue a European bank. But it could definitely help address solvency problems and provide centralised resources and information to be used in the restructuring of distressed banks. All other institutions could be left to decentralised supervision and support, although it would be natural to foster some form of coordination and information sharing within the ESCB. However, the extension of the power of the ECB would of course not address issues raised by the internationalisation of banks outside the euro area - experienced for example by banks operating in the UK and some of the countries adopting the euro.

As discussed in Box 2.8 it would also be important to recognise explicitly and formally the specificity of the banking sector in competition policy. This would ensure coherence between competition policy and financial stability policy, and help stem the political pressure to extend financial bailouts to other sectors of the economy.

Ten years into the introduction of the euro, the global turmoil has challenged our thinking on optimal currency areas, stressing the need to understand financial stability preconditions for adopting a common currency without political union. Not only inefficient provision of the public good of financial stability appears to be a threat to the balance of benefits from a common currency; it may also create and magnify political divides. In fact, the main issues at stake are only in part technical. The resolution of the crisis will require political initiatives that address international policy cooperation and institution building. In this sense, the future of Europe is at the cross-roads.

\subsection{Fiscal policy and the financial crisis}

Before this crisis, scepticism on fiscal policy as a stabilisation tool dominated the intellectual and policy debate. Quantitative fiscal interventions were considered irrelevant if not counterproductive. Monetary policy was instead praised as the main stabilisation tool, effective and flexible. With the crisis, this climate has completely turned around, with a spectacular "rediscovery" of fiscal policy (see our discussion in chapter 1). The call for commitment of public resources is almost universal. Governments are supposed to spend to restore the health of the financial system and sustain growth. The Keynesian multiplier in its simplest form is shaping the political debate, with parametric exercises assuming a value in the range between 1 and 2 - extremely high given the empirical evidence - but nonetheless deemed acceptable on the grounds that the current situation is unprecedented. This commitment of public resources is mirrored by market assessment of default risk.

Figure 2.13 shows the spreads for the credit default swaps for 5 year bonds issued by 7 governments - US, 
Figure 2.13

CDS spreads of 5 year treasury bills

CDS spread 5 year government bond

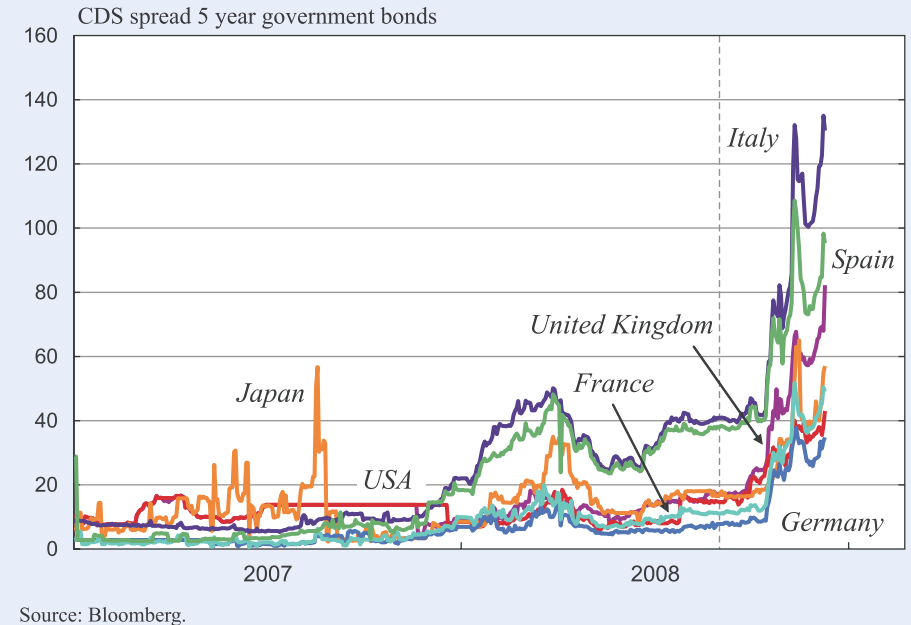

negative terms of trade shock, due to the sharp fall in commodity prices triggered by the crisis which in most cases erodes the core sources of their public revenues.

Interestingly, in the euro area, large international banks in crisis have eventually been broken up into independent national institutions, arguably as a function of the bailout resources and guarantees that each independent state in the area is able to provide. In this sense, the effect of the crisis on banking size and competition has been quite different in the euro area relative to the US. In

the UK, Japan, Germany, France, Italy and Spain. The spike in the market perception of sovereign risk is apparent in autumn 2008. Note that the premium on Italy and Spanish euro-denominated debt, very low at the onset of the crisis, already rises at the end of 2007 - in the case of Italy, arguably because of the high public debt; in the case of Spain, because of the contraction in the housing sector after the recent large boom. Most striking is the case of the UK, whose premium moves much closer to that of Spain and Italy, in October 2008 - this move is accompanied by a sharp depreciation of the pound. Within the euro area, interest differentials among sovereign borrowers have risen to levels unseen for more than a decade.

The high level of the premia shown in the graph clearly reflects market apprehension about the state of public finances in the face of the rapidity in the deterioration of all economic indicators in autumn 2008, motivating a generalised flight to quality.

The state of government budgets is in fact emerging as the key dimension to understanding the dynamics of the crisis at a global as well as at a country level. As an important instance, the implications of the flight to quality are actually strongest for small countries with independent currencies, whose intermediaries are highly leveraged in international markets, hence potentially exposed to the crisis but without a large tax base and/or the fiscal capacity to back their external liabilities - as is the case of Iceland (see Buiter and Sibert 2008b and Portes 2008). Arguably for a similar reason, the effects of the flight to quality are apparent for countries exporting commodities that suffer from a strong the euro area, the crisis has reversed the movements towards the development of pan-European financial intermediaries. In the US, mergers and bailouts have created larger intermediaries, while at the same time shifting the weight in favour of universal banking (Angeloni 2008).

What if the size of the bailout of financial intermediaries, and the fiscal support to the economy, ends up deteriorating the balance sheet of governments beyond their political ability to engineer a correction via higher tax revenues and spending cuts? Could this lead to a reconsideration of the trade-off between fiscal distortions and inflation in favour of the latter? We first reconsider how inflation can help correct budget imbalances.

In their celebrated model of "unpleasant monetarist arithmetic", Sargent and Wallace (1981) stress the link between a permanent deterioration of fiscal deficit, and the role of inflation in generating real resources for the public sector - seigniorage. A steady monetisation of the public debt raises inflation and nominal interest rates: unless the economy operates on the "wrong side" of the Laffer curve, rising inflation increases seigniorage revenue. While the intellectual merit of this model cannot be overemphasised, however, there are empirical and theoretical arguments that cast doubts on seigniorage revenue as a meaningful source of public revenues. Nobody can seriously consider the option of pursuing an increase in long-run inflation to this end, simply because there would be very little gains from it. 
Recent literature has indeed shifted attention to other possible fiscal gains from temporary and possibly moderate inflation, which operate via devaluation of nominal liabilities of the government. A striking example of an assessment of these gains is provided by Persson, Persson and Svensson (1998), with a case study of the potential benefits of moderate inflation on the Swedish budget. The same idea is at the core of the models by Burnside, Eichenbaum and Rebelo (2001) and Corsetti and Mackowiak (2006) in their study of the link between (prospective) deficits and currency crises. In these contributions, a currency crisis cum temporary inflation occurs when agents anticipate large future deficits that will not be adjusted by explicit taxes or cuts in spending - in the first study the information used by agents to predict the large future deficits is precisely the state of the financial sector, in particular of the banking system (see also Corsetti Pesenti and Roubini 1999). A crisis depreciating the currency and raising the price level lowers the real value of outstanding nominal liabilities and spending commitments in nominal terms, so as to balance the intertemporal budget of the public sector. Key to this argument is the recognition that most of government liabilities, both in the form of debt and in the form of commitments to future spending, are only partially indexed, if at all, to inflation. Then, an unexpected change in the price level, achieved with temporary inflation, amounts to a cut in real spending and a reduction in the real burden of debt.

Based on these considerations, many contributions have suggested that, in response to a large negative fiscal shock, countries face a trade-off between adjusting (distortionary) tax rates and (useful) spending, and a temporary increase in inflation.18 Yet we should note here that the efficiency of moderate inflation in redressing fiscal issue is heavily dependent on the ability of the central bank to maintain credibility. If this is lost in the process, the balance of costs and benefits from the policy may well tilt in favour of the former. Obviously, deteriorating inflation expectations usually generate a premium raising the costs of borrowing.

These trade-offs in raising resources through moderate inflation has an interesting institutional counterpart. On the one hand, this option is more readily available in countries where the fiscal and monetary authorities are not entirely independent, for it is trivially easier to coordinate monetary and fiscal policies

${ }_{18}$ See e.g., chapter 24 in the macro textbook by Ljungqvist and Sargent (2004) when both are ultimately handled by the same institution. Marimon (2008) recently argued that China is in this position, and Sims (2008) provides some evidence to the extent of interdependence between US public finances and Fed's balance sheet. For exactly these reasons, however, inflation expectations may deteriorate more quickly in a crisis situation. On the other hand, regions in which the central bank is truly independent and has a clear mandate for price stability, as is the case in the euro area, have much less flexibility of the type reviewed above for using inflation to address public sector budgetary concerns. Yet this may anchor market expectations better, leaving more room for such policies.

From a macro perspective, the foregoing arguments suggest that, at least in some countries in which central banks are not fully independent, it may be possible to witness some inflationary pressures resulting from balance sheet interactions, were public budgets to deteriorate sharply. In a severe fiscal crisis situation, however, even central bank independence would be sufficient to counteract inflationary pressure from fiscal instability. If prospective deficits are perceived by the public as too large relative to the current value of outstanding debt, either government debt will experience credit rationing, facing the alternative between retrenchment and default, or the price level will carry the adjustment via depreciation of nominal debt. Were the crisis to require a large financial sector bailout, it would not be unreasonable to expect some adjustment in the price level, taxing the holders of the government's nominal liabilities. These fiscal benefits would of course be counterbalanced by whatever distortionary costs, including fiscal costs, inflation may generate.

Once again, one obvious danger is that inflationary financing, whether pursued as an explicit policy or implied by fiscal instability, would undermine the credibility of monetary policy for years to come. Another danger is that any explicit choice for inflationary financing would also motivate some form of financial repression (such as caps on interest rate), which would enhance the fiscal benefits from the choice, at least in the short run.

\section{Conclusions}

This chapter has conducted a broad analysis of the current financial crisis. To begin with, we have analysed the process of securitisation of subprime mort- 
gages in the US. Through this process, cash flows from heterogeneous mortgage contracts between borrowers and banks were transformed into homogenous asset backed securities (ABSs), with distinct rating, traded in global markets. Per se, securitisation is a good idea: by favouring diversification of mortgage risk, it can allow intermediaries to increase lending, to the benefits of households and firms. However, because of a combination of macroeconomic factors, bad/insufficient regulation and agency problems, in the last few years this process was fundamentally flawed. First, massive undervaluation of fundamental risk and market liquidity risk caused the amount of ABSs with AAA rating derived from the underlying pool of mortgages to be too large by any reasonable standards; second, several layers of securitisation, each involving some form of credit enhancement and insurance, translated into high opacity of ABSs, which hampered the ability of an intermediary to assess the amount and the location of risk in its portfolio; finally, risk diversification was only apparent, in the sense that the high-rating ABSs sold to endinvestors (pension funds, mutual funds, etc) were guaranteed by intermediaries - when the crisis erupted, in large part ABSs were absorbed back by highly leveraged financial institutions. With a high level of opacity, diversification of ABSs among intermediaries actually created systemic risk, by generating dangerous network externalities which eventually undermined market liquidity for many classes of assets and financial markets.

Looking at the development of the crisis, we distinguish two distinct phases. The initial phase, from 2007 to the summer of 2008, is consistent with a model/ expectations of a soft-landing. Over many months into the crisis, markets and policymakers tended to attribute the crisis to liquidity, rather than solvency problems: estimates of fundamental losses were relatively small. On the macro side, there were expectations of a financial-real decoupling as well as growth decoupling - initially, the crisis left many market unscathed, and emerging market economies and to some extent the EU were expected to continue to grow independently of cyclical development in the US. Monetary authorities granted unlimited liquidity provision to financial intermediaries, while governments adopted a case-by-case approach to bailout (Bear Stearns being the primary example). The main idea, or hope, was that over time the financial system would find ways to digest and eliminate the "toxic assets" in the balance sheets of the intermediaries, matching write-downs with re-capitalisation.
Perhaps unfortunately, this approach appeared to work for some time. While banks were indeed able to raise new equity, the US kept growing, in part driven by a weak dollar and global demand, correcting the external deficit despite the peak in oil prices. Global growth remained high. But the scenario completely changed in the summer of 2008, when it became clear that fundamental losses were much larger than suggested by early estimates, and hopes for financial/real decoupling and growth decoupling vanished. The market response to the US decision to let Lehman Brothers go bankrupt, while saving AIG, dramatically showed the inadequacy of a case-by-case approach to the crisis. A generalised run on financial intermediaries and a large fall in asset prices marked the beginning of the deleveraging cycle and a large contraction in global economic activity.

The soft-landing scenario in the first months of the crisis was arguably an illusion. Had expectations of growth and real financial decoupling been less optimistic, perhaps policymakers would have intervened more swiftly and comprehensively early on, preventing market illiquidity from eroding progressively the value of banks' assets well beyond the toxic ABSs.

At the end of 2008, governments worldwide had to adopt emerging measure to stem incipient runs on commercial banks; commit the largest resources to bank bailout and the cleaning up of the balanced sheets of financial intermediaries; and attempt to design effective plans to resurrect market activity and guarantee market liquidity.

With the deepening of the crisis, the strain on government budgets is apparent. Large quantitative fiscal stimulus is called for in the hope that it will have a strong multiplier effect on output. Combined with the cost of bailouts, the next few years will record a sharp increase in public debt and deficits. There are reasons to be cautious in assessing the effect of the stimulus on the real economy. The multiplier effects of government spending and tax cuts may be quite contained, especially in light of uncertainty about economic conditions that may induce precautionary saving by households. Large interventions do increase uncertainty about the tax burden, and the associated distortions in the economy (as it may have been the case in Japan since 1995). There is even the possibility that large interventions paradoxically exacerbate the fall in consumer and business confidence, by conveying the message that the crisis is far worse than expected. 
While one may argue that even a small multiplier makes spending valuable when output is in free fall, the ongoing massive transfer of risk from the private to the public sector may in fact destabilise the trust of markets in sovereign debt. Not only would this raise the cost of the interventions; it could also create the temptation to return to forms of financial repression and/or public control of financial intermediation. Possible short-run benefits from such moves would, however, run into the cost of inefficiency over the medium and long run, as is vastly documented by the literature.

It is hard to see a way out of the current crisis without creating the conditions for a new, stronger and more stable, international financial system. While the temptation to go back to the golden days of plain over-regulated commercial banking may seem attractive, it is doubtful that this model would be feasible and desirable in a globalised economy. Rather, the crisis has planted the seed for a deep reform, addressing the gap between markets on the one hand and institutions and rules on the other.

Proposals of reforms abound. In this chapter, we have focused on deriving a small set of lessons from the crisis towards the definition of broad-based principles to follow in correcting the flaws in the system. The merits of different proposals do not necessarily lie in their being radical but in their consistency with the ultimate goals of public governance of financial system.

Some of these lessons are shared by many other institutions and scholars. Intermediaries that, like banks, engage in maturity transformation and are exposed to liquidity runs should be subject to the same principles of regulation and supervision as banks. Regulation and supervision is motivated by the implicit government commitment to bail out the intermediaries when their default would have systemic effects and negative externalities on the payment system. Bankruptcy of commercial banks threatens the payment system directly, via its implications for depositors. For other intermediaries, one argument is that such threat is rooted in the network externality, via the systemic implications of their bankruptcy for market liquidity and the balanced sheets of other intermediaries. Indeed, with the subprime crisis, trust among banks evaporated: the interbank market virtually disappeared. A different view is that the activities of these intermediaries grew into a threat to financial stability because bailout guarantees according to the too-big- to-fail doctrine provide an incentive for them to grow excessively, take on excessive risk and become too leveraged. However, unless these guarantees can be eliminated completely - which is not credible in light of past and recent experiences - it is rational to associate the provision of contingent public resources to regulation and supervision.

Thus, a first lesson is that investment banks, as well as any other institution that perform bank functions must be subjected to the same rules that apply to commercial banks. The regulatory constraints should be dependent on the type of business rather than the legal status of the bank that pursues this business. This applies in particular to capital requirements.

Second, broad international agreements must be finally reached on the harmonisation of banking supervision. These agreements can be based on a reformed Basel-II system, which encompasses all institutions performing banking functions and takes into account systemic and cyclical factors. Minimum equity requirements in Basel II should be reconsidered, so as to increase the incentive for shareholders to pursue more prudent business models and choose more conservative incentive schemes for bank managers. In any case, failures of corporate governance controls and pitfalls in executive compensation should be addressed.

The apparent failure of the current system to elicit the use of proper models of risk assessment by intermediaries and guarantee transparency is perhaps the main sticky point for rebuilding trust in the financial system. Simply increasing a coefficient of equity requirement will not do. What matters is instead a standard of asset valuation that (eventually) addresses the main problems in prudential regulation: the possibility of mispricing due to bubbles and market illiquidity, generating non-fundamental volatility of asset prices; procyclicality of lending; and transparency and information to investors.

Third, whenever possible, derivative products, such as CDS, should be traded in transparent organized markets and not in opaque OTC markets. A common argument is that, while centralised trade may be feasible for some derivative products, many others are specialised and designed specifically for an investor/company, so that no organised market would be economical. However, following the recent problems of marking to market when no market exists, those buying such products probably now realise a major benefit 
from having centralised, transparent and liquid markets for derivatives. The specific needs of customers, in many cases, can probably be addressed by forming appropriate portfolios of existing contracts traded on liquid markets. By the same token, short sales should not be prohibited; instead vigilance of potential market manipulation should be enhanced.

Fourth, Europe needs a common system of financial regulation and supervision. The European System of Central Banks should assume an explicit role of guarantor of the system, acquire supervisory powers over European groups and coordinate with national central banks the national financial intermediaries. We propose a two-tier system. For pan-European financial groups, supervision should be allocated to the European Central Bank. These groups should then be required to subscribe to a European Deposit Insurance Fund to complement national deposit insurance schemes. Otherwise countries should individually have the responsibility for bearing losses created by their own intermediaries.

Fifth, the specificity of the banking sector in competition policy should be recognised explicitly and formally. This would ensure coherence between competition policy and financial stability policy and help stem the political pressure to extend financial bailouts to other sectors of the economy.

Furthermore, it is highly advisable to reconsider limited personal liability limitations for mortgages and other real-estate loans where they exist (such as in the United States). The promotion of house ownership should be examined carefully from a financial point of view, given the potential systemic implications of incentives raising the risk profile of borrowers against public guarantees.

\section{List of abbreviations:}

\begin{tabular}{|c|c|}
\hline AAA & Triple-A credit rating \\
\hline $\mathrm{ABCP}$ & Asset backed commercial paper \\
\hline ABS & Asset-backed security \\
\hline ABX.HE & An index of asset-backed securities \\
\hline AIG & American International Group \\
\hline Alt-A & Alternative A-paper \\
\hline ARM & Adjustable rate mortgage \\
\hline $\mathrm{CDO}$ & Collateralised debt obligation \\
\hline CDS & Credit default swap \\
\hline $\mathrm{CFG}$ & Caballero, Fahri and Gourinchas \\
\hline CMBS & Commercial mortgage backed security \\
\hline CMBX & $\begin{array}{l}\text { An index of commercial mortgage- } \\
\text { backed securities }\end{array}$ \\
\hline ECB & European Central Bank \\
\hline FDIC & Federal Deposit Insurance Corporation \\
\hline FHA & Federal Housing Administration \\
\hline FSLIC & $\begin{array}{l}\text { Federal Savings and Loan Insurance } \\
\text { Company }\end{array}$ \\
\hline GSE & Government sponsored enterprise \\
\hline HEL & Home equity loan \\
\hline ISDA & $\begin{array}{l}\text { International Swaps and Derivatives } \\
\text { Association }\end{array}$ \\
\hline LIBOR & London Interbank Offered Rate \\
\hline LTCM & Long-Term Capital Management \\
\hline MBS & Mortgage backed security \\
\hline M-LEC & Master-Liquidity Enhancement Conduit \\
\hline OTC & Over the counter \\
\hline PDFC & Primary Dealer Credit Facility \\
\hline RTC & Resolution Trust Corporation \\
\hline RMBS & Residential mortgage backed security \\
\hline SEC & Securities and Exchange Commission \\
\hline SIV & Structured investment vehicle \\
\hline SPE & Special purpose enterprise \\
\hline SPV & Special purpose vehicle \\
\hline TAF & Term Auction Facility \\
\hline TED & Treasury-Eurodollar Deposit \\
\hline TBTF & Too big to fail \\
\hline TSLF & Term Securities Lending Facility \\
\hline
\end{tabular}




\section{References}

Adrian, T. and H. S. Shin (2008a), "Money, Liquidity and Monetary Policy", mimeo.

Adrian, T. and H. S. Shin (2008b), "Financial Intermediation, Financial Stability and Monetary Policy", Maintaining Price Stability in a Changing Financial System, Jackson Hole.

Allen, F. and E. Carletti (2008), "The Role of Liquidity in Financial Crisis", Maintaining Price Stability in a Changing Financial System, Jackson Hole.

Angeletos, G. M. and L. E. Calvet (2006), "Idiosyncratic Production Risk, Growth and the Business Cycle", Journal of Monetary Economics 53, 1095-1115.

Angeloni, I. (2008), "Europe and the Financial Crisis", Panel discussion, The Global Financial Crisis: Policy Choices in Asia and Europe. Beijing December 9-10

Bank for International Settlement (2008), BIS 78th Annual Report, June.

Bank of England (2007), "Markets and Operations," Bank of England Quarterly Bulletin-Q4 47/4, 490-510

Benmelech, E. and J. Dlugosz (2008), "The Alchemy of CDO Ratings”, Working Paper, Harvard Business School.

Bilbiie, F. and G. Corsetti (2008), "Hard Landing at Last?! From Global Inflation to Financial Crisis, Deflationary Shocks and Global Recession", Paper prepared for the conference "The Global Financia Crisis: Policy Choices in Asia and Europe", organized by the Asia Europe Economic Forum, Beijing, 8-10 December 2008.

Borio, C. and W. Nelson (2008), "Monetary Operations and the Financial Turmoil”, BIS Quarterly Review, March.

Brunnermeier, M. (2009), "Deciphering the Liquidity and Credi Crunch 2007-08", Journal of Economic Perspectives 23/1, forthcoming.

Buiter, W. (2008), "Central Banks and Financial Crises", Maintaining Price Stability in a Changing Financial System, Jackson Hole.

Buiter, W. and A. Sibert (2008a), "The Central Bank as the Market Maker of Last Resort: From Lender of Last Resort to Market Maker of Last Resort", www.voxeu.org, August 13, 2007.

Buiter, W. and A. Sibert (2008b), "The Icelandic Banking Crisis and What to Do about it", mimeo.

Burnside, C., M. Eichenbaum, and S. Rebelo, (2001) "Prospective Deficits and the Asian Currency Crisis", Journal of Political Economy 109/6, 1155-1197.

Caballero, R. and A. Krishnamurthy (2008), "Knightian Uncertaint and its Implications for the TARP", November 24, Financial Times.

Caballero, R., E. Fahri and P.-O. Gourinchas (2008a), "An Equilibrium Model of Global Imbalances and Low Interest Rates", American Economic Review 98/1, 358-393.

Caballero R., E. Fahri and P.-O. Gourinchas (2008b), "Financial Crash, Commodity prices and Global Imbalances", Brookings Paper on Economic Activity, forthcoming.

Calomiris, C. (2008), “The Subprime Turmoil: What's Old, What's New, and What's Next", Maintaining Price Stability in a Changing Financial System, Jackson Hole.

Chari, V.V., L. Christiano and P. Kehoe, "Facts and Myths about the Financial Crisis of 2008", Minneapolis Fed Working Paper No. 666

Corneli, F. (2008), "The Saving Glut Explanation of Global Imbalances: the Role of Underinvestment", mimeo, European University Institute, Florence.

Corsetti, G. (2007), The anatomy of dollar depreciation (Has the dollar fallen enough?), November 6, Vox, www.vox.eu.

Corsetti, G. and B. Mackowiak (2006), "Fiscal Imbalances and the Dynamics of Currency Crises", European Economic Review 50, $1317-1338$

Corsetti, G., P. Pesenti and Roubini, N. (1999), "Paper tigers? A model of the Asian crisis", European Economic Review 43/7, 1211-1236.

Corsetti, G., P. Martin and P. Pesenti (2008), "Varieties and the Transfer Problem: the Extensive Margin of Current Account
Adjustment", CEPR Discussion Papper No. 6660, NBER Working Paper No. 13795

Diamond, D. W. and P. H. Dybvig (1983), "Bank runs, deposit insurance, and liquidity", Journal of Political Economy 91/3, 401-19.

EEAG (2003), Report on the European Economy 2003, CESifo, Munich.

EEAG (2006), Report on the European Economy 2006, CESifo, Munich.

EEAG (2008), Report on the European Economy 2008, CESifo, Munich.

European Central Bank (ECB) (2008a), Financial Stability Review, June.

European Central Bank (ECB) (2008b), Financial Stability Review, December.

Eichengreen, B. and R. Baldwin (2008), "Rescuing Our Jobs and Savings: What G7/8 Leaders Can Do to Solve the Global Credit Crisis", VoxEU.org publication.

Faruqee, H., D. Laxton, P. Pesenti and D. Muir (2007), "Smooth Landing or Crash? Model-Based Scenarios of Global Current Account Rebalancing", in R. Clarida (ed.), G7 Current Account Imbalances: Sustainability and Adjustment, University of Chicago Press, 377-451.

Feldstein, M. (2008a), "How to Stop the Mortgage Crisis", The Wall Street Journal, March 7.

Feldstein, M. (2008b), "How to Help People Whose Home Values Are Underwater - The economic spiral will get worse unless we do something about negative equity", The Wall Street Journal, November 18

Felton, A. and C. Reinhardt (2008), "The First Global Financial Crisis of the 21st Century", VoxEU.org publication.

Geanakoplos, J. and S. Koniak (2008), "Mortgage Justice is Blind", The New York Times, October 30.

Goldman Sachs (2007), "The Subprime Issue: A Global Assessment of Losses, Contagion, and Strategic Implications", November 20.

Gorton, G. (2008), "The Panic of 2007, Maintaining Price Stability in a Changing Financial System", Jackson Hole.

Greenlaw, D., J. Hatzius, A. Kashyap and Y. S. Shin (2008),"Leveraged Losses: Lessons from the Mortgage Market Meltdown", Prooceeding of the U.S. Monetary Policy Forum.

International Monetary Fund (2008a), Global Financial Stability Report, April.

International Monetary Fund (2008b), Global Financial Stability Report, October.

Jacklin, C. and S. Bhattacharya (1988), "Distinguishing Panics and Information-Based Bank Runs: Welfare and Policy Implications", Journal of Political Economy 96/3, 568-592.

Kaplan, S. (2008), "The Financial Crisis and the Bailout", mimeo, University of Chicago.

Keys, B. J., T. K. Mukherjee, A. Seru, and V. Vig (2008), "Did securitisation Lead to Lax Screening? Evidence from Subprime Loans", EFA 2008 Athens Meetings Paper.

Krugman, P. (2007), "Will there be a Dollar Crisis?" Economic Policy 51, 435-467.

Lehman Brothers (2007), "Securitized Products Outlook 2008: Bumpy Road to Recovery", December.

Ljungqvist, L. and T. Sargent, (2004), Recursive Macroeconomic Theory, MIT Press.

Marimon, R. (2008), La “aritmética incomoda" del nuevo orden financiero, Cinco Dias.

Mendoza, E. G., V. Quadrini and J.-V. Rios-Rull (2007), "Financial Integration, Financial Deepness and Global Imbalances", NBER Working Paper No. 12909.

Mertens, K. (2007), "The Role of Expectations in Sudden Stops", CAE working paper No. $07-10$. 
Michaud, F.-L., and C. Upper (2008), "What Drives Interbank Rates? Evidence from the LIBOR Panel", Bank for International Settlements Quarterly Review (March), 47-58.

Morris, S. and H. S. Shin (2001), "Rethinking Multiple Equilibria in Macroeconomics", NBER Macroeconomics Annual 2000, 139-161, M.I.T. Press.

Morris S. and H. S. Shin (2003), "Global Games: Theory and Applications," in M. Dewatripont, L. Hansen and S. Turnovsky (eds.) Advances in Economics and Econometrics (Proceedings of the Eighth World Congress of the Econometric Society), Cambridge University Press.

Morrison, A. (2008), "Ratings Agencies, regulation and Financial Market Stability”, Saïd Business School, Oxford.

Obstfeld, M. and K. Rogoff (2007), "The Unsustainable US Current Account Position Revisited", in R. Clarida (ed.), G7 Current Account Imbalances: Sustainability and Adjustment, University of Chicago Press, 339-376.

Perssson, M., T. Persson and L. E. O. Svensson, (1998), "Debt, Cash Flow, and Inflation Incentives: A Swedish Example", in G. Calvo and M. King (eds): The Debt Burden and its Consequences for Monetary Policy, Macmillan Press, London.

Portes, R. (2008), "The shocking errors of Iceland's meltdown", Financial Times, Oct 13.

Postlewaite, A. and X. Vives (1987), "Bank Runs as an Equilibrium Phenomenon", Journal of Political Economy 95, 485-491.

Rochet, J. C. and X. Vives (2004), "Coordination Failures and the Lender of Last Resort: Was Bagehot Right After All?", Journal of the European Economic Association 2/6, 1116-1147.

Roubini, N. and B. Setser (2004), "The US as a Net Debtor: The Sustainability of the US External Imbalances", mimeo, New York University.

Sargent, T. and N. Wallace, (1981), "Some unpleasant monetarist arithmetic", Quarterly Review, Federal Reserve Bank of Minneapolis, Fall.

Shiller, R. (2008), The Subprime Solution, Princeton University Press.

Sims, C. A. (2008), "Government and Central Bank Balance Sheets, Inflation and Monetary Policy", mimeo, Princeton University.

Sinn, H.-W. (1981), Economic Decisions under Uncertainty, North Holland Publishing Company, Amsterdam, New York etc.

Sinn, H.-W. (2009), Risk Taking, Limited Liability, and the Banking Crisis, Selected Reprints, Ifo Institute, Munich.

Stiglitz, J. and A. Weiss (1981), "Credit Rationing in Markets with Imperfect Information”, American Economic Review, 71/3, 393-410.

Stucke, R. and D. Tsomocos (2008), "Out of Sight, Out of Mind! How Economic Developments, Off-Balanced Sheet Transactions and Opportunistic Behaviour Caused the Crunch in the Credit Markets", mimeo, Oxford University

Vives, X. (2008a), "Bagehot, central banking, and the financial crisis", March 31, www.vox.eu.

Vives, X. (2008b), "The Singularity of Banks", December 18, Wall Street Journal.

Zingales, L. (2008), Testimony on "Causes and Effects of the Lehman Brothers Bankruptcy" before the Committee on Oversight and Government Reform of the United States House of Representatives.

Zwart, S. (2008), "Liquidity runs with endogenous information acquisition", Economics Letters 100/1, 64-67. 
Appendix:

The chronology of the financial crisis

\begin{tabular}{|c|c|c|}
\hline Market events & Date & Policy actions \\
\hline & February 7, 2007 & $\begin{array}{l}\text { US Senate Banking Committee holds hearing } \\
\text { on predatory lending in subprime sector. }\end{array}$ \\
\hline \multirow{2}{*}{$\begin{array}{l}\text { HSBC losses top } \$ 10.5 \text { billion. Head of HSBC US } \\
\text { mortgage-lending business is fired. }\end{array}$} & February 22,2007 & \\
\hline & March 7, 2007 & $\begin{array}{l}\text { The Federal Deposit Insurance Corporation } \\
\text { issues a cease-and-desist order against } \\
\text { subprime lender Fremont Investment \& Loan, } \\
\text { which had been "operating without adequate } \\
\text { subprime mortgage loan underwriting criteria". }\end{array}$ \\
\hline $\begin{array}{l}\text { Donald Tomnitz, the CEO of D. R. Horton, the } \\
\text { largest US homebuilder, tells investors: "I don't } \\
\text { want to be too sophisticated here, but } 2007 \text { is going } \\
\text { to suck, all } 12 \text { months of the calendar year." }\end{array}$ & March 8, 2007 & \\
\hline $\begin{array}{l}\text { Lenders to New Century Financial, a large subprime } \\
\text { lender, cut off its credit lines. Trading in its shares } \\
\text { is suspended by the New York Stock Exchange. }\end{array}$ & March 12, 2007 & \\
\hline $\begin{array}{l}\text { Subprime lender Accredited Home Lenders to sell, } \\
\text { at a heavy discount, } \$ 2.7 \text { billion of loans. }\end{array}$ & March 16, 2007 & $\begin{array}{l}\text { The New York Attorney General announces an } \\
\text { investigation of subprime lending. }\end{array}$ \\
\hline New Century Financial files for bankruptcy. & April 2, 2007 & \\
\hline $\begin{array}{l}\text { The National Association of Realtors announces } \\
\text { that existing home sales fell } 8.4 \% \text { during March, the } \\
\text { greatest drop in } 18 \text { years. }\end{array}$ & April 24, 2007 & \\
\hline \multirow{2}{*}{$\begin{array}{l}\text { GMAC, the finance arm of General Motors, reports } \\
\text { losses of } \$ 1 \text { billion. } \\
\text { UBS closes its US subprime business. }\end{array}$} & May 3, 2007 & $\begin{array}{l}\text { First comprehensive plan to help homeowners } \\
\text { avoid foreclosures presented in US Senate. }\end{array}$ \\
\hline & June 6,2007 & $\begin{array}{l}\text { The Bank of England reduces the overnight } \\
\text { bank rate by } 25 \text { basis points to } 5.5 \% \text {. }\end{array}$ \\
\hline \multirow{2}{*}{$\begin{array}{l}\text { Bear Stearns injects } \$ 3.2 \text { billion into two of its } \\
\text { hedge funds hurt by falling CDO prices. }\end{array}$} & June 22,2007 & \\
\hline & July 4, 2007 & $\begin{array}{l}\text { UK authorities take action against five brokers } \\
\text { selling subprime mortgages. }\end{array}$ \\
\hline $\begin{array}{l}\text { All three major credit-ratings agencies announce } \\
\text { review of subprime bonds. }\end{array}$ & July 10,2007 & \\
\hline $\begin{array}{l}\text { General Electric to sell WMC Mortgage, its } \\
\text { subprime lending business. }\end{array}$ & July 13,2007 & \\
\hline \multirow{2}{*}{$\begin{array}{l}\text { US housing starts down } 20 \% \text { from the previous } \\
\text { year. }\end{array}$} & July 18,2007 & \\
\hline & July 20,2007 & $\begin{array}{l}\text { Federal Reserve chairman Ben Bernanke gives } \\
\text { a warning that the US subprime crisis could } \\
\text { cost up to } \$ 100 \text { billion. }\end{array}$ \\
\hline $\begin{array}{l}\text { The two Bear Stearns hedge funds that were under } \\
\text { stress file for bankruptcy protection. }\end{array}$ & July 31,2007 & \\
\hline $\begin{array}{l}\text { American Home Mortgage, one of the largest US } \\
\text { home-loan providers, files for bankruptcy. }\end{array}$ & August 6, 2007 & \\
\hline $\begin{array}{l}\text { BNP Paribas suspends three investment funds hit by } \\
\text { subprime crisis. }\end{array}$ & August 9, 2007 & \\
\hline \multicolumn{3}{|l|}{$\begin{array}{l}\text { AIG warns that mortgage defaults are spreading } \\
\text { beyond subprime sector. }\end{array}$} \\
\hline $\begin{array}{l}\text { The interest rate on } 15 \text {-day triple-A asset-backed } \\
\text { commercial paper hits } 6.14 \% \text { for a historic high. }\end{array}$ & August 10, 2007 & $\begin{array}{l}\text { The ECB provides } € 61 \text { billion of funds for } \\
\text { banks. The Federal Reserve says it will } \\
\text { provide as much overnight money. }\end{array}$ \\
\hline $\begin{array}{l}\text { Goldman Sachs to pump } \$ 3 \text { billion to rescue a } \\
\text { hedge fund. }\end{array}$ & August 13, 2007 & $\begin{array}{l}\text { The ECB and central banks in the United } \\
\text { States and Japan continue supplying liquidity } \\
\text { to markets. }\end{array}$ \\
\hline \multirow{2}{*}{$\begin{array}{l}\text { Countrywide draws down its } \$ 11.5 \text { billion credit } \\
\text { line. }\end{array}$} & August 16, 2007 & \\
\hline & August 17, 2007 & $\begin{array}{l}\text { The Federal Reserve cuts the primary discount } \\
\text { rate to } 5.75 \% \text {, warning the credit crunch could } \\
\text { be a risk to economic growth. }\end{array}$ \\
\hline $\begin{array}{l}\text { Four large US banks announce coordinated } \\
\text { borrowing of } \$ 2 \text { billion from the Federal Reserve's } \\
\text { discount window. } \\
\text { Bank of America purchases } 16 \% \text { of Countrywide } \\
\text { Financial for } \$ 2 \text { billion. }\end{array}$ & August 23, 2007 & \\
\hline
\end{tabular}




\begin{tabular}{|c|c|c|}
\hline Market events & Date & Policy actions \\
\hline $\begin{array}{l}\text { German regional bank Sachsen Landesbank faces } \\
\text { collapse after investing in the subprime market; it is } \\
\text { sold to larger rival Landesbank Baden- } \\
\text { Wuerttemberg. } \\
\text { The S\&P/Case-Shiller Home Price Index for the } \\
\text { second quarter } 2007 \text { is down } 3.2 \% \text { from a year } \\
\text { earlier, the greatest drop in the } 17 \text {-year history of } \\
\text { the index. }\end{array}$ & August 28, 2007 & \\
\hline Subprime lender Ameriquest files for bankruptcy. & August 31, 2007 & \\
\hline $\begin{array}{l}\text { IKB, a German regional lender, records } \$ 1 \text { billion } \\
\text { loss due to US subprime market exposure. }\end{array}$ & September 3, 2007 & \\
\hline $\begin{array}{l}\text { The rate at which banks lend to each other rises to } \\
\text { its highest level since December 1998; banks either } \\
\text { worry whether other banks will survive or urgently } \\
\text { need the money themselves. } \\
\text { Bank of China reveals } \$ 9 \text { billion in subprime losses. }\end{array}$ & September 4, 2007 & \\
\hline $\begin{array}{l}\text { The delinquency rate on FHA mortgages on one- to } \\
\text { four-family houses reaches } 5.1 \% \text { in the US, } \\
\text { according to the Mortgage Bankers Association. }\end{array}$ & September 6, 2007 & \\
\hline $\begin{array}{l}\text { Global Alpha, a hedge fund managed by Goldman } \\
\text { Sachs, reveals that it lost } 22 \% \text { during August. }\end{array}$ & September 13, 2007 & $\begin{array}{l}\text { British mortgage lender Northern Rock has } \\
\text { asked for and been granted emergency } \\
\text { financial support from the Bank of England. }\end{array}$ \\
\hline \multirow{3}{*}{$\begin{array}{l}\text { A run on the deposits of Northern Rock begins: } \\
\text { Depositors withdraw } £ 1 \text { billion in what is the } \\
\text { biggest run on a British bank in more than a } \\
\text { century. }\end{array}$} & September 14, 2007 & $\begin{array}{l}\text { British government steps in to guarantee } \\
\text { depositor savings of Northern Rock to stop } \\
\text { bank run. }\end{array}$ \\
\hline & September 18, 2007 & $\begin{array}{l}\text { The Federal Reserve cuts the federal funds rate } \\
\text { by } 50 \text { basis points to } 4.75 \% \text {. This is the first } \\
\text { cut since } 2003 \text {. }\end{array}$ \\
\hline & September 19, 2007 & $\begin{array}{l}\text { After previously refusing to inject any funding } \\
\text { into the markets, the Bank of England } \\
\text { announces that it will auction } £ 10 \text { billion. }\end{array}$ \\
\hline $\begin{array}{l}\text { UBS and Citigroup announce losses of } \$ 3.4 \text { billion } \\
\text { and } \$ 3.1 \text { billion, respectively. }\end{array}$ & October 1,2007 & \\
\hline \multirow{2}{*}{$\begin{array}{l}\text { The Dow Jones Industrial Average closes at 14,164, } \\
\text { its all-time high. }\end{array}$} & October 9,2007 & \\
\hline & October 10,2007 & $\begin{array}{l}\text { The US government teams up with mortgage } \\
\text { servicers and investors to launch the HOPE } \\
\text { NOW alliance, to encourage the voluntary } \\
\text { modification of adjustable-rate mortgages to } \\
\text { fixed rates. }\end{array}$ \\
\hline $\begin{array}{l}\text { Citigroup, JPMorgan Chase and Bank of America, } \\
\text { with the support of the Treasury Department, } \\
\text { announce a plan to form a Master-Liquidity } \\
\text { Enhancement Conduit (M-LEC) that would } \\
\text { purchase asset-backed commercial paper from } \\
\text { liquidation SIVs. }\end{array}$ & October 14,2007 & \\
\hline $\begin{array}{l}\text { Citigroup and the Japanese bank Nomura announce } \\
\text { subprime losses of } \$ 5.9 \text { billion and } \$ 621 \text { million, } \\
\text { respectively. }\end{array}$ & October 15,2007 & \\
\hline $\begin{array}{l}\text { The National Association of Home Builders } \\
\text { confidence index hits 19, the lowest since the series } \\
\text { began in } 1985 .\end{array}$ & October 16,2007 & \\
\hline $\begin{array}{l}\text { Countrywide Financial reports a loss of } \$ 1.2 \text { billion } \\
\text { for third-quarter } 2007 \text {. This is its first loss in } 25 \\
\text { years. }\end{array}$ & October 26,2007 & \\
\hline $\begin{array}{l}\text { Merrill Lynch announces losses of } \$ 7.9 \text { billion and } \\
\text { the resignation of the CEO, Stan O'Neal. }\end{array}$ & October 30,2007 & \\
\hline Deutsche Bank reveals a $\$ 2.2$ billion loss. & October 31,2007 & $\begin{array}{l}\text { The Federal Reserve cuts the federal funds rate } \\
\text { by } 25 \text { basis points to } 4.5 \% \text {. }\end{array}$ \\
\hline $\begin{array}{l}\text { Credit Suisse discloses a } \$ 1 \text { billion loss. } \\
\text { Fed injects } \$ 41 \text { billion. }\end{array}$ & November 1,2007 & \\
\hline $\begin{array}{l}\text { Citigroup announces that its } \$ 55 \text { billion portfolio of } \\
\text { subprime-related investments has declined in value } \\
\text { between } \$ 8 \text { billion and } \$ 11 \text { billion. The CEO, } \\
\text { Charles Prince, resigns. }\end{array}$ & November 5, 2007 & \\
\hline
\end{tabular}




\begin{tabular}{|c|c|c|}
\hline Market events & Date & Policy actions \\
\hline $\begin{array}{l}\text { Morgan Stanley and BNP Paribas disclose mortgage } \\
\text { losses of } \$ 3.7 \text { billion and } € 197 \text { million, respectively. } \\
\text { AIG writes down } \$ 2 \text { billion of mortgage } \\
\text { investments. }\end{array}$ & November 8, 2007 & \\
\hline Wachovia announces $\$ 1.7$ billion loss. & November 9, 2007 & \\
\hline $\begin{array}{l}\text { Bank of America announces } \$ 3 \text { billion subprime } \\
\text { loss. }\end{array}$ & November 13, 2007 & \\
\hline $\begin{array}{l}\text { Japan's second largest banking group, Mizuho, } \\
\text { reports full-year operating profit fell 13\%. } \\
\text { HSBC reports losses of } \$ 3.4 \text { billion. }\end{array}$ & November 14, 2007 & \\
\hline Barclays reveals $\$ 2.7$ billion loss. & November 15, 2007 & $\begin{array}{l}\text { The US House of Representatives passes the } \\
\text { Predatory Lending and Mortgage Protection } \\
\text { Act. }\end{array}$ \\
\hline $\begin{array}{l}\text { Goldman Sachs forecasts financial losses due to } \\
\text { subprime crises at } \$ 400 \text { billion. }\end{array}$ & November 16,2007 & \\
\hline $\begin{array}{l}\text { The reinsurance company, Swiss Re, to lose } \$ 1 \\
\text { billion on insurance of clients hit by subprime } \\
\text { crises. }\end{array}$ & November 19, 2007 & \\
\hline Freddie Mac reports a $\$ 2$ billion loss. & November 20,2007 & \\
\hline $\begin{array}{l}\text { Freddie Mac and Citigroup raise } \$ 6 \text { billion and } \$ 7.5 \\
\text { billion of capital respectively. } \\
\text { US house prices record biggest quarterly drop in } 21 \\
\text { years. }\end{array}$ & November 27, 2007 & \\
\hline \multirow[t]{2}{*}{$\begin{array}{l}\text { The Bank of England reveals the number of } \\
\text { mortgage approvals has fallen to a near three-year } \\
\text { low. }\end{array}$} & November 29, 2007 & \\
\hline & December 5, 2007 & $\begin{array}{l}\text { The New York Attorney General sends } \\
\text { subpoenas to major investment banks to } \\
\text { investigate subprime mortgage securitization. }\end{array}$ \\
\hline $\begin{array}{l}\text { UBS and Lloyds TSB report } \$ 10 \text { billion and } £ 200 \mathrm{~m} \\
\text { losses due to bad debts in the US housing market. }\end{array}$ & December 6, 2007 & $\begin{array}{l}\text { US President George W. Bush outlines plans } \\
\text { to help more than a million homeowners facing } \\
\text { foreclosure. } \\
\text { The Bank of England cuts interest rates by a } \\
\text { quarter of one percentage point to } 5.5 \% \text {. }\end{array}$ \\
\hline \multirow[t]{3}{*}{$\begin{array}{l}\text { Washington Mutual subprime losses to reach } \$ 1.6 \\
\text { billion. }\end{array}$} & December 11, 2007 & $\begin{array}{l}\text { The Federal Reserve lowers the federal funds } \\
\text { rate by } 25 \text { basis points to } 4.25 \% \text {. }\end{array}$ \\
\hline & December 12, 2007 & $\begin{array}{l}\text { The Bank of Canada, the Bank of England, the } \\
\text { European Central Bank, the Federal Reserve } \\
\text { and the Swiss National Bank announce } \\
\text { measures designed to address elevated } \\
\text { pressures in short-term funding markets. } \\
\text { Actions taken by the Federal Reserve include } \\
\text { the establishment of a temporary Term } \\
\text { Auction Facility and the establishment of } \\
\text { foreign exchange swap lines with the European } \\
\text { Central Bank and the Swiss National Bank. }\end{array}$ \\
\hline & December 13, 2007 & $\begin{array}{l}\text { The US Federal Reserve co-ordinates an } \\
\text { unprecedented action by five leading central } \\
\text { banks around the world to offer billions of } \\
\text { dollars in loans to banks. The move succeeds } \\
\text { in temporarily lowering the rate at which banks } \\
\text { lend to each other. }\end{array}$ \\
\hline \multirow{3}{*}{$\begin{array}{l}\text { Citigroup takes } \$ 49 \text { billion worth of SIV assets back } \\
\text { on its balance sheet. }\end{array}$} & December 14, 2007 & \\
\hline & December 17, 2007 & $\begin{array}{l}\text { Federal Reserve makes } \$ 20 \text { billion available to } \\
\text { commercial banks. }\end{array}$ \\
\hline & December 18, 2007 & $\begin{array}{l}\text { The Federal Reserve Bank tightens rules on } \\
\text { subprime lending. } \\
\text { The ECB lends European commercial banks } \\
\$ 500 \text { billion. } \\
\text { The Bank of England makes } £ 10 \text { billion } \\
\text { available to UK banks. }\end{array}$ \\
\hline
\end{tabular}




\begin{tabular}{|c|c|c|}
\hline Market events & Date & Policy actions \\
\hline $\begin{array}{l}\text { As subprime losses reach } \$ 9.4 \text { billion, Morgan } \\
\text { Stanley sells } 9.9 \% \text { stake in the company. } \\
\text { Ratings agency Standard and Poor's downgrades its } \\
\text { investment rating of a number of monoline insurers. } \\
\text { There is concern that insurers will not be able to pay } \\
\text { out, forcing banks to announce another big round of } \\
\text { losses. }\end{array}$ & December 19, 2007 & \\
\hline $\begin{array}{l}\text { The spread of 15-day AAA asset-backed } \\
\text { commercial paper over equivalent duration AAA } \\
\text { non-financial commercial paper hits } 173 \text { basis } \\
\text { points as banks scramble for funding through the } \\
\text { end of the year. The spread is usually less than } 10 \\
\text { basis points. }\end{array}$ & December 21, 2007 & \\
\hline $\begin{array}{l}\text { The M-LEC plan to rescue struggling SIVs is } \\
\text { abandoned by the sponsoring banks. }\end{array}$ & December 22, 2007 & \\
\hline $\begin{array}{l}\text { US job losses in residential construction and } \\
\text { mortgage lending for } 2007 \text { estimated at } \$ 35,000 \text {. }\end{array}$ & January 4, 2008 & \\
\hline $\begin{array}{l}\text { Bear Stearns reveals subprime losses of } \$ 1.9 \text { billion. } \\
\text { The CEO, James Cayne, steps down. } \\
\text { The World Bank says that world economic growth } \\
\text { will slow in } 2008 \text { due to subprime crisis credit } \\
\text { crunch. }\end{array}$ & January 9,2008 & \\
\hline $\begin{array}{l}\text { Bank of America buys Countrywide for } \$ 4 \text { billion } \\
\text { after its shares plunge } 48 \% \text {. } \\
\text { Merrill Lynch doubles projection of subprime losses } \\
\text { to } \$ 15 \text { billion. }\end{array}$ & January 11,2008 & \\
\hline $\begin{array}{l}\text { Citigroup reports a } \$ 9.8 \text { billion loss for the fourth } \\
\text { quarter, including } \$ 18 \text { billion loss in mortgage } \\
\text { portfolio. }\end{array}$ & January 15,2008 & \\
\hline $\begin{array}{l}\text { Lehman Brothers withdraws from wholesale } \\
\text { mortgage lending and will cut } 1,300 \text { jobs. }\end{array}$ & January 17,2008 & \\
\hline $\begin{array}{l}\text { Crisis of monoline insurers: Fitch Ratings } \\
\text { downgrades Ambac Financial Group's insurance } \\
\text { financial strength rating to AA, Credit Watch } \\
\text { Negative. Standard and Poor's place Ambac's AAA } \\
\text { rating on CreditWatch Negative. }\end{array}$ & January 18,2008 & \\
\hline $\begin{array}{l}\text { Global stock markets suffer their biggest falls since } \\
11 \text { September } 2001 \text {. }\end{array}$ & January 21, 2008 & \\
\hline $\begin{array}{l}\text { Stock markets around the world recover the } \\
\text { previous day's heavy losses. }\end{array}$ & January 22,2008 & $\begin{array}{l}\text { The Federal Reserve cuts rates by three } \\
\text { quarters of a percentage point to } 3.5 \% \text { - its } \\
\text { biggest cut in } 25 \text { years - to try and prevent the } \\
\text { economy from slumping into recession. } \\
\text { It is the first emergency cut in rates since } 2001 \text {. }\end{array}$ \\
\hline $\begin{array}{l}\text { The French bank Société Générale announces that it } \\
\text { lost } € 4.9 \text { billion due to the unauthorized activity of } \\
\text { one of its traders. While the bank closed out the } \\
\text { trades of this trader during a holiday weekend in the } \\
\text { United States, stock markets plunged round the } \\
\text { world. }\end{array}$ & January 24,2008 & \\
\hline $\begin{array}{l}\text { Regularly scheduled auctions for municipal debt of } \\
\text { the state of Nevada and Georgetown University fail } \\
\text { due to lack of bidders and uncertainty about } \\
\text { monocline insurers. The debt issuers are forced to } \\
\text { pay a penalty rate. }\end{array}$ & January 30,2008 & $\begin{array}{l}\text { The Federal Reserve cuts the federal funds rate } \\
\text { by } 50 \text { basis points to } 3.00 \% \text {. }\end{array}$ \\
\hline \multirow{2}{*}{$\begin{array}{l}\text { A major bond insurer MBIA, announces a loss of } \\
\$ 2.3 \text { billion - its biggest to date for a three-month } \\
\text { period - blaming its exposure to the US subprime } \\
\text { mortgage crisis. }\end{array}$} & January 31,2008 & \\
\hline & February 7,2008 & $\begin{array}{l}\text { US Federal Reserve boss Ben Bernanke adds } \\
\text { his voice to concerns about monoline insurers, } \\
\text { saying he is closely monitoring developments } \\
\text { "given the adverse effects that problems of } \\
\text { financial guarantors can have on financial } \\
\text { markets and the economy". } \\
\text { The Bank of England cuts interest rates by a } \\
\text { quarter of one percent to } 5.25 \% \text {. }\end{array}$ \\
\hline
\end{tabular}




\begin{tabular}{|c|c|c|}
\hline Market events & Date & Policy actions \\
\hline & February 10,2008 & $\begin{array}{l}\text { Leaders from the G7 group of industrialised } \\
\text { nations say worldwide losses stemming from } \\
\text { the collapse of the US subprime mortgage } \\
\text { market could reach } \$ 400 \text { billion. }\end{array}$ \\
\hline & February 13,2008 & $\begin{array}{l}\text { President Bush signs the Economic Stimulus } \\
\text { Act of } 2008 \text {. The Act provides approximately } \\
\$ 100 \text { billion of tax rebates to be distributed } \\
\text { during summer } 2008 \text { and } \$ 50 \text { billion of } \\
\text { investment incentives. }\end{array}$ \\
\hline $\begin{array}{l}\text { UBS announces fourth-quarter } 2007 \text { loss of } \\
\text { CHF12.4 billion ( } \$ 12 \text { billion). }\end{array}$ & February 14,2008 & \\
\hline \multirow{2}{*}{$\begin{array}{l}\text { Problems in the auction-rate securities market } \\
\text { continue to spread; over } 1,000 \text { auctions } \\
\text { fail this week. Investment banks do not allow } \\
\text { investors to withdraw funds invested in those } \\
\text { securities. }\end{array}$} & February 15,2008 & \\
\hline & February 17,2008 & $\begin{array}{l}\text { British government announces that struggling } \\
\text { Northern Rock is to be nationalised for a } \\
\text { temporary period. }\end{array}$ \\
\hline $\begin{array}{l}\text { AIG announces fourth-quarter } 2007 \text { losses of } \$ 5.3 \\
\text { billion due to more than } \$ 11 \text { billion of losses on its } \\
\text { credit-default swap portfolio. }\end{array}$ & February 28,2008 & \\
\hline \multirow{4}{*}{$\begin{array}{l}\text { The delinquency rate on family mortgages was } \\
5.82 \% \text { during the fourth quarter of } \\
2007 \text {, up } 87 \text { basis points from a year earlier, } \\
\text { according to MBA's National Delinquency } \\
\text { Survey. }\end{array}$} & March 6, 2008 & \\
\hline & March 7, 2008 & $\begin{array}{l}\text { In its biggest intervention yet, the Federal } \\
\text { Reserve makes } \$ 200 \text { billion of funds available } \\
\text { to banks and other institutions to try to } \\
\text { improve liquidity in the markets. }\end{array}$ \\
\hline & March 11, 2008 & $\begin{array}{l}\text { The Federal Reserve Bank of New York } \\
\text { announces the creation of the term securities } \\
\text { lending facility (TSLF), which lets primary } \\
\text { dealers swap AAA-rated securities for } \\
\text { Treasury securities. }\end{array}$ \\
\hline & & $\begin{array}{l}\text { The Federal Reserve, the ECB and SNB } \\
\text { increase the size of their dollar swap lines to } \\
\$ 30 \text { billion and } \$ 6 \text { billion respectively }\end{array}$ \\
\hline \multirow{2}{*}{$\begin{array}{l}\text { The investment firm, Carlyle Capital, defaults on } \\
\$ 17 \text { billion of debt. The fund is } \\
\text { leveraged more than } 30: 1 \text { and invests mostly in } \\
\text { agency-backed residential mortgage- } \\
\text { backed securities (RMBS). }\end{array}$} & March 14, 2008 & \\
\hline & March 16, 2008 & $\begin{array}{l}\text { The Federal Reserve Bank of New York } \\
\text { announces the creation of the primary dealer } \\
\text { credit facility (PDCF), which essentially opens } \\
\text { the discount window to primary dealers, } \\
\text { including non-depository institutions. }\end{array}$ \\
\hline \multirow{3}{*}{$\begin{array}{l}\text { Wall Street's fifth-largest bank, Bear Stearns, is } \\
\text { acquired by larger rival JPMorgan Chase for } \\
\$ 240 \text { million in a deal backed by } \$ 30 \text { billion of } \\
\text { central bank loans. A year earlier, Bear Stearns had } \\
\text { been worth } £ 18 \text { billion. }\end{array}$} & March 17, 2008 & $\begin{array}{l}\text { The Federal Reserve Bank of New York agrees } \\
\text { to guarantee } \$ 30 \text { billion of Bear Stearns assets, } \\
\text { mostly mortgage-related. }\end{array}$ \\
\hline & March 18, 2008 & $\begin{array}{l}\text { The Federal Reserve cuts the federal funds rate } \\
\text { by } 75 \text { basis points to } 2.25 \% \text {. }\end{array}$ \\
\hline & March 24, 2008 & $\begin{array}{l}\text { The Fed announces that it will provide term } \\
\text { financing to facilitate JPMorgan Chase\&Co's } \\
\text { acquisition of the Bear Sterns Companies, Inc. }\end{array}$ \\
\hline \multirow{3}{*}{$\begin{array}{l}\text { Washington Mutual, one of the largest US mortgage } \\
\text { originators, raises } \$ 7 \text { billion from TPG, a private } \\
\text { equity firm. } \\
\text { The IMF's Global Financial Stability estimates that } \\
\text { the total credit losses will be } \$ 1 \text { trillion. }\end{array}$} & April 8, 2008 & \\
\hline & & \\
\hline & April 10, 2008 & $\begin{array}{l}\text { The Bank of England cuts interest rates by a } \\
\text { quarter of one percent to } 5 \% \text {. }\end{array}$ \\
\hline
\end{tabular}




\begin{tabular}{|c|c|c|}
\hline Market events & Date & Policy actions \\
\hline $\begin{array}{l}\text { Alpha magazine reports that hedge-fund owner John } \\
\text { Paulson was the highest-paid trader in } 2007 \text {. His } \\
\text { fund, Paulson \& Co., rose more than } \$ 20 \text { billion in } \\
\text { value during the year by shorting the mortgage } \\
\text { market. } \\
\text { Confidence in the UK housing market falls to its } \\
\text { lowest point in } 30 \text { years. }\end{array}$ & April 15, 2008 & \\
\hline $\begin{array}{l}\text { Citigroup announces another } \$ 12 \text { billion of losses } \\
\text { related to subprime mortgages, leveraged loans, } \\
\text { exposure to monoline insurers, auction-rate } \\
\text { securities and consumer credit. }\end{array}$ & April 18, 2008 & \\
\hline $\begin{array}{l}\text { National City Corporation, a large regional US } \\
\text { bank, announces a } \$ 7 \text { billion capital infusion from } \\
\text { Corsair Capital, a private-equity firm. }\end{array}$ & April 21, 2008 & $\begin{array}{l}\text { The Bank of England announces details of an } \\
\text { ambitious } £ 50 \text { billion plan designed to help } \\
\text { credit-squeezed banks by allowing them to } \\
\text { swap potentially risky mortgage debts for } \\
\text { secure government bonds. }\end{array}$ \\
\hline $\begin{array}{l}\text { Royal Bank of Scotland announces that it will raise } \\
\text { about } £ 16 \text { billion from investors by selling assets. }\end{array}$ & April 22, 2008 & \\
\hline \multirow[t]{2}{*}{$\begin{array}{l}\text { In UK, the first annual fall in house prices in } 12 \\
\text { years is recorded by Nationwide. }\end{array}$} & April 30, 2008 & $\begin{array}{l}\text { The Federal Reserve lowers the federal funds } \\
\text { rate by } 25 \text { basis points to } 2.0 \% \text {. }\end{array}$ \\
\hline & May 2,2008 & $\begin{array}{l}\text { The Fed expands Term Auction Facility (TAF) } \\
\text { auctions from } \$ 50 \text { billion to } \$ 75 \text { billion. }\end{array}$ \\
\hline $\begin{array}{l}\text { UBS announces CHF11.5 billion ( } \$ 11.1 \text { billion) } \\
\text { loss during first-quarter } 2008 \text {. }\end{array}$ & May 6, 2008 & \\
\hline $\begin{array}{l}\text { Monoline insurer MBIA announces a } \$ 2.4 \text { billion } \\
\text { loss during first-quarter } 2008 \text {. }\end{array}$ & May 12,2008 & \\
\hline $\begin{array}{l}\text { UBS, one of the worst affected by the credit crunch, } \\
\text { launches a } \$ 15.5 \text { billion rights issue to cover some } \\
\text { of the } \$ 37 \text { billion it lost on assets linked to US } \\
\text { mortgage debt. }\end{array}$ & May 22,2008 & $\begin{array}{l}\text { The Federal Reserve has auctioned } \$ 75 \text { billion } \\
\text { in loans to squeezed banks to help them } \\
\text { overcome credit problems. }\end{array}$ \\
\hline \multirow[t]{3}{*}{$\begin{array}{l}\text { Standard and Poor's downgrades monoline bond } \\
\text { insurers AMBAC and MBIA from AAA to AA. }\end{array}$} & June 5,2008 & \\
\hline & June 17,2008 & $\begin{array}{l}\text { The FBI arrests } 406 \text { people, including brokers } \\
\text { and housing developers, as part of a } \\
\text { crackdown on alleged mortgage frauds worth } \\
\$ 1 \text { billion. } \\
\text { Separately, two former Bear Stearns workers } \\
\text { face criminal charges related to the collapse of } \\
\text { two hedge funds linked to subprime } \\
\text { mortgages. }\end{array}$ \\
\hline & June 19,2008 & \\
\hline $\begin{array}{l}\text { Barclays announces plans to raise } £ 4.5 \text { billion in a } \\
\text { share issue to bolster its balance sheet. The Qatar } \\
\text { Investment Authority, the state-owned investment } \\
\text { arm of the Gulf state, will invest } £ 1.7 \text { billion in the } \\
\text { British bank, giving it a } 7.7 \% \text { share in the business. }\end{array}$ & June 25,2008 & \\
\hline \multirow[t]{3}{*}{$\begin{array}{l}\text { US mortgage lender IndyMac collapses - the } \\
\text { second-biggest bank in US history to fail. }\end{array}$} & July 13,2008 & $\begin{array}{l}\text { Financial authorities step in to assist America's } \\
\text { two largest lenders, Fannie Mae and Freddie } \\
\text { Mac. As owners or guarantors of } \$ 5 \text { trillion } \\
\text { worth of home loans, they are crucial to the US } \\
\text { housing market and authorities agree they } \\
\text { could not be allowed to fail. }\end{array}$ \\
\hline & July 15,2008 & $\begin{array}{l}\text { The Securities Exchange Commission (SEC) } \\
\text { issues an emergency order temporarily } \\
\text { prohibiting naked short selling in the securities } \\
\text { of Fannie Mae, Freddie Mac and primary } \\
\text { dealers at commercial and investment banks. }\end{array}$ \\
\hline & July 30,2008 & $\begin{array}{l}\text { President Bush signs into law the Housing and } \\
\text { Economic Recovery Act of } 2008 \text {, which, } \\
\text { among other provisions, authorises the } \\
\text { Treasury to purchase GSE obligations and } \\
\text { reforms the regulatory supervision of the GSE } \\
\text { under a new Federal Housing Finance Agency. }\end{array}$ \\
\hline
\end{tabular}




\begin{tabular}{|c|c|c|}
\hline Market events & Date & Policy actions \\
\hline $\begin{array}{l}\text { UK house prices show their biggest annual fall } \\
\text { since Nationwide began its housing survey in } 1991 \text {, } \\
\text { a decline of } 8.1 \% \text {. } \\
\text { Britain's biggest mortgage lender HBOS reveals } \\
\text { that profits for the first half of the year sank } 72 \% \text { to } \\
£ 848 \mathrm{~m} \text {, while bad debt rose } 36 \% \text { to } £ 1.31 \text { billion as } \\
\text { customers failed to repay loans. }\end{array}$ & July 31,2008 & \\
\hline $\begin{array}{l}\text { HSBC profits fall } 28 \% \text { as bad debt rises £10billion. } \\
\text { US inflation hits } 27 \text {-year high. }\end{array}$ & August 4, 2008 & \\
\hline Freddie Mac reports $\$ 821$ million loss. & August 62008 & \\
\hline \multirow[t]{2}{*}{$\begin{array}{l}\text { RBS reports a pre-tax loss of } £ 692 \text { million in the } \\
\text { first half, after writing down } £ 5.9 \text { billion on } \\
\text { investments hit by the credit crunch }\end{array}$} & August 8,2008 & $\begin{array}{l}\text { European Central Bank cuts growth forecast } \\
2009 \text { to } 1.2 \% \text { from } 1.5 \%\end{array}$ \\
\hline & August 17, 2008 & $\begin{array}{l}\text { Following an intermeeting conference call, the } \\
\text { Fed's Federal Open Market Committee } \\
\text { (FOMC) releases a statement about the current } \\
\text { financial market turmoil, and notes that the } \\
\text { "downside risks to growth have increased } \\
\text { appreciably". }\end{array}$ \\
\hline US unemployment rate rises to $6.1 \%$ & September 5, 2008 & $\begin{array}{l}\text { US government decides to take control of } \\
\text { Fannie Mae and Freddie Mac }\end{array}$ \\
\hline $\begin{array}{l}\text { Fannie Mae and Freddie Mac announce outstanding } \\
\text { liabilities of about } \$ 5,400 \text { billion. }\end{array}$ & September 7, 2008 & $\begin{array}{l}\text { The Federal Reserve has auctioned another } \\
\$ 25 \text { billion in loans to squeezed banks to help } \\
\text { them overcome credit problems. }\end{array}$ \\
\hline $\begin{array}{l}\text { Lehman Brothers shares fall by more than } 40 \\
\text { percent because of worries about its ability to raise } \\
\text { capital. }\end{array}$ & September 9,2008 & \\
\hline $\begin{array}{l}\text { Lehman Brothers posts a loss of } \$ 3.9 \text { billion for the } \\
\text { three months to August. }\end{array}$ & September 10,2008 & $\begin{array}{l}\text { Treasury Secretary Paulson claims that there } \\
\text { will be no public funds involved in a possible } \\
\text { rescue of Lehman Brothers. }\end{array}$ \\
\hline $\begin{array}{l}\text { Lehman Brothers seek rescue. Bank of America is a } \\
\text { candidate for taking it over. }\end{array}$ & September 12,2008 & \\
\hline $\begin{array}{l}\text { Bank of America and Barclays head list of potential } \\
\text { purchasers of Lehman Brothers. }\end{array}$ & September 13,2008 & \\
\hline $\begin{array}{l}\text { Lehman Brothers battles to avoid bankruptcy. } \\
\text { Barclays pulls out of the bidding. } \\
\text { Bank of America bids for Merrill Lynch. } \\
\text { AIG seeks help for } \$ 10-20 \text { billion. }\end{array}$ & September 14,2008 & $\begin{array}{l}\text { US authorities trying to put a rescue package } \\
\text { together for insurance giant AIG agree a } \$ 20 \\
\text { billion lifeline. }\end{array}$ \\
\hline $\begin{array}{l}\text { US bank Merrill Lynch, also stung by the credit } \\
\text { crunch, agrees to be taken over by Bank of America } \\
\text { for } \$ 50 \text { billion. } \\
\text { Lehman files for bankruptcy. } \\
\text { Shares in HBOS, Britain's biggest mortgage lender, } \\
\text { crash } 34 \% \text { in early trading. } \\
\text { On Wall Street the Dow Jones industrial average } \\
\text { plunges } 504 \text { points to close at } 10,917.51\end{array}$ & September 15,2008 & $\begin{array}{l}\text { US government takes control of AIG, after an } \\
\text { injection of } \$ 85 \text { billion. }\end{array}$ \\
\hline Goldman Sachs reports $70 \%$ drop in profits. & September 16,2008 & $\begin{array}{l}\text { The Federal Reserve Board authorizes the } \\
\text { Federal Reserve Bank of New York to lend up } \\
\text { to } \$ 85 \text { billion to the American International } \\
\text { Group (AIG) under Section 13(3) of the } \\
\text { Federal Reserve Act. }\end{array}$ \\
\hline $\begin{array}{l}\text { Lloyds TSB announces it is to take over Britain's } \\
\text { biggest mortgage lender HBOS in a } £ 12 \text { billion deal } \\
\text { creating a banking giant holding close to one-third } \\
\text { of the UK’s savings and mortgage market. The deal } \\
\text { follows a run on HBOS shares. } \\
\text { Panic grips credit markets, causing huge flight to } \\
\text { safety. US treasury yield at a minimum since } 1941 \text {. }\end{array}$ & September 17, 2008 & $\begin{array}{l}\text { Central banks around the world pump } \$ 180 \\
\text { billion into the system in a concerted effort to } \\
\text { end the crisis. } \\
\text { The SEC announces a temporary emergency } \\
\text { ban on short selling in the stocks of all } \\
\text { companies in the financial sector. }\end{array}$ \\
\hline $\begin{array}{l}\text { Russian stock markets remain closed for a second } \\
\text { day. } \\
\text { Nikkei drops } 260 \text { points to } 11,489 \text {. } \\
\text { Wall Street closes } 410 \text { points higher as the US } \\
\text { Federal Reserve starts briefing on an ambitious plan } \\
\text { to create a federal "bad bank". }\end{array}$ & September 18,2008 & $\begin{array}{l}\text { US plan is announced. US government } \\
\text { pledges } \$ 50 \text { billion to guarantee money market } \\
\text { mutual funds. } \\
\text { British government rushes through increase in } \\
\text { guarantees for bank deposits to } £ 50,000 \text {. }\end{array}$ \\
\hline
\end{tabular}




\begin{tabular}{|c|c|c|}
\hline Market events & Date & Policy actions \\
\hline $\begin{array}{l}\text { Asia starts the recovery, with the Nikkei closing up } \\
431 \text { points at } 11,920 \text {. } \\
\text { FTSE roars back, up } 315 \text { points in early trading to } \\
5,195 \text { thanks to the short-selling ban and the US } \\
\text { "bad bank" plan. } \\
\text { Russian stock markets bounce back after the } \\
\text { government pledges } 500 \text { billion roubles to fight the } \\
\text { crisis. }\end{array}$ & September 19, 2008 & $\begin{array}{l}\text { The US treasury secretary, Henry Paulson, } \\
\text { spends the weekend trying to thrash out his } \\
\$ 700 \text { billion "bad bank" plan. } \\
\text { The Federal Reserve Board announces the } \\
\text { creation of the Asset Backed Commercial } \\
\text { Paper Money Market Mutual Fund Liquidity } \\
\text { Facility (AMLF) to extend non recourse loans } \\
\text { at the primary credit rate to U.S. depository } \\
\text { institutions and bank holding companies to } \\
\text { finance their purchase of high quality asset } \\
\text { backed commercial paper from money market } \\
\text { mutual funds. } \\
\text { The US Treasury Department announces a } \\
\text { temporary guaranty program that will make } \\
\text { available up to } \$ 50 \text { billion from the Exchange } \\
\text { Stabilization Fund to guarantee investments in } \\
\text { participating money market mutual funds. }\end{array}$ \\
\hline $\begin{array}{l}\text { Morgan Stanley and Goldman Sachs give up their } \\
\text { status as investment banks and become traditional } \\
\text { commercial banks }\end{array}$ & September 22, 2008 & $\begin{array}{l}\text { Political opposition to the } \$ 700 \text { billion bail-out } \\
\text { plan grows in Washington. }\end{array}$ \\
\hline $\begin{array}{l}\text { New figures show UK mortgage approvals hit a } \\
\text { record low in August. }\end{array}$ & September 23, 2008 & $\begin{array}{l}\text { Henry Paulson bows to intense pressure to } \\
\text { include limits on what Wall Street bankers can } \\
\text { be paid in his } \$ 700 \text { billion bail-out plan. }\end{array}$ \\
\hline $\begin{array}{l}\text { Warren Buffett invests } \$ 5 \text { billion ( } £ 2.7 \text { billion) in } \\
\text { Goldman Sachs and warns that failure to agree a } \\
\$ 700 \text { billion bailout could result in an "economic } \\
\text { Pearl Harbour". }\end{array}$ & September 24, 2008 & $\begin{array}{l}\text { Overnight the } \$ 700 \text { billion bail-out plan in the } \\
\text { US appears to have stalled. }\end{array}$ \\
\hline \multirow{2}{*}{$\begin{array}{l}\text { Ireland becomes the first state in the eurozone to fall } \\
\text { into recession. } \\
\text { Jobless figures are up and orders are down in the } \\
\text { US, signalling the dire state of the economy. } \\
\text { In the largest bank failure yet in the United States, } \\
\text { Washington Mutual, the giant mortgage lender, } \\
\text { which had assets valued at } \$ 307 \text { billion, is closed } \\
\text { down by regulators and sold to JPMorgan Chase. }\end{array}$} & September 25, 2008 & $\begin{array}{l}\text { Traders are worried about the possible failure } \\
\text { of the } \$ 700 \text { billion bail-out plan. The plan } \\
\text { appears to be coming apart despite Paulson } \\
\text { actually begging before congress on one knee } \\
\text { for the deal to be passed. }\end{array}$ \\
\hline & September 26, 2008 & $\begin{array}{l}\text { The government of Belgium, the Netherlands } \\
\text { and Luxembourg rescue insurance giant Fortis. } \\
\text { In the US, lawmakers announce they have } \\
\text { reached a bipartisan agreement on a rescue } \\
\text { plan for the American financial system. } \\
\text { The package, to be approved by Congress, } \\
\text { allows the Treasury to spend up to } \$ 700 \text { billion } \\
\text { buying bad debts from ailing banks. It will be } \\
\text { the biggest intervention in the markets since } \\
\text { the Great Depression of the } 1930 \text { s. }\end{array}$ \\
\hline $\begin{array}{l}\text { Spain’s Santander buys Bradford \& Bingley’s } 200 \\
\text { branches and } £ 22 \text { billion savings book and the UK } \\
\text { taxpayer gets lumbered with the mortgages. }\end{array}$ & September 28, 2008 & $\begin{array}{l}\text { Congress rejects } \$ 700 \text { billion plan: George } \\
\text { Bush takes the podium to urge the House of } \\
\text { Representatives to pass the } \$ 700 \text { billion bail- } \\
\text { out plan. His short speech falls on deaf ears } \\
\text { and a few hours later the House of } \\
\text { Representatives votes down the bail-out. } \\
\text { Nationalisation of Bradford and Bingley in the } \\
\text { UK. } \\
\text { Iceland takes control of Glitnir (country's third } \\
\text { largest bank). } \\
\text { Germany underwrites } 35 \text { billion bailout of } \\
\text { Hypo Real Estate. } \\
\text { Citigroup saves Wachovia, with a } \$ 12 \text { billion } \\
\text { stake by the government. }\end{array}$ \\
\hline
\end{tabular}




\begin{tabular}{|c|c|c|}
\hline Market events & Date & Policy actions \\
\hline $\begin{array}{l}\text { Markets plunge around the world. } \\
\text { Wall Street is in turmoil. The Dow Jones plunges } \\
777 \text { points, its biggest ever fall in points terms. } \\
\text { As news of the Bradford \& Bingley rescue sinks in, } \\
\text { the London Stock Market plummets in what will } \\
\text { end up being one of the FTSE } 100 \text { index's worst } \\
\text { ever trading days. } \\
\text { As a result of the intense fear among bankers about } \\
\text { which institution will be next to fold, the interbank } \\
\text { lending rate goes through the roof despite desperate } \\
\text { attempts by central banks to pump cash into the } \\
\text { system } \\
\text { The FDIC announces that Citigroup will purchase } \\
\text { the banking operations of Wachovia Corporation }\end{array}$ & September 29, 2008 & $\begin{array}{l}\text { Ireland extends bank guarantee, covering an } \\
\text { estimated } 400 \text { billion bank liabilities including } \\
\text { deposits, covered bond, senior debt and dated } \\
\text { subordinated debt for two years, de facto } \\
\text { putting other countries at a disadvantage. } \\
\text { Rescue of Dexia ( } € 6.4 \text { billion) by France } \\
\text { Belgium and Luxembourg. } \\
\text { Dominique Strauss-Kahn, the managing } \\
\text { director of the IMF, believes a bail-out is the } \\
\text { only option for the US economy. } \\
\text { The Fed expands Term Auction Facility (TAF) } \\
\text { auctions to a total of } \$ 150 \text { billion. }\end{array}$ \\
\hline $\begin{array}{l}\text { Problems in money market intensify. } \\
\text { Asian stock markets react to the shock news that the } \\
\$ 700 \text { billion Wall Street bailout has failed. } \\
\text { In the US, July recorded the biggest ever fall in } \\
\text { house prices. } \\
\text { The banks themselves are finding it increasingly } \\
\text { difficult to raise financing, with the cost of } \\
\text { interbank borrowing experiencing its biggest ever } \\
\text { one-day rise. }\end{array}$ & September 30, 2008 & $\begin{array}{l}\text { European leaders do not agree on a common } \\
\text { fund ( } € 300 \text { billion estimate). }\end{array}$ \\
\hline $\begin{array}{l}\text { New data shows British manufacturing shrinking at } \\
\text { the fastest rate since records began nearly } 17 \text { years } \\
\text { ago. } \\
\text { Share traders are praying that a rescue package can } \\
\text { still be put together in the US. } \\
\text { Warren Buffett decides to snap up } \$ 3 \text { billion worth } \\
\text { of General Electric as part of a } \$ 15 \text { billion } \\
\text { fundraising by the industrial conglomerate. }\end{array}$ & October 1,2008 & $\begin{array}{l}\text { The US Senate votes in favour of the Wall } \\
\text { Street bail-out. } \\
\text { EU focus shifts from common fund, to tighten } \\
\text { regulation of rating agencies, improve } \\
\text { coordination among supervisors, review } \\
\text { accounting rule and, common standards for } \\
\text { deposit insurance. } \\
\text { Greece extends guarantees on bank deposits. } \\
\text { European leaders are considering their own } \\
\text { bail-out, which could cost up to } € 300 \text { billion. } \\
\text { The French president, Nicolas Sarkozy, leads } \\
\text { the push. }\end{array}$ \\
\hline & October 2, 2008 & $\begin{array}{l}\text { US Congress finally passes the } \$ 700 \text { billion } \\
\text { financial rescue package. } \\
\text { Sarkozy urges EU government to "play by the } \\
\text { rules" and form a common front. } \\
\text { UK raises deposit protection cap to } £ 50,000 \text {. } \\
\text { Dutch government announces that it will take } \\
\text { up full control of Fortis; this is an effective } \\
\text { nationalization of ABN Amro. } \\
\text { Iceland takes step to avoid bank meltdown } \\
\text { (repatriation of pension funds). }\end{array}$ \\
\hline $\begin{array}{l}\text { Reaction in financial markets is subdued. } \\
\text { Wells Fargo announces a competing proposal to } \\
\text { purchase Wachovia Corporation that does not } \\
\text { require assistance from the FDIC. } \\
\text { The State of California is in need of } \$ 7 \text { billion. } \\
\text { US jobs data are worse than expected. }\end{array}$ & October 3, 2008 & $\begin{array}{l}\text { Emergency summit in Paris to discuss the } \\
\text { crisis with French, German, British and Italian } \\
\text { leaders. } \\
\text { Congress passes and President Bush signs into } \\
\text { law the Emergency Economic Stabilization } \\
\text { Act of } 2008 \text {, which establishes the } \$ 700 \text { billion } \\
\text { Troubled Asset Relief Program (TARP). }\end{array}$ \\
\hline & October 4, 2008 & $\begin{array}{l}\text { Germany guarantees all private German bank } \\
\text { accounts (up from } € 20,000 \text { ). } \\
\text { US Treasury working on details of the plan. }\end{array}$ \\
\hline
\end{tabular}




\begin{tabular}{|c|c|c|}
\hline Market events & Date & Policy actions \\
\hline Italian Unicredit raises capital by 6 billion. & October 5, 2008 & $\begin{array}{l}\text { EU leaders vow to use any measure necessary. } \\
\text { Germany announces a } € 50 \text { billion plan to save } \\
\text { Hypo Real Estate. } \\
\text { Iceland announces part of a plan to shore up its } \\
\text { troubled banking sector. The country's largest } \\
\text { banks agree to sell some of their foreign assets. } \\
\text { Germany is criticized for its deposit guarantee } \\
\text { policy. Danish government extend its own. } \\
\text { Fed ready to move into unsecured loans. }\end{array}$ \\
\hline $\begin{array}{l}\text { Currency and financial crises around the world. } \\
\text { Very strong in Iceland, but also Korea, Pakistan etc. } \\
\text { The FTSE sees its largest one-day fall in points. }\end{array}$ & October 6, 2008 & $\begin{array}{l}\text { UK unveils rescue plan for } £ 35-50 \text { billion, } \\
\text { with the government injecting capital into the } \\
\text { country's largest lenders. Recapitalisation as a } \\
\text { step towards restoring confidence: but by how } \\
\text { much? } \\
\text { The Icelandic government takes control of } \\
\text { Landsbanki, the country's second largest bank, } \\
\text { which owns Icesave in the UK. } \\
\text { FED announces intervention in commercial } \\
\text { paper markets - with little effect on markets. } \\
\text { Spain follows US lead, offering to buy assets } \\
\text { from banks. } \\
\text { EU leaders agree on set of "principles" but not } \\
\text { on detailed guidelines. Coordination was } \\
\text { achieved only on "minimum deposit } \\
\text { insurance", not on cap. }\end{array}$ \\
\hline $\begin{array}{l}\text { Bank shares fall sharply. } \\
\text { The Icelandic internet bank Icesave blocks savers } \\
\text { from withdrawing money. }\end{array}$ & October 7, 2008 & $\begin{array}{l}\text { Historic coordinated rate cut by central banks } \\
\text { around the world (FED, ECB,BoE, } \\
\text { BoC,SwissNB, Swedish Riskbank). People's } \\
\text { Bank of China joins without formal } \\
\text { coordination. ECB changes its procedure, } \\
\text { making unlimited funding available at the } \\
\text { current interest rate (banks no longer have to } \\
\text { bid for funds), and reduce the penalty to its } \\
\text { lending rate to } 50 \text { basis point (down from } 100 \\
\text { basis points). } \\
\text { Iceland: State ownership of the three largest } \\
\text { banks. } \\
\text { Ireland extends guarantees to foreign owned } \\
\text { banks. } \\
\text { The UK government announces details of } \\
\text { a rescue package for the banking system } \\
\text { worth at least } £ 50 \text { billion. The government is } \\
\text { also offering up to } £ 200 \text { billion in short-term } \\
\text { lending support. } \\
\text { The FDIC announces an increase in deposit } \\
\text { insurance coverage to } \$ 250,000 \text { per depositor. }\end{array}$ \\
\hline $\begin{array}{l}\text { Large fall in commodities prices. } \\
\text { Russia, Ukraine and Romania close down stock } \\
\text { exchanges. } \\
\text { Iceland suspends all trading on stock exchanges. }\end{array}$ & October 8,2008 & $\begin{array}{l}\text { Resistance to adopt UK approach around the } \\
\text { world. Disagreement among G7. } \\
\text { ECB sharply focuses on growth risk, signalling } \\
\text { rates cut. } \\
\text { The International Monetary Fund announces } \\
\text { emergency plans to bail out governments } \\
\text { affected by the financial crisis, after warning } \\
\text { that no country would be immune from the } \\
\text { ripple effects of the credit crunch. }\end{array}$ \\
\hline $\begin{array}{l}\text { House prices fall at record rate during the year to } \\
\text { the end of September, losing } 13.3 \% \text { of their value, } \\
\text { Halifax reports. } \\
\text { The Dow falls to a five-year low, ending the day } \\
7.3 \% \text { lower at } 8579 \text { points. }\end{array}$ & October 9, 2008 & $\begin{array}{l}\text { President Bush urges confidence in the US } \\
\text { government's ability to manage the worsening } \\
\text { financial crisis, but his words have little effect. }\end{array}$ \\
\hline
\end{tabular}




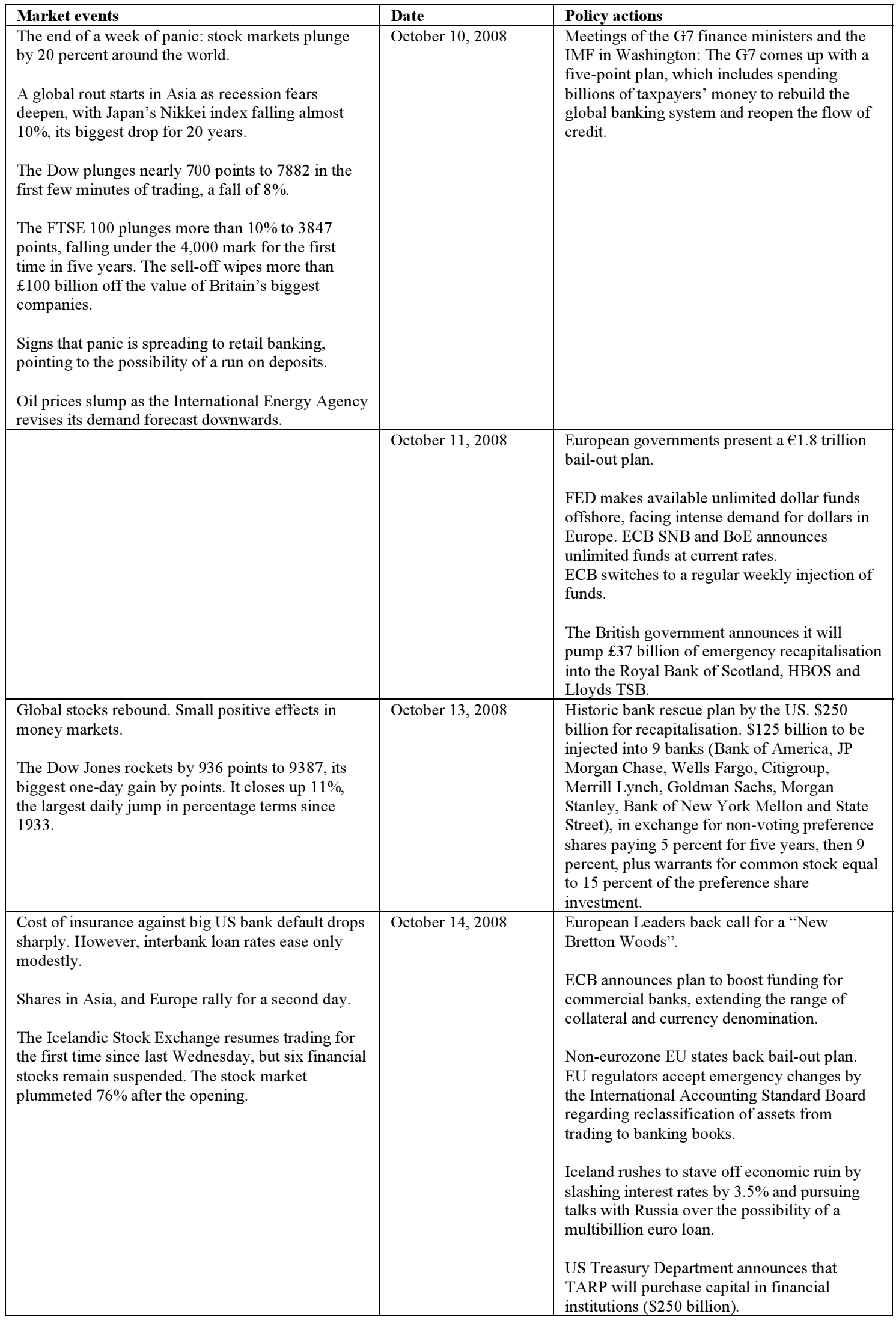




\begin{tabular}{|c|c|c|}
\hline Market events & Date & Policy actions \\
\hline $\begin{array}{l}\text { Recession fears drive down stocks around the } \\
\text { world. The foreign exchange market "almost ceases } \\
\text { to function" amid row with UK over assets. } \\
\text { The Hungarian florint falls by } 7 \text { percent, as the } \\
\text { stock market plunges by } 12 \text { percent. } \\
\text { Run on Russian banks intensifies. } \\
\text { Dow Jones industrial average drops by } 7.8 \% \text { - its } \\
\text { biggest percentage fall since } 26 \text { October } 1987 \text {. } \\
\text { Unemployment figures in the UK showed the } \\
\text { biggest rise since the country's last recession } 17 \\
\text { years ago, up to } 5.7 \% \text { - } 1.79 \text { million people. } \\
\text { US banks JPMorgan and Wells Fargo report big } \\
\text { falls in profits } \\
\text { Figures for US retail sales in September show a fall } \\
\text { of } 1.2 \% \text {, the biggest monthly decline in more than } \\
\text { three years, with the drop in car sales hitting } 3.8 \% \text {. }\end{array}$ & October 15,2008 & $\begin{array}{l}\text { European Central Bank sets } € 5 \text { billion facilities } \\
\text { to help Hungary. This is the first time support } \\
\text { is extended outside the eurozone: the ECB } \\
\text { signals its willingness to do more. } \\
\text { Swiss National Bank provides } \$ 60 \text { billion to } \\
\text { take on most of the US toxic debt held by UBS } \\
\text { (third capital raising by UBS in the year), after } \\
\text { UBS suffered } \$ 50 \text { billion capital outflows in } \\
\text { the third quarter of the year. } \\
\text { An EU summit ends in Brussels with a clear } \\
\text { message that there is no time to lose in coming } \\
\text { up with concerted action to tackle the financial } \\
\text { emergency. } \\
\text { OPEC calls an emergency meeting in Vienna } \\
\text { as the oil price falls to less than half the } \$ 147 \text { it } \\
\text { traded at in July. }\end{array}$ \\
\hline $\begin{array}{l}\text { Japan's Nikkei Index suffers its worst fall since } \\
1987 . \\
\text { In the US, Citigroup suffered its fourth consecutive } \\
\text { quarterly loss after taking hits of more than } \$ 13 \\
\text { billion to cover liabilities arising from the credit } \\
\text { crunch. }\end{array}$ & October 16,2008 & \\
\hline $\begin{array}{l}\text { Sharp fall in US consumer confidence (sharpest } \\
\text { monthly fall since 1978). } \\
\text { French savings bank Caisse d'Epargne } \\
\text { announces a loss of } 600 \text { million euros in a "trading } \\
\text { incident", which the bank says was triggered by } \\
\text { what it called "extreme market volatility" amid the } \\
\text { market crash during the week of } 6 \text { October. }\end{array}$ & October 17,2008 & $\begin{array}{l}\text { Korea launches a } \$ 130 \text { billion loan and } \\
\text { liquidity rescue; tax cuts and spending } \\
\text { increases announced. } \\
\text { Dutch savings bank ING accepts } € 10 \text { billion } \\
\text { capital injection (granting no voting right to } \\
\text { government but } 2 \text { out of } 12 \text { supervisory board } \\
\text { seats), to bring Tier } 1 \text { capital up to } 8 \text { percent. } \\
\text { Debt to equity falls from } 15 \text { to } 10 \text { percent. }\end{array}$ \\
\hline & October 19, 2008 & $\begin{array}{l}\text { Federal Reserve backs plan for second US } \\
\text { stimulus package. } \\
\text { Iceland to announce a } \$ 6 \text { billion IMF rescue } \\
\text { package. } \\
\text { Sweden's government sets out its own bank } \\
\text { rescue plan, with credit guarantees to banks } \\
\text { and mortgage lenders up to a level of } 1.5 \\
\text { trillion krona ( } \$ 205 \text { billion). The government } \\
\text { says it will also set aside } 15 \text { billion krona as a } \\
\text { bank stabilisation fund. } \\
\text { India's central bank unexpectedly cuts its } \\
\text { short-term lending rates in response to } \\
\text { continued pressure from the global financial } \\
\text { crisis. The Reserve Bank of India cuts the repo } \\
\text { rate by a full percentage point to } 8 \% \text {. }\end{array}$ \\
\hline $\begin{array}{l}\text { Small signs of relief in the money markets. } \\
\text { UK: Mortgage lending slumped by } 10 \% \text { in } \\
\text { September to its lowest level for more than three- } \\
\text { and-a-half years. } \\
\text { China revises growth down to } 9 \text { percent. }\end{array}$ & October 20,2008 & $\begin{array}{l}\text { Fed ready to finance up to } \$ 540 \text { billion to } \\
\text { purchase short term debt from money market } \\
\text { mutual funds through } 5 \text { special purpose } \\
\text { vehicles managed by JPMorgan, complement- } \\
\text { ing previously set vehicles to purchase } \\
\text { potentially unlimited three month debt from } \\
\text { banks and non-financial companies. The size } \\
\text { of Fed balance sheet has nearly doubled. Each } \\
\text { of the five vehicles purchase paper from } 10 \\
\text { financial institutions. The size of the } \\
\text { programme is } \$ 60 \text { billion. } \\
\text { IMF forecasts sharp squeeze in business credit. } \\
\text { For the EU, growth forecasts are down from } \\
1.7 \text { to } 0.6 \text { percent. }\end{array}$ \\
\hline
\end{tabular}




\begin{tabular}{|c|c|c|}
\hline Market events & Date & Policy actions \\
\hline $\begin{array}{l}\text { Anticipation of Argentina's pension funds } \\
\text { nationalization plan drives down Argentina's } \\
\text { markets. }\end{array}$ & October 21, 2008 & $\begin{array}{l}\text { Hungary lifts rates } 300 \text { basis point to support } \\
\text { currency. } \\
\text { Pakistan seeks emergency bail-out funds from } \\
\text { the IMF. }\end{array}$ \\
\hline $\begin{array}{l}\text { The stricken US bank Wachovia reports the biggest } \\
\text { quarterly loss of any bank since the onset of the } \\
\text { credit crunch, with a deficit of } \$ 24 \text { billion. }\end{array}$ & October 22, 2008 & $\begin{array}{l}\text { Former Fed chief Alan Greenspan admits he } \\
\text { had been "partially wrong" in his hands-off } \\
\text { approach towards the banking industry. The } \\
\text { credit crunch had left him in a state of } \\
\text { "shocked disbelief", he admitted before a } \\
\text { congressional committee. }\end{array}$ \\
\hline $\begin{array}{l}\text { Daimler, maker of Mercedes cars, issues its second } \\
\text { profits warning this year after third-quarter earnings } \\
\text { plunge by two-thirds. }\end{array}$ & October 23, 2008 & $\begin{array}{l}\text { In Denmark, the central bank raises its key } \\
\text { interest rate by } 0.5 \text { percentage points to } 5.5 \% \text {. }\end{array}$ \\
\hline $\begin{array}{l}\text { Large fall in share prices worldwide. } \\
\text { Yen and dollar strengthen. Yen appreciation, } \\
\text { attributed to a reversal of the "yen carry trade", } \\
\text { creates global concern. } \\
\text { The UK is on the brink of a recession according to } \\
\text { figures released by the Office for National } \\
\text { Statistics. The economy shrank for the first time in } \\
16 \text { years between July and September, as economic } \\
\text { growth fell by } 0.5 \% \text {. }\end{array}$ & October 24, 2008 & $\begin{array}{l}\text { IMF unveils a plan for } \$ 16.5 \text { billion to support } \\
\text { the Ukraine }\end{array}$ \\
\hline $\begin{array}{l}\text { The spectre of a cascade of failing economies from } \\
\text { the Baltic to Turkey is raised as a } \$ 16.5 \text { billion IMF } \\
\text { bailout for Ukraine is mired in political infighting } \\
\text { and Hungary seeks its own } \$ 10 \text { billion rescue } \\
\text { package. }\end{array}$ & October $25-26,2008$ & \\
\hline $\begin{array}{l}\text { Swedish banks, relatively immune to the crisis, } \\
\text { move to recapitalise }\end{array}$ & October 27, 2008 & $\begin{array}{l}\text { Iceland raises interest rates to } 18 \text { percent, in } \\
\text { negotiations for a loan by the IMF ( } \$ 2 \text { billion) } \\
\text { and other countries. }\end{array}$ \\
\hline $\begin{array}{l}\text { Autumn's market mayhem has left the world's } \\
\text { financial institutions nursing losses of } \$ 2.8 \text { trillion, } \\
\text { according to the Bank of England. }\end{array}$ & October 28,2008 & $\begin{array}{l}\text { The US Treasury Department purchases a total } \\
\text { of } \$ 125 \text { billion in preferred stock in nine US } \\
\text { banks under the Capital Purchase Program. } \\
\text { The International Monetary Fund, the Euro- } \\
\text { pean Union and the World Bank announce a } \\
\text { massive rescue package for Hungary. }\end{array}$ \\
\hline $\begin{array}{l}\text { The prospect of fresh cuts in interest rates on both } \\
\text { sides of the Atlantic helped propel Wall Street } \\
\text { stocks to a dramatic rebound, with the Dow scoring } \\
\text { its second-biggest points gain ever, just short of } \\
900 \text {. }\end{array}$ & October 29, 2008 & $\begin{array}{l}\text { The Federal Reserve cuts its key interest rate } \\
\text { from } 1.5 \% \text { to } 1 \% \text {. }\end{array}$ \\
\hline $\begin{array}{l}\text { Deutsche Bank reports steep falls in pre-tax and net } \\
\text { profits and a further series of write-downs in the } \\
\text { third quarter. } \\
\text { The Commerce Department issues figures showing } \\
\text { the US economy shrank at an annualised rate of } \\
0.3 \% \text { between July and September. }\end{array}$ & October 30, 2008 & $\begin{array}{l}\text { The Bank of Japan cuts interest rates for the } \\
\text { first time in seven years in response to the } \\
\text { global financial crisis. The bank cuts the key } \\
\text { interest rate from } 0.5 \% \text { to } 0.3 \% \text {, a move some } \\
\text { criticise as half-hearted. }\end{array}$ \\
\hline \multirow[t]{3}{*}{$\begin{array}{l}\text { Barclays said it will raise up to } £ 7.3 \text { billion, mainly } \\
\text { from Middle East investors who could end up } \\
\text { owning nearly a third of the UK's second largest } \\
\text { bank. }\end{array}$} & October 31, 2008 & $\begin{array}{l}\text { The International Monetary Fund (IMF) } \\
\text { approves a } \$ 16.4 \text { billion loan to the Ukraine to } \\
\text { bolster its economy, shaken by global financial } \\
\text { turmoil. } \\
\text { The Bank of England slashes interest rates } \\
\text { from } 4.5 \% \text { to } 3 \% \text { - the lowest level since } 1955 \text {. } \\
\text { The European Central Bank lowers eurozone } \\
\text { rates to } 3.25 \% \text { from } 3.75 \% \text {. }\end{array}$ \\
\hline & November 6, 2008 & $\begin{array}{l}\text { China sets out a two-year } \$ 586 \text { billion } \\
\text { economic stimulus package to help boost the } \\
\text { economy by investing in infrastructure and } \\
\text { social projects, and by cutting corporate taxes. }\end{array}$ \\
\hline & November 9, 2008 & $\begin{array}{l}\text { US Treasury Secretary Henry Paulson says the } \\
\text { government has abandoned plans to use some } \\
\text { of the } \$ 700 \text { billion bail-out money to buy up } \\
\text { banks' bad debts and has decided instead to } \\
\text { concentrate on improving the flow of credit for } \\
\text { the US consumer. }\end{array}$ \\
\hline
\end{tabular}




\begin{tabular}{|c|c|c|}
\hline Market events & Date & Policy actions \\
\hline & November 12,2008 & $\begin{array}{l}\text { Leaders of the G20 and emerging economies } \\
\text { gather in Washington to discuss ways to } \\
\text { contain the financial crisis and agree on } \\
\text { longer-term reforms. }\end{array}$ \\
\hline \multirow[t]{6}{*}{$\begin{array}{l}\text { The eurozone officially slips into recession after EU } \\
\text { figures show that the economy shrank by } 0.2 \% \text { in } \\
\text { the third quarter. }\end{array}$} & November 14, 2008 & $\begin{array}{l}\text { The International Monetary Fund (IMF) } \\
\text { approves a } \$ 2.1 \text { billion loan for Iceland, after } \\
\text { the country's banking system collapsed in } \\
\text { October. It is the first IMF loan for a Western } \\
\text { European nation since } 1976 \text {. }\end{array}$ \\
\hline & November 20,2008 & $\begin{array}{l}\text { The US government announces a } \$ 20 \text { billion } \\
\text { rescue plan for troubled banking giant } \\
\text { Citigroup after its shares plunge by more than } \\
60 \text { percent in a week. }\end{array}$ \\
\hline & November 23, 2008 & $\begin{array}{l}\text { The UK government announces a temporary } \\
\text { cut in the rate of VAT - to } 15 \% \text { from } 17.5 \% \text {. }\end{array}$ \\
\hline & November 24, 2008 & $\begin{array}{l}\text { The International Monetary Fund (IMF) } \\
\text { approves a } \$ 7.6 \text { billion loan for Pakistan to } \\
\text { shore up the country's economy. Pakistan } \\
\text { needs the money in order to avoid defaulting } \\
\text { on international debt. } \\
\text { The US Federal Reserve announces it will } \\
\text { inject another } \$ 800 \text { billion into the economy in } \\
\text { a further effort to stabilise the financial system } \\
\text { and encourage lending. About } \$ 600 \text { billion will } \\
\text { be used to buy up mortgage-backed securities } \\
\text { while } \$ 200 \text { billion is being targeted at } \\
\text { unfreezing the consumer credit market. }\end{array}$ \\
\hline & November, 252008 & $\begin{array}{l}\text { The European Commission unveils an } \\
\text { economic recovery plan worth } € 200 \text { billion } \\
\text { euros which it hopes will save millions of } \\
\text { European jobs. The scheme aims to stimulate } \\
\text { spending and boost consumer confidence. }\end{array}$ \\
\hline & November 26, 2008 & $\begin{array}{l}\text { The UK government becomes the majority } \\
\text { owner of Royal Bank of Scotland with a stake } \\
\text { of almost } 60 \text { per cent after the bank revealed } \\
\text { that just } 0.24 \text { per cent of its capital raising had } \\
\text { been taken up by investors. }\end{array}$ \\
\hline $\begin{array}{l}\text { The Labor Department reports that the US lost } \\
533,000 \text { jobs in November, the biggest monthly loss } \\
\text { since } 1974 \text {. This raises the unemployment rate from } \\
6.5 \% \text { to } 6.7 \% \text {. } \\
\text { The US recession is confirmed by the NBER; the } \\
\text { US economy started to contract in January } 2008 \text {. }\end{array}$ & December 1, 2008 & \\
\hline \multirow[t]{2}{*}{$\begin{array}{l}\text { US carmakers appeal to Congress for } \$ 34 \text { billion in } \\
\text { emergency loans }\end{array}$} & December 3, 2008 & $\begin{array}{l}\text { The European Central Bank announces a three- } \\
\text { quarters of a percentage point cut in its main } \\
\text { policy interest rate to } 2.5 \text { per cent - its largest } \\
\text { cut ever - just hours after Sweden's central } \\
\text { bank surprised markets by reducing the } \\
\text { country's official borrowing costs by a record } \\
175 \text { basis points. The Bank of England slashes } \\
\text { its rates by another } 1 \text { percentage point to } 2 \text { per } \\
\text { cent, equal to the lowest rate since the central } \\
\text { bank was founded in } 1694 \text {. } \\
\text { French President Nicolas Sarkozy unveils a } \\
€ 26 \text { billion stimulus plan to help France fend } \\
\text { off financial crisis, with money to be spent on } \\
\text { public sector investments and loans for the } \\
\text { country's troubled carmakers. }\end{array}$ \\
\hline & December 4, 2008 & $\begin{array}{l}\text { Bank of Canada lowers its key interest rate by } \\
0.75 \% \text { to } 1.5 \% \text {, the lowest it has been since } \\
1958 \text {; at the same time the Bank officially } \\
\text { announces that Canada's economy is in } \\
\text { recession. }\end{array}$ \\
\hline $\begin{array}{l}\text { Canada lost } 70,600 \text { jobs in the month of November, } \\
\text { the most since } 1982 \text {. }\end{array}$ & December 9, 2008 & $\begin{array}{l}\text { The European Central Bank as well as central } \\
\text { banks in England, Sweden and Denmark, slash } \\
\text { interest rates again in an effort to prevent a } \\
\text { deep recession. } \\
\text { Bernard Madoff, former Nasdaq chairman, is } \\
\text { arrested after confessing to running a } 50 \text { billion } \\
\text { dollar Ponzi scheme. }\end{array}$ \\
\hline
\end{tabular}




\begin{tabular}{|c|c|c|}
\hline Market events & Date & Policy actions \\
\hline $\begin{array}{l}\text { Bank of America announces up to } 35,000 \text { job losses } \\
\text { over three years following its takeover of Merrill } \\
\text { Lynch in the New Year. }\end{array}$ & December 11, 2008 & \\
\hline \multirow{3}{*}{$\begin{array}{l}\text { The dollar slides to its lowest in } 13 \text { years against the } \\
\text { yen as the Senate fails to agree on a bailout for the } \\
\text { three US automakers. The number of new workers } \\
\text { filing claims for unemployment benefits jumps to a } \\
\text { 26-year high. }\end{array}$} & December 12, 2008 & \\
\hline & December 16, 2008 & $\begin{array}{l}\text { President Bush says the US government will } \\
\text { use up to } \$ 17.4 \text { billion of the } \$ 700 \text { billion } \\
\text { meant for the banking sector to help the Big } \\
\text { Three US carmakers, General Motors, Ford } \\
\text { and Chrysler. } \\
\text { Japan's central bank and cuts rates from } 0.3 \% \\
\text { to } 0.1 \% \text {. The government says the world's } \\
\text { second largest economy will not grow in } 2009 \text {. } \\
\text { The US Federal Reserve slashes its key interest } \\
\text { rate from } 1 \% \text { to a range of zero to } 0.25 \% \text { - the } \\
\text { lowest since records began. }\end{array}$ \\
\hline & December 19, 2008 & $\begin{array}{l}\text { The US Treasury unveils a } \$ 6 \text { billion bail-out } \\
\text { for GMAC, the car-loan arm of General } \\
\text { Motors. }\end{array}$ \\
\hline \multirow[t]{2}{*}{$\begin{array}{l}\text { The FTSE } 100 \text { closes the year down by } 31.3 \% \text {, } \\
\text { which is the biggest annual fall in the } 24 \text { years since } \\
\text { the index was started. } \\
\text { The Dax in Frankfurt loses } 40.4 \% \text { for the year, } \\
\text { while the Cac } 40 \text { in Paris drops } 42.7 \% \text {. }\end{array}$} & December 31, 2008 & $\begin{array}{l}\text { The Federal Reserve Bank of New York } \\
\text { begins purchasing fixed-rate mortgage-backed } \\
\text { securities guaranteed by Fannie Mae, Freddie } \\
\text { Mac and Ginnie Mae under a programme first } \\
\text { announced on November 25, 2008. }\end{array}$ \\
\hline & January 5, 2009 & $\begin{array}{l}\text { German Commerzbank partly nationalised as } \\
\text { the government buys } 25 \% \text { of shares to rescue } \\
\text { one of the biggest German banks. } \\
\text { The Bank of England cuts interest rates to a } \\
300 \text { year low. }\end{array}$ \\
\hline
\end{tabular}

\section{Sources:}

Daily press

FED, The Financial Crisis: A timeline of Events and Policy Actions

Felton, A. and C. M. Reinhart (Eds.), The First Global Financial Crisis of the 21st Century: Chronology,

http://www.voxeu.org/index.php?q=node/1352

BBC News.com http://news.bbc.co.uk/2/hi/business/7521250.stm

Guardian.co.uk http://www.guardian.co.uk/business/2008/oct/08/creditcrunch.marketturmoil

Roubini, N., Global EconoMonitor, http://www.rgemonitor.com/blog/roubini/

Krugman, P., New York Times Blog, http://krugman.blogs.nytimes.com/

Buiter, W., Financial Times Blog, http://blogs.ft.com/maverecon/

Mankiew, G, Greg Mankiw's Blog, http://gregmankiw.blogspot.com/ 